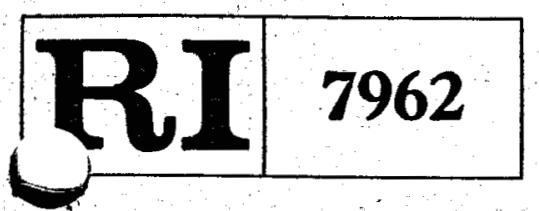

Bureau of Mines Report of Investigations/1974

( RECEIVED BY TIC AUG 221975

In Situ Determination of Rock Behavior by Overcore Stress Relief Method, Physical Property Measurements, and Initial Deformation Method

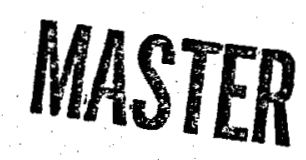

UNITED STATES DEPARTMENT OF THE INTERIOR 


\section{DISCLAIMER}

This report was prepared as an account of work sponsored by an agency of the United States Government. Neither the United States Government nor any agency Thereof, nor any of their employees, makes any warranty, express or implied, or assumes any legal liability or responsibility for the accuracy, completeness, or usefulness of any information, apparatus, product, or process disclosed, or represents that its use would not infringe privately owned rights. Reference herein to any specific commercial product, process, or service by trade name, trademark, manufacturer, or otherwise does not necessarily constitute or imply its endorsement, recommendation, or favoring by the United States Government or any agency thereof. The views and opinions of authors expressed herein do not necessarily state or reflect those of the United States Government or any agency thereof. 


\section{DISCLAIMER}

Portions of this document may be illegible in electronic image products. Images are produced from the best available original document. 
Report of Investigations 7962

In Situ Determination of Rock Behavior by Overcore Stress Relief Method,

Physical Property Measurements, and Initial Deformation Method

By Eugene H. Skinner, Galen G. Waddell, and John P. Conway Spokane Mining Research Center, Spokane, Wash.

UNITED STATES DEPARTMENT OF THE INTERIOR Rogers C. B. Morton, Secretary

Jack W. Carlson, Assistant Secretary-Energy and Minerals BUREAU OF MINES

Thomas V. Falkie, Director 
This publication has been cataloged as follows:

\section{Skinner, Eugene H}

In situ determination of rock behavior by overcore stress relief method, physical property measurements, and initial deformation method, by Eugene H. Skinner, Galen G. Waddell, and John P. Conway. [Washington] U.S. Bureau of Mines [1974]

87 p. illus., tables. (U.S. Bureau of Mines. Report of investigations 7962)

Includes bibliography.

1. Rock deformation. 2. Rock mechanics. I. U.S. Bureau of Mines. II. Waddell, Galen G., jt. auth. III. Conway, John P., jt. auth. IV. Title. (Series)

TN23.U7 no. $7962 \quad 622.06173$

U.S. Dept. of the Int. Library 


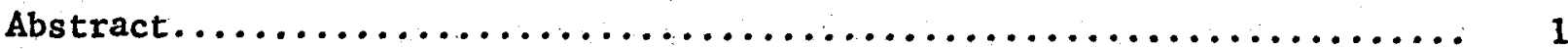

Introduction. ......................................

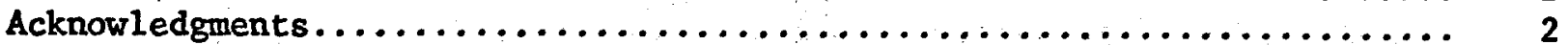

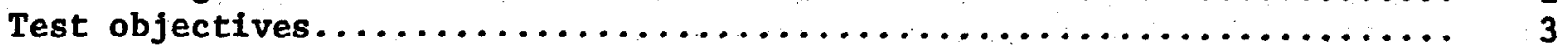

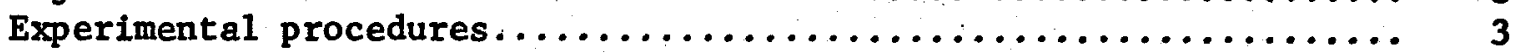

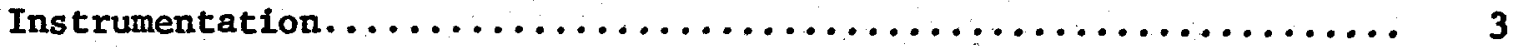

Crescent mine................................... 4

Location and history............................ 4

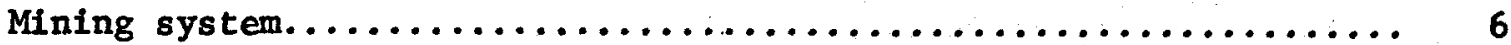

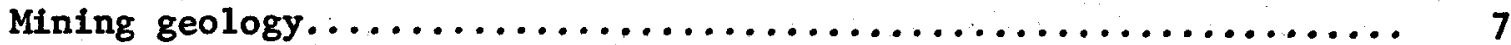

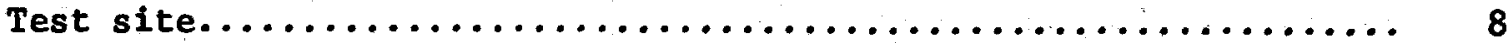

Stress determination.................................. 10

General....................................... 10

Strain analysis................................... 12

Secondary principal stresses.......................... 19

Stress ellipsoid.................................. 21

Vertical loading.................................. 24

Rock behavior.................................. 25

Physical properties................................... 27

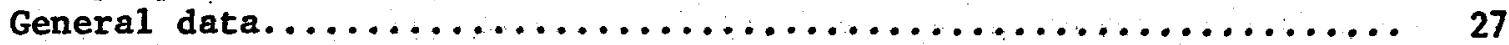

Histograms...................................... 29

Analysis of variance............................... 32

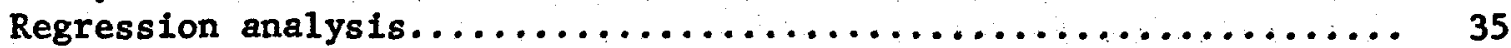

Curvilinear analysis.............................. 44

Thermal measurements ............................... 45

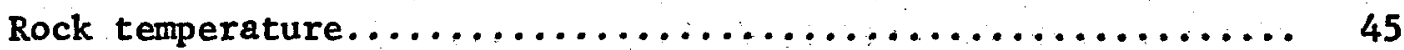

Heat-flow determinations............................ 45

Testing procedures............................... 46

Sumary.................................... 47

Initial deformation measurements....................... 48

Theory. ..................................... 48

Experimental procedure........................... 49

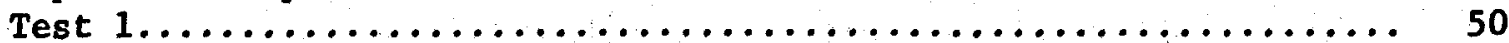

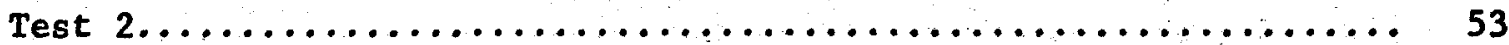

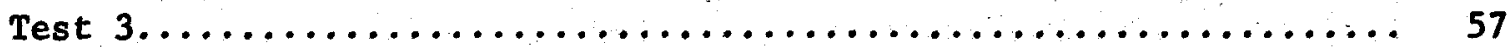

Jacking tests.................................60

Finite element modeling. ............................ 65

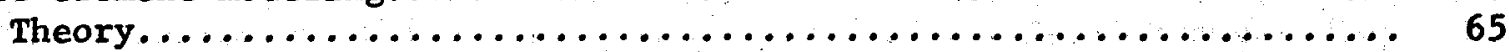

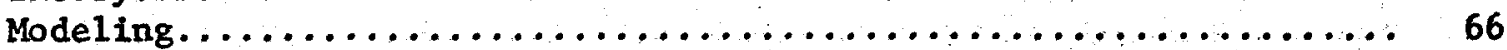

Results.................................. 67

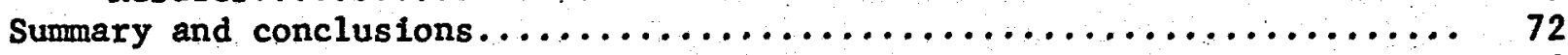

References........................................ 75

Appendix A. --overcore drilling operations................... 79

Appendix B.--Initial deformation instrumentation................. 84 
1. Location of Silver Belt, Coeur d'Alene mining district......... 4

2. Vertical section of Crescent mine workings................. 6

3. Geologic cross section across Big Creek....................

4. Schematic diagram of test site location.....................

5. Overcore test site...............................

6. Overcore drilling operations........................

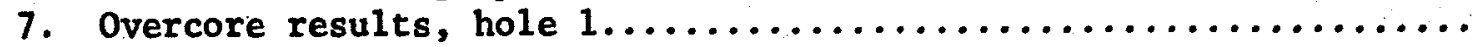

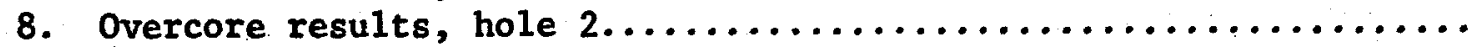

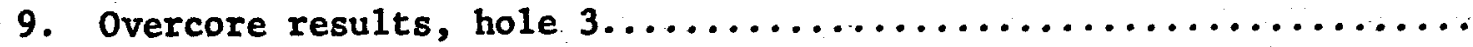

10. Overcore strain analysis, hole $2 \ldots \ldots \ldots \ldots \ldots \ldots \ldots \ldots \ldots \ldots \ldots \ldots$

11. Secondary principal stresses, hole $2 \ldots \ldots \ldots \ldots \ldots \ldots \ldots \ldots \ldots \ldots \ldots$

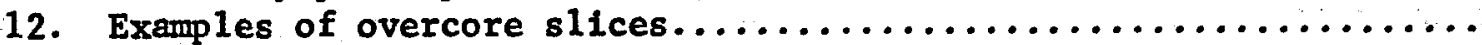

13. Cracked rib of overcore hole $2 \ldots \ldots \ldots \ldots \ldots \ldots \ldots \ldots \ldots \ldots \ldots \ldots \ldots$

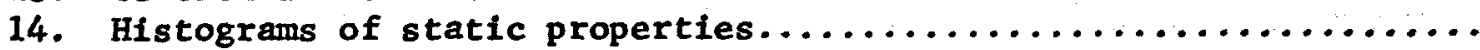

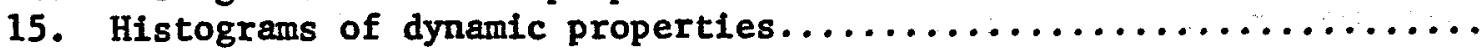

16. Histogram of biaxial test results $\ldots \ldots \ldots \ldots \ldots \ldots \ldots \ldots \ldots \ldots \ldots \ldots \ldots$

17. Static elastic modulus versus dynamic elastic modulus............

18. Compressive strength versus longitudinal velocity.............

19. Static elastic modulus versus longitudinal velocity............

20. Compressive strength versus static elastic modulus..............

21. Predicted and measured elastic modulus....................

22. Predicted and measured compressive strength................

23. Three-hole experimental procedure......................

24. Drill hole layout at collar...........................

25. Three-hole experiment during field tests..................

26. Overcore record, tests $1,2,3 \ldots \ldots \ldots \ldots \ldots \ldots \ldots \ldots \ldots \ldots \ldots \ldots \ldots \ldots$

27. Tunnel stress relaxation deformation, tests $1,2,3 \ldots \ldots \ldots \ldots \ldots \ldots$

28. Single-component borehole deformation gage, test $2 \ldots \ldots \ldots \ldots \ldots \ldots$

29. Example of wall rock failure during drilling. ................

30. Overcore recovered from test $2 \ldots \ldots \ldots \ldots \ldots \ldots \ldots \ldots \ldots \ldots \ldots \ldots \ldots \ldots$

31. Anomalous portion of record from test $3 \ldots \ldots \ldots \ldots \ldots \ldots \ldots \ldots \ldots \ldots$

32. Typical field jacking records $\ldots \ldots \ldots \ldots \ldots \ldots \ldots \ldots \ldots \ldots \ldots \ldots \ldots \ldots$

33. Reduced jacking record, test 1 , run $H-3, H-4 \ldots \ldots \ldots \ldots \ldots \ldots \ldots$

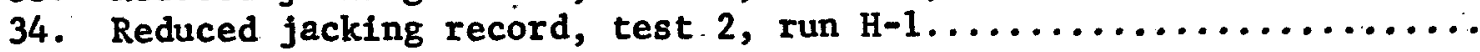

35. Reduced jacking record, test 2 , run $H-2 \ldots \ldots \ldots \ldots \ldots \ldots \ldots \ldots \ldots \ldots \ldots$

36. Reduced jacking record, test 3 , run $H-2 \ldots \ldots \ldots \ldots \ldots \ldots \ldots \ldots \ldots \ldots$

37. Reduced jacking record, test 3 , run $H-4 \ldots \ldots \ldots \ldots \ldots \ldots \ldots \ldots \ldots$

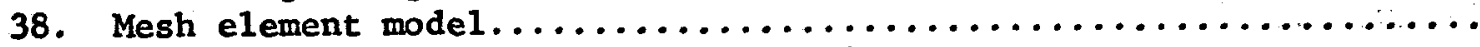

39. Surface geology near overcore hole $4 \ldots \ldots \ldots \ldots \ldots \ldots \ldots \ldots \ldots \ldots \ldots$

$\mathrm{B}-1$. Installation diagram of $\mathrm{TSR}$ gage $\ldots \ldots \ldots \ldots \ldots \ldots \ldots \ldots \ldots \ldots \ldots \ldots \ldots \ldots$

B-2. Typical calibration output..........................

\section{TABLES}

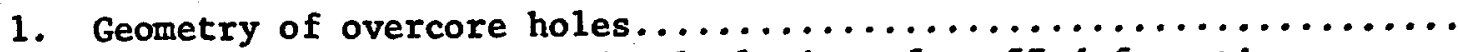

2. Crescent stress ellipsoid calculations from 57 deformation

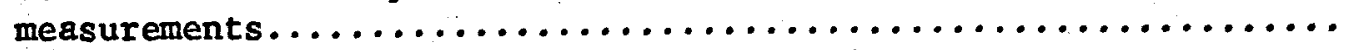

3. Sumbry of physical properties, Crescent mine...............

4. One-way analysis of variance........................... 
5. Means of compressive strength and elastic modulus............. 34

6. Pairwise stepwise regression correlations.................. 37

7. Stepwise regression predictor equation coefficients........... 38

8. Input data for jacking analysis...................... 63

9. Borehole deformation and jacking results................... 64

10. Summary of finite element results...................... 67

11. Comparative elastic modulus values....................... 70

12. Elastic modulus and compressive strength for test 2 core........ 71

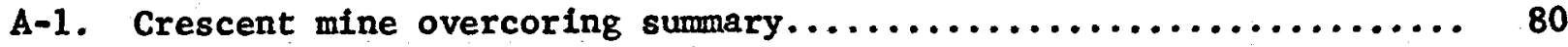

A-2. Crescent mine overcoring results ........................ 82

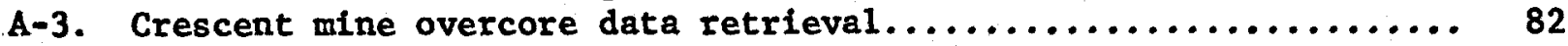




\title{
IN SITU DETERMINATION OF ROCK BEHAVIOR BY OVERCORE STRESS RELIEF METHOD, PHYSICAL PROPERTY MEASUREMENTS, AND INITIAL DEFORMATION METHOD
}

\author{
by
}

Eugene H. Skinner, ' Galen G. Waddell, ${ }^{2}$ and John P. Conway'

\begin{abstract}
This Bureau of Mines report describes the fieldwork and subsequent analysis to determine physical properties, stress distribution, and several aspects of rock behavior as a necessary evaluation for a typical mine opening. A11 work was done at a test site on the 3300 level, Crescent mine, Coeur d'Alene mining district, Idaho. Free field stress beyond the influence of the opening was also determined. Conventional overcore technique with the three-component borehole deformation gage developed by the Bureau of Mines was used in three drill holes.
\end{abstract}

Three field verification tests were performed using a gage newly developed by the Spokane Mining Research Center in an approach herein termed "Initial deformation method." Use of this method validated that aspect of overcore theory which predicts that similar deformation effect occurs in the wall rock around the perimeter of an opening in rock under stress. Also described are all drilling procedures and performances.

Physical property determinations were made on rock samples obtained from the three overcore drill holes. Twelve physical properties with a total of 532 values were obtained at various drill hole orientations and depths. Exhaustive statistical tests were utilized in the analysis of these physical properties. Further elaborated are statistical inferences based on these analyses. Extensive analysis and interpretation of Crescent mine geology are also described.

\section{INTRODUCTION}

As part of a continuing series of studies in the Coeur d'Alene mining district directed toward many aspects of mining research, the ground support determination group of the Spokane Mining Research Center (SMRC) conducted an investigation to further develop methods for predicting magnitude, direction, and nature of loading expected on underground artificial supports. The determination of magnitude and direction of initial deformation for that rock 
immediately surrounding an underground opening is one of the most essential factors in predicting support behavior. The ultimate objective of this research is ground control achleved through a better understanding of the behavior of the immediate rock surrounding an opening, generally within two dlameters of the opening. An understanding of such ground behavior will naturally lead to improved mine support design practices. Another research goal is to establish practical methods for conducting ground control research in a typical mine of the Coeur d'Alene mining district. The two methods described herein are the overcoring method using the borehole deformation gage developed by the Bureau of Mines and a new approach also developed by the Bureau of Mines referred to as the initial deformation method.

This relatively new instrumentation technique is being developed to establish relationships between the rate of initial deformation about newly created mine openings and overall rock competence. Predicting the initial deformation behavior of an underground opening is of great importance for designing an appropriate ground support system. Certainly, such prediction of intial deformation behavior around nonsupported and supported openings in deep-level mines is required before the mine designer can apply safe, efficient, and economical ground support design practices. This prediction is desired for each particular mining method as well as the geometry of the individual mine openings. Lack of such knowledge will lead to inappropriate support selection, with consequent increased costs and safety hazards. Therefore, the initial deformation method has been devised to better reflect actual opening geometry, in situ stress profiles, geologic features, and rock property characteristics without actually defining the significance and magnitude of each parameter.

This report is the second in a proposed sequence of reports on the initial deformation method of support determination conducted by the Spokane Mining Research Center. Research reported herein will describe the transition from the overcore borehole deformation method to measurement based on initial deformation of rib rock outside the hole perimeter. Another report in preparation will describe deformations in 3- and 6-foot-diameter drill-and-blast openings. A published report of investigations RI 7505 (49), ${ }^{3}$ has described initial rock deformation surrounding a 4-foot-diameter raise borehole. It is anticipated that most future efforts will concern deformations surrounding machine-bored openings.

\section{ACKNOWLEDGMENTS}

The Bureau is appreciative of the cooperation of The Bunker Hill Co., a wholly owned subsidiary of Gulf Resources and Chemical Corp., and the special assistance of John Songstad, mine superintendent of the Crescent mine. Recognition is extended to Earl L. Phillips, Donald E. Wilson, and Barbee J. Scheibner, engineering technicians and physical science technician, respectively, of the Spokane Mining Research Center (SMRC), Spokane, Wash. The assistance of Paul C. McWilliams, SMRC, operations research analyst, in

3 Underlined numbers in parentheses refer to items in the list of references preceding the appendixes. 
formulating the statistical procedures for rock property correlation, and Robert R, Thompson, SMRC, research structural engineer, for conducting that portion of work dealing with finite element analysis, is also appreciated. The assistance of many individuals at the Twin Cities Mining Research Center (TCMRC) Twin Cities, Minn., In providing physical properties on rock samples is also acknowledged. Great appreciation is extended to Vern Hooker, Denver Mining Research Center, Denver, Colo., for use of overcore stress computer programs.

\section{TEST OBJECTIVES}

\section{Experimental Procedures}

To realistically define the overall problem of opening behavior, adequate experimental information must be obtained in the following five categories:

(1) Summary of the geologic and mining environment, (2) definitive physical properties of the rock, (3) stress profiles surrounding the opening, (4) the opening geometry, and (5) the initial deformation based on a time history of mine opening behavior taken upon creation of the opening. Experimental procedures subsequently described in this report are directed toward verification of these five objectives.

Field experiments utilizing the three-component borehole deformation gage were conducted in three overcore holes on the 3300 level of the Crescent mine to determine stress profiles about the opening. Geologic and mining details of the test site, experimental methods, and overcore drilling procedures are described as appropriate in succeeding sections of this report. All equipment, procedures, and techniques for the overcore borehole deformation gage have been previously developed and are described in published Bureau of Mines reports. The initial deformation method was successfully field tested contiguously with overcoring in a fourth drill hole during this investigation. This instrumentation and technique will also be described in detail as appropriate later in this report. Extensive sampling of rock cores was undertaken as part of the overcore borehole deformation program. Physical property determinations on these cores were made by standardized Bureau of Mines procedures.

\section{Instrumentation}

The technique and measurement of true rock stresses about typical mine openings has always been a major endeavor of Bureau of Mines mining research. In recent years, a number of methods have been devised for making stress measurements. Of these, few have accepted capability, and virtually none are suitable for use concurrent with creation of full-scale mine openings. The evaluation of in situ rock stress from measurement of the change in diameter of a borehole stress relieved by overcoring has become a common measurement technique. Generally, the resulting stress evaluation is based on uniform geologic conditions and isotroplc rock behavior.

The present instrumentation effort described herein unifies the overcore ting procedure with a general type of stress evaluation for mining 
conditions in a typical deep Coeur d'Alene mine. Extensive field measurement and data acquisition in the Coeur d'Alene mining district reflect this important aspect of in situ measurement technique. Appendix $A$ is included to fully document the effort involved in obtaining overcore measurement data in the deep, hot, and humid environment of the Coeur d'Alene mines. . Appendix B, in concept, presents the opposing method of stress measurement herein called the initial deformation method. This method obviates some of the problems inherent with the overcore method and offers the possibility of use to fullscale mine openings for directly determining stress conditions immediately surrounding the opening while in the process of creating the opening.

\section{CRESCENT MINE}

\section{Location and History}

The Crescent mine of the Bunker Hill Co. 1ies about 7 miles east of Kellogg, Idaho, on the west slope of Big Creek, and about 2 miles south of Interstate Highway 90 , which locally follows the south fork of the Coeur d'Alene river. The mine is contained between workings of the Bunker Hill mine near Kellogg and the Sunshine mine, which has surface facilities directly across Big Creek canyon, about $1 / 4$ mile to the southeast. From a portal elevation of 2,691 feet at the Crescent mine, elevations of 5,000 feet or more are rapidly attained to the south and west. Less than 2 miles to the southwest, the contiguous Kellogg and Wardner Peaks crest at elevations of of 6,297 and 6,198 feet, respectively (fig. 1).

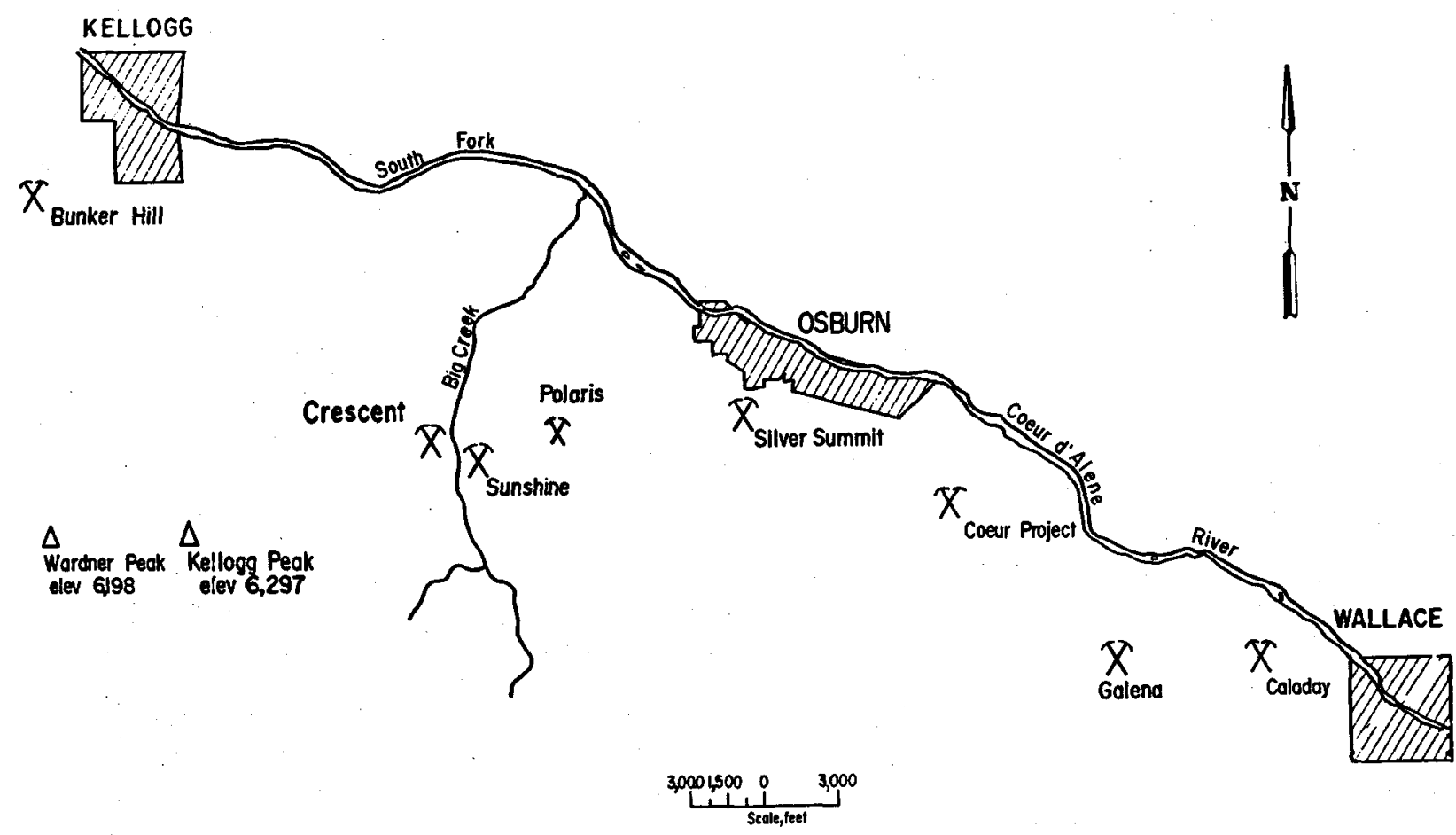

FIGURE 1. - Location of Silver Belt, Coeur d'Alene mining district. 
The Crescent mine lies near the extreme west end of the "Silver Belt." This is a structural and mineralogical subdivision of the Coeur d'Alene mining district defined by Shenon and McConnel (47) because of the high silver content of ore from mines of the area, especially those that have attained depth. This subdistrict lies between the Osburn fault, which somewhat follows the south fork of the Coeur d'Alene river, and Big Creek anticline to the south. From the Crescent mine, the silver belt extends southeastward beyond Wa11ace.

Mining discoveries in the Silver Belt were among the very earliest in the Coeur d'Alene mining district. As these early mines attained depth, the term "dry belt" (44, p. 188, 29, p. 94) was used. Serious interest was not shown in Silver Belt mines until after a significant ore body was developed in the Sunshine mine on the 1700 level during the 1930's. Since the Sunshine discovery, exploration and development work has been continuous; and substantial production has been recorded from about half-dozen mines along the Silver Belt.

The Crescent mine is typical of this exploration and development activity. From a series of adits higher on the hillside to the west, which came to be known as the Big Creek and Alhambra (44, p. 189), the early mine workings were extensively developed in the interval between initial discovery and World War I. The property was eventually acquired by Bunker Hill in 1927 ( the 3,800-foot-long Hooper adit was driven in 1928-29. Mining ceased during World War II owing to several factors, among them being exhaustion of these shallow ore bodies. All prior mining was confined to shallow ore bodies in the immediate vicinity of the Alhambra fault.

Reopening of the mine began in 1953 ( $\underline{30}, \mathrm{p} .146)$. Reopening of the older Crescent workings below the Hooper was sponsored by Defense Minerals Exploration Administration Contract (DMEA-2764) with sinking of the E11is shaft to the 3100 level in 1954 (39). Technical descriptions of this work are also found in Bureau of Mines information circular (IC) 7961 (31) and IC 7964 (26). Another part of this exploration project was the driving of a drift and raise. A 2,000-foot drift was driven westward to prospect the block of ground lying between the Alhambra and Syndicate faults by diamond drilling. The Coeur d'Alene raise was driven to continue development and mining of downward ore extensions projected from the older workings. Exploration drifts on the 3100 level are within 1,800 feet of corresponding drifts on the 3100 level of the Sunshine mine.

The Ellis shaft was chosen to satisfy two requirements: (1) To be at depth ( 400 feet below sea level) sufficient for exploration of deep ore bodies and (2) to be able to connect with existing Bunker Hill workings. The connection to the 2300 level of the Bunker Hill mine was made on the 31001 evel of the Crescent mine in July 1965 by completion of the 3-1/2-mile Yreka-United crosscut. Encouraged by favorable results from diamond drilling, the Alhambra winze was sunk from the 3100 level to the 3300 level in 1964 and to the 3500 level in 1965. Ore developed on these levels led to sinking of the No. 2 ary in the sense that no galena ore bodies were found. Dry ore was known as

Jan argentiferous ore that did not contain enough lead for smelting processes of that time. 
winze from the 3100 level (about 500 feet from the Alhambra winze eastward toward the Ellis shaft). The No. 2 winze was begun in 1968, and sinking has presently reached the 4100 level with the 3700 and 3900 levels in development. The 4100 level is 1,390 feet below sea level. General features of mine development are shown in figure 2 .

\section{Mining System}

The Crescent mine is principaliy a silver-copper mine, with chalcopyrite and tetrahedrite being the chief ore minerals. Richer ore of high silver content is found at deeper levels. Since 1966, silver production from the Crescent mine has annually exceeded 1 million ounces ( $\underline{3}, p .6)$. Below the 3100 level, stopes are mined by the horizontal cut-and-f111 method using waste rock backfill. This rock is slushed into stopes from waste raises and carried to within 3 feet of the back as each horizontal cut is completed. Levels are vertically spaced at 200 feet with stopes developed from timber-cribbed manway and service raises on 200-foot centers. Mining widths in the stopes average about 6 feet with an average round advanced about 8 feet.

Ground support in the stopes and haulage drifts uses 5-foot-long rock bolts fastened to lengths of steel plate mats. Some timber sets are also placed as needed. Some trouble has been experienced with ground support when stoping has advanced vertically to near the sill pillar between vertical levels. Of note, a 300-ton cooling system is used for the entire mine (46).

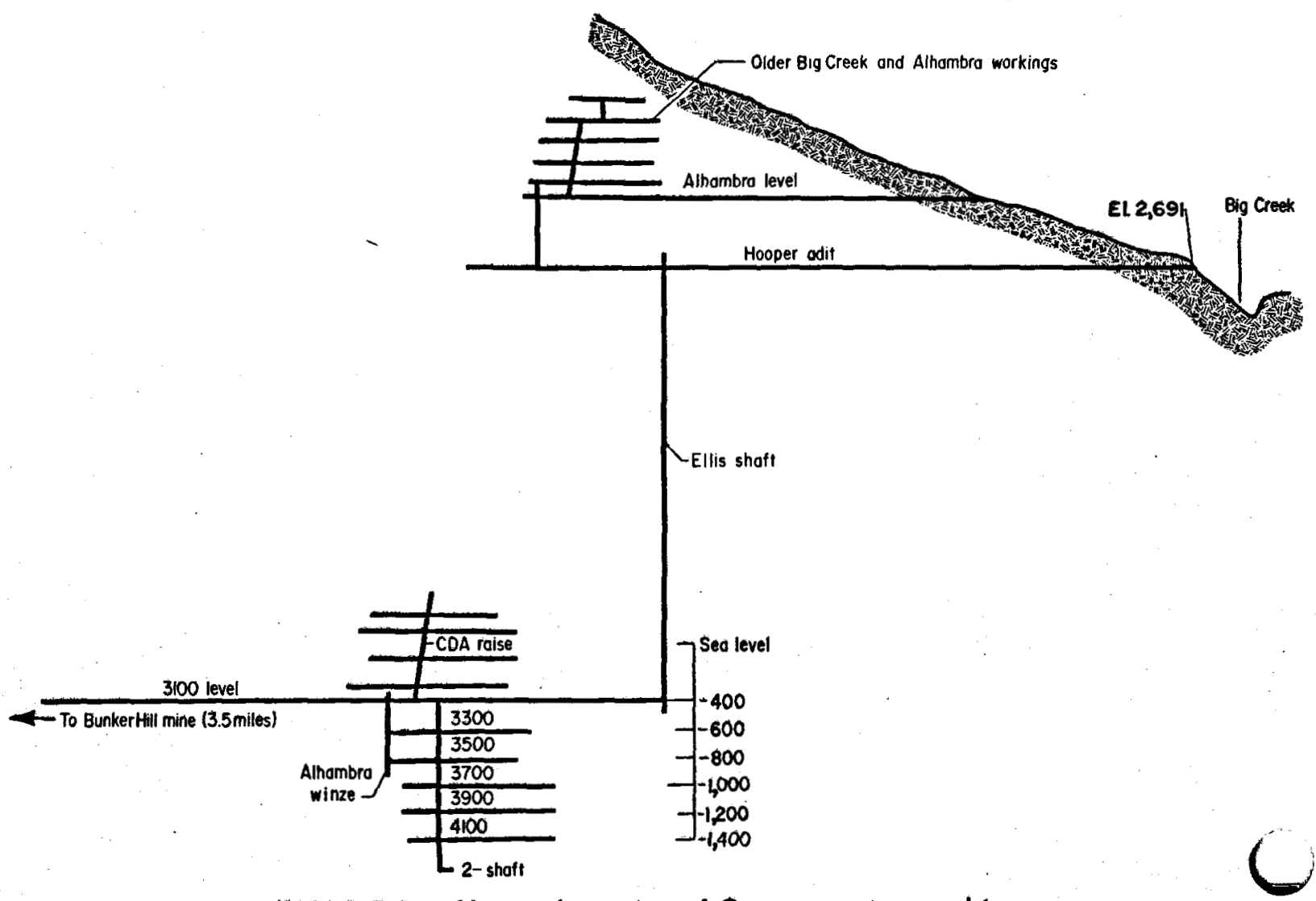

FIGURE 2. - Vertical section of Crescent mine workings. 


\section{Mine Geology}

More complete reference to Crescent mine geology is found in U.S. Geological Survey Professional Paper 445 (16, pp. 70, 81, 89-95). Three of the more distinguishing features of the Crescent mine, pertinent to this report, are the Alhambra fault, the Big Creek anticline, and the Revett Quartzite.

Throughout the Silver Belt the most prominent structural feature is the Big Creek anticline. It is an asymetrical fold with a gently dipping south flank, an overturned axis, and a partially overturned north flank. Minor folds occur on the north flank as well as many faults, several of considerable magnitude. Eastward from the crescent mine, ore veins are either parallel or contiguous with folds and faults. However, structural control of ore veins is not always assured. Evidence of shear forces is common. A similar situation exists at the Crescent mine except that the locally overturned axis of Big Creek anticline appears to uniquely become nearly coincident with the Alhambra fault and the adjacent ore vein, especially at depth. The vein, however; becomes slightly separated from the fault, and more so with depth.

On the 3700 level, the anticline axis can be mapped into the east footwall of the vein (ㅁ) and apparently follows the vein with depth. Previous geologic work based on higher levels in the mine show an undetermined eastward projection of the Alhambra fault. More recent geologic work shows the eastern end of the vein structure turning sharply southeastward toward the Sunshine mine. As a very broad generalization for the Crescent mine portion of the Silver Belt, the shallower ore bodies are more associated with the Alhambra fau1t, and deeper ore bodies are more associated with the axis of the Big Creek anticline.

Most of these relations are shown in figure 3. The section, however, is looking east and projected along Big Creek valley to show these incongruent relations with respect to the overall structure along Big Creek anticline. The folded structures are difficult to show as well as being imperfectly known.

At about the 3100 level, the Alhambra fault apparently lies on the contact between the St. Regis and Revett. The Revett is mapped on the vein hanging wall. The contact is transitional and may vary rather widely, contacts being placed at color changes rather than lithologic characteristics. All the Revett is dominantly siliceous, contains some sericite, with highly slaty or micaceous beds very sparce. The Revett also exhibits bleaching (16, pp. 89-95), but this is less striking in the Revett because of its naturally pale color. Bleaching is a guide to ore in the District, but its origin and significance are unknown.

Silver Belt mines, including the Crescent mine, are also unique in containing radioactive minerals ( 16$)$. Vein material containing lead isotopes of uranium has been determined to be about 1,250 million years in age. This evidence is suggestive, but not necessarily valid, that the age of mineralization is Precambrian. 


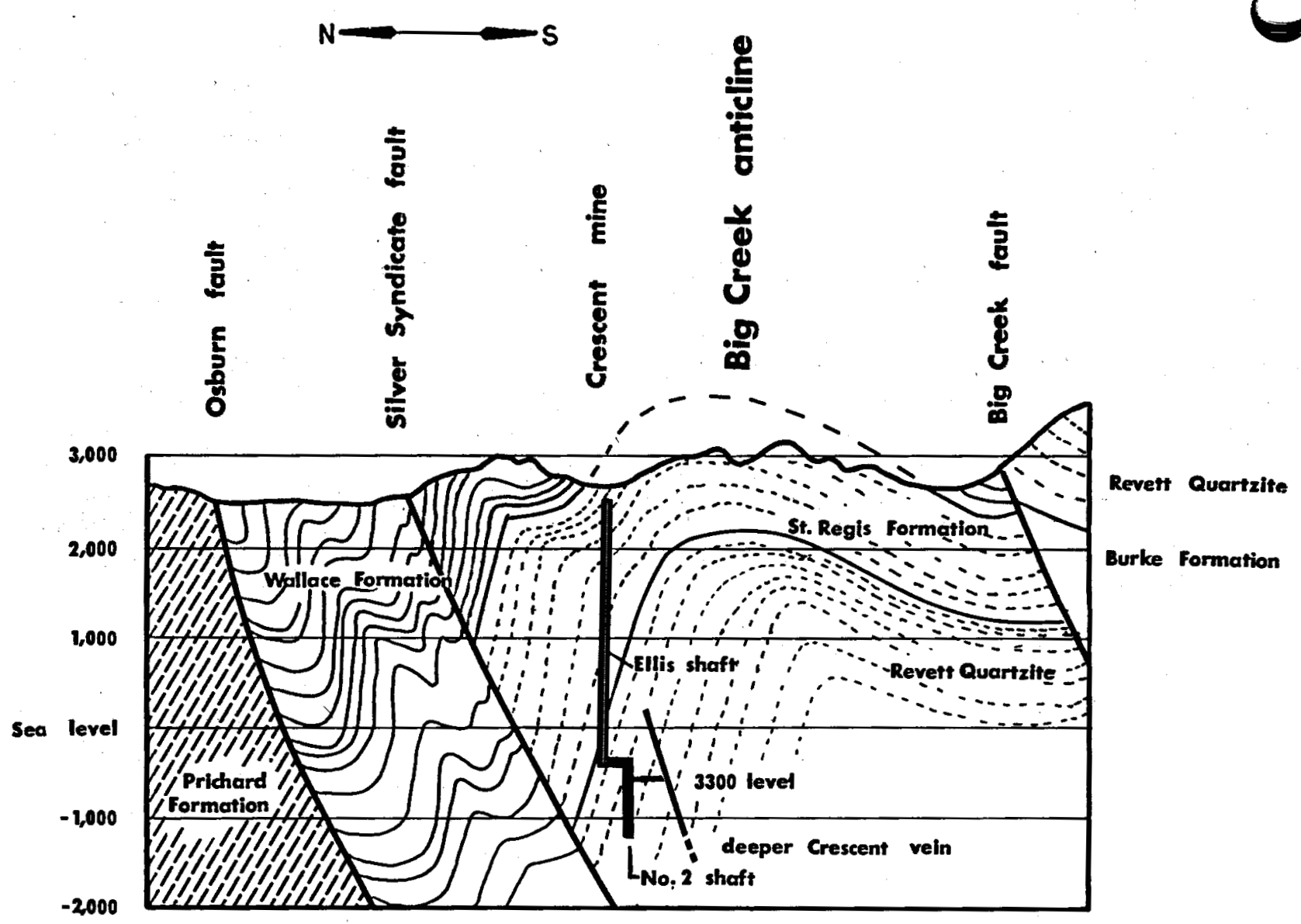

Section projected along Big Creek valley

FIGURE 3. - Geologic cross section across Big Creek.

\section{Test Site}

The test site was located along an exploratory drift driven from the vein about 550 feet into the hanging wall on the 3300 level (fig. 4). The test site utilized a selected location about 300 feet from the vein. At the test site, the dominant jointing system along the ribs has a $\mathrm{S} 70 \mathrm{E}$ strike with an $80^{\circ}$ dip to the north. This joint system is nearly parallel to the vein. Later during core examination, some joints on this orientation were found slightly mineralized. Some cross joints along the drift ribs appear on a strike of $\mathrm{N} 10 \mathrm{E}$ and $60^{\circ}$ east dip. The back of the drift appears to have somewhat air slacked into a loosely interlocked ragged surface essentially parallel to the drift back. All other joints in the back appear to be lacking in detail. Many sections along the drift ribs exhibited thin, splintery sheeting structure of 1 to 2 inches thick, although the extent of this type of fracture is not extensive. In downhole examination of drill holes, this thin sheeting fracturing did not extend to any depth and was probably related to blasting. The drift was not examined in detail ahead (to the south) of the test site alcove. Regular Crescent mine geology maps were examined in cooperation with company geologists (). 


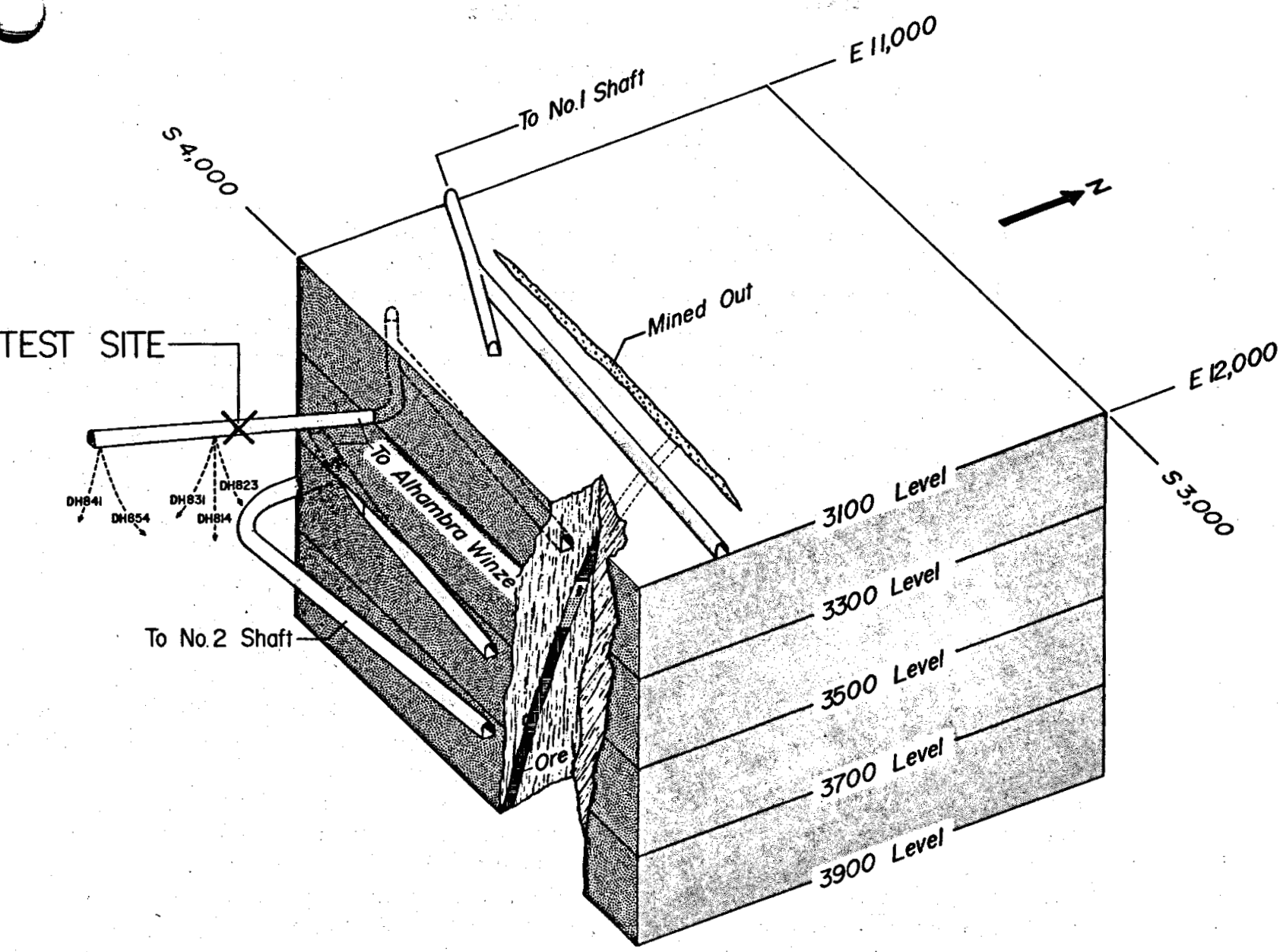

FIGURE 4. - Schematic diagram of test site location.

Mapping of face geology at the test site (and before any active project work had been done) defined the most prominent joint and cross-joint sets and their relative importance. The location and magnitude of these joints upon any results of overcoring or excavation could not be determined. No bleached rock could be determined.

Therefore, the test site for this experimental work is either known or inferred from these discussions to be (1) in the hanging wall about 300 feet from a faulted vein, (2) about 400 feet stratigraphically below the Precambrian St. Regis-Revett contact, (3) to be very nearly along the projected axis of Big Creek anticline, (4) associated with an ore vein dated at least 1,250 million years old, (5) at a depth of about 600 feet below sea level and about 5,300 feet vertically below the ground surface, (6) in rock opened by a drift not over 2 years previous, and (7) lying about 400 feet from active vein mining. 


\section{STRESS DETERMINATION}

\section{General}

The first portion of fleldwork for this project was the determination of stresses about the test site opening and determination of the stress ellipsoid. This work was considered essential to a meaningful interpretation of the stress profile around an underground opening and in particular for later portions of this project. The overcore technique of stress measurement developed by the Bureau of Mines was used for all stress determinations. A brief review is made of fundamental assumptions underlying the overcore technique because of its importance to this project. Basically, the theoretical deformation of a drill hole in an isotropic elastic body can be related to a corresponding change of stress by fairly simple equations of linear elasticity involving the following three assumptions: (1) The superposition theory of mechanics is valid, (2) the material is completely homogeneous, and (3) the material is 1inearly elastic.

The physical basis for overcoring is that if a small volume of rock under stress and containing the drill hole is cut away from the main rock body, the assumption is then made that all stresses are relieved in the detached portion of rock and that the resulting state of stress is numerically equal, al though opposite in a deformation sense (hole dilation versus hole closure), to the stresses existing in the parent rock (41, p. 2). A soft inclusion type of indirect stress gage has been developed by the Bureau of Mines (34) to record this change of stress through rosette measurement of three components of diametral hole deformation. With hole deformation known, the elastic solution for deformation of a circular hole in an elastic medium is then used to calculate stresses in the rock. Necessary physical properties must also be obtained, and for this project, they are described in the following chapter of this report. In addition, the overcore field procedures used for the Crescent mine investigation are described in appendix A. The overcoring test site is shown in figure 5. Typical overcoring fleldwork in hole 3 is shown in figure 6. All overcore holes were drilled without prior knowledge of the stress field but were drilled to best utilize drill site geometry.

However, before final results are presented in terms of stresses (through use of appropriate elastic constants), data must be analyzed in terms of strains. The next sections of this report will discuss the overcore data in that sequence--strain analysis and then stress analysis. Strain analysis will also be used as a basis for predicting opening behavior. 


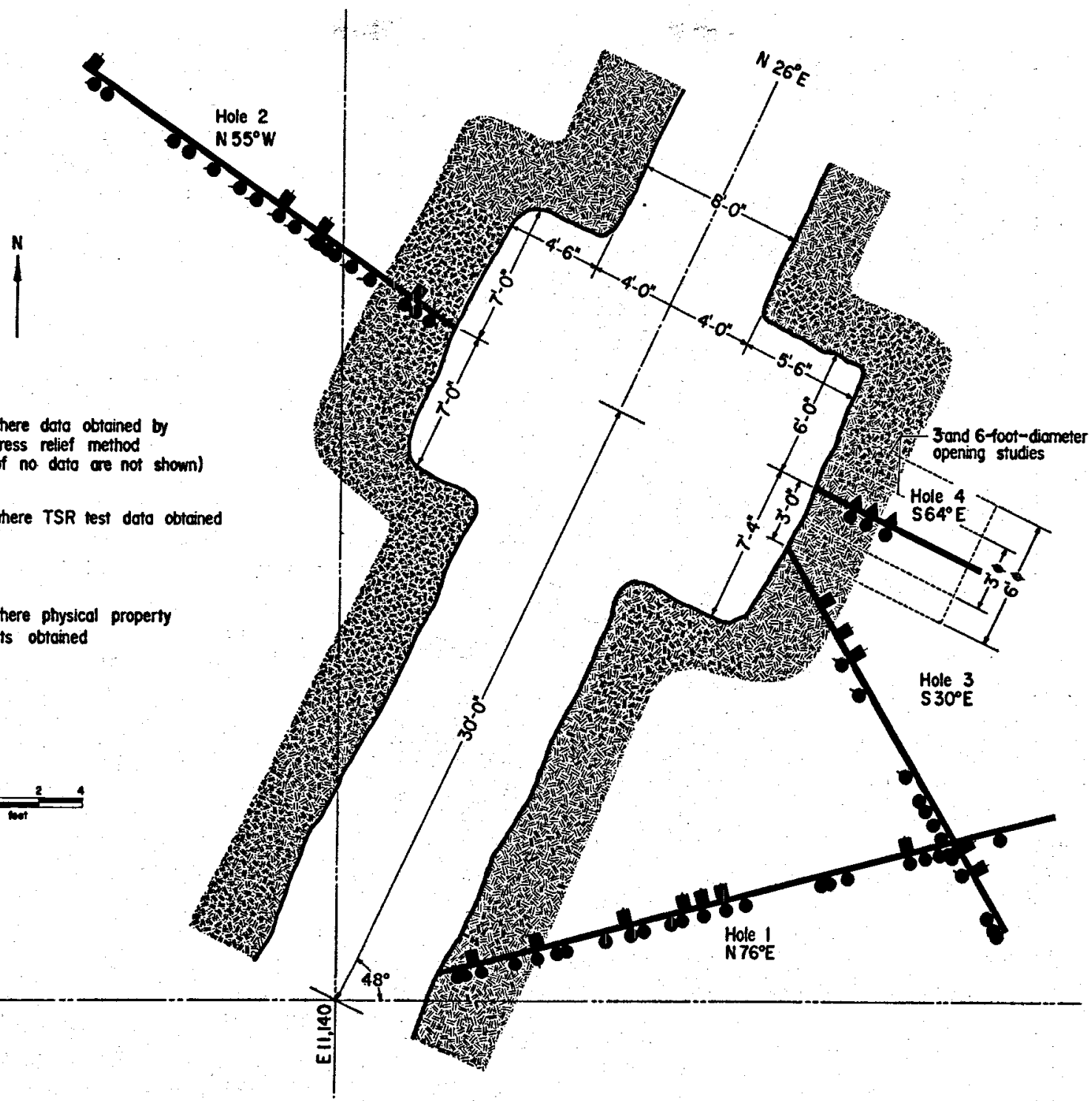

Locations where data obtained by overcore stress relief method

(locations of no dato are not shown)

- Locations where TSR rest dato obtained

Locations where physical property meosurements obtained

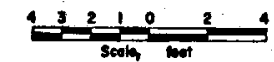

FIGURE 5. - Overcore test site.

All field data were reduced to true diametral hole deformation strain as further explained in appendix A. Each record was then individually edited point by point, run by run, and throughout each of the three holes. The aggregate of all final selected runs for each hole used in analysis of Crescent mine overcore data are shown in figures 7-9. 


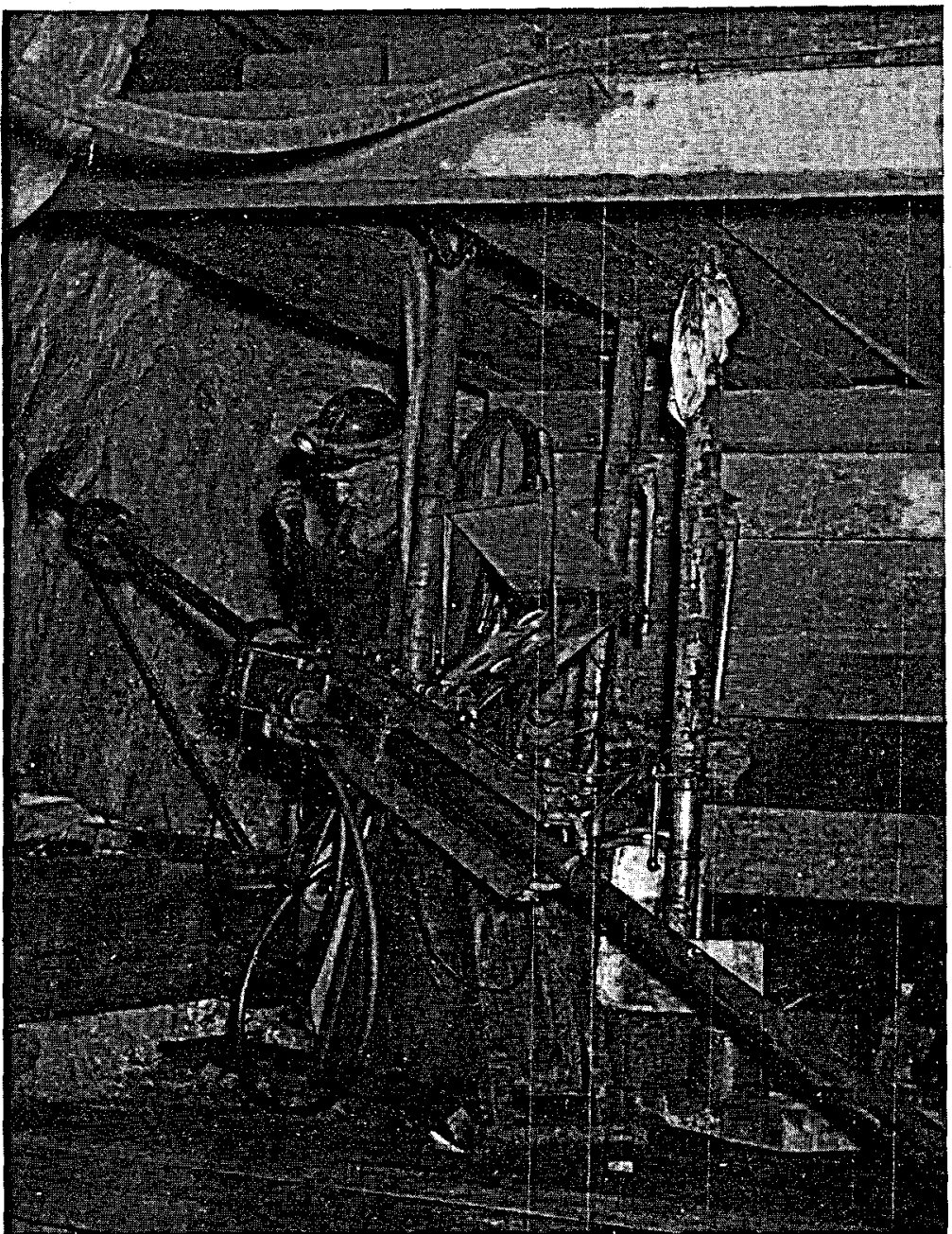

FIGURE 6. - Overcore drilling operations.
All overcore data appears to reflect a normal compressive stress field from the opening rib outward to free field stress conditions. Only hole 1 data exhibited greater dilation strain (later this hole was found to lie somewhat in the direction of maximum stress). Overcore runs through the zone of stress concentration are reflected as the greatest dilation deformation--that is, 4,000 or more microinches. Normal free field dilation deformation was between 1,500 and 2,500 microinches. For purposes of the initial deformation method, record character at the beginning of the overcore run is of great interest. The envelope of all runs up to the point of gage placement shows characteristic closure of the EX hole beginning about three diameters before the measurement point (figs. 7-9) and before normal dilation of overcore stress relief occurs. The identical but reverse

phenomena (hole dilation versus hole closure) will be shown to occur near the wall rock outside the overcore hole and will be described in the section of this report entitled "Initial Deformation Measurements."

\section{Strain Analysis}

It is common practice in the field of stress analysis to first determine strain distribution from strain measured with the strain rosette. Such procedures and methods are well documented (20, 42). Data from the threecomponent borehole deformation gage is ideally amenable to this analysis since three measurements of strain across the borehole diameter are taken with a fixed three-element, $60^{\circ}$ delta rosette normal to the axis of the borehole. Either graphic or computation procedures can be used (42, pp. 140-144). Each method has its advantages, and both methods were used on each success ful overcore run. The graphic method permits ease of visual examination of the data. Typical results obtained from such strain analysis will show maximum 


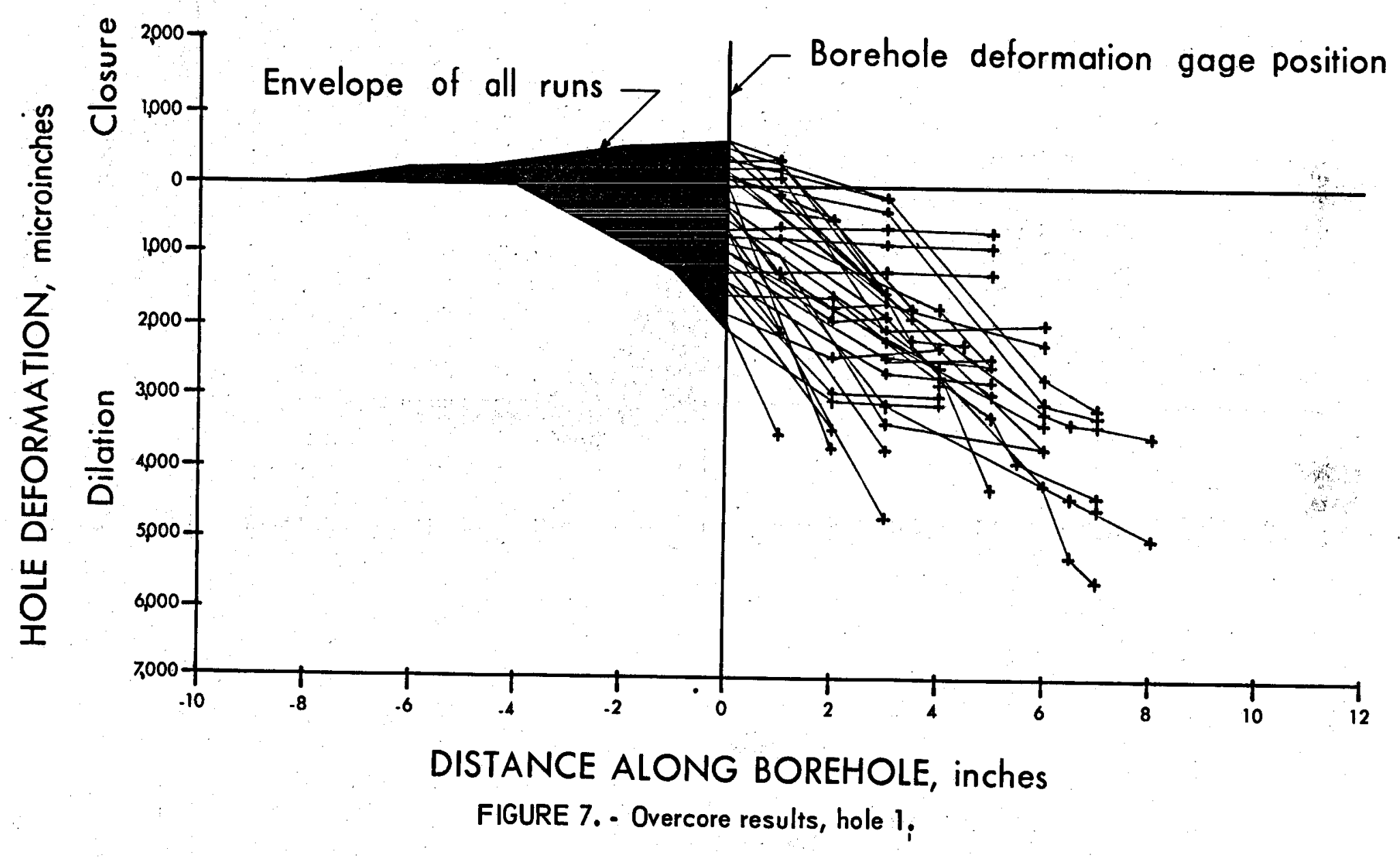


Crescent mine hole 2

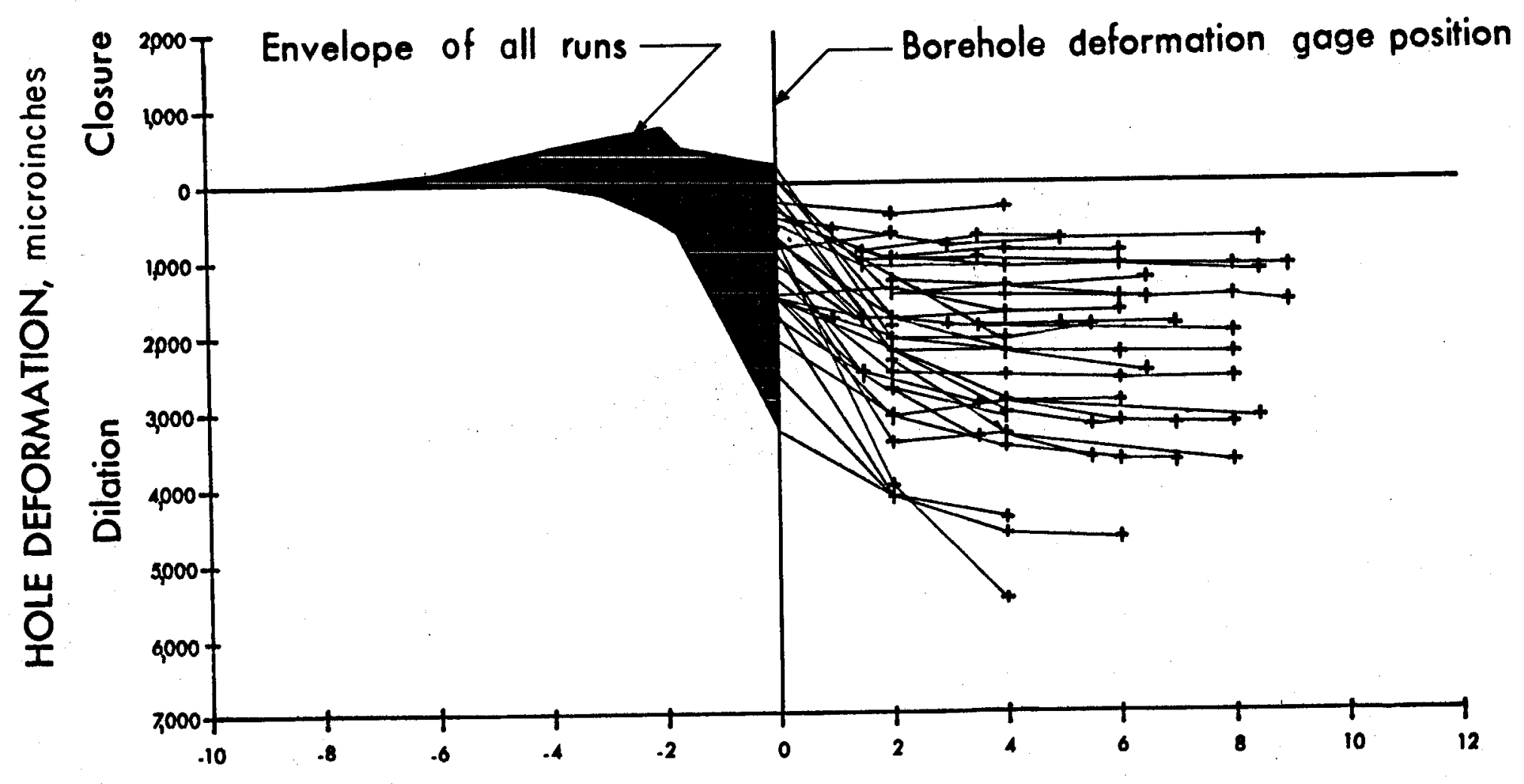

DISTANCE ALONG BOREHOLE, inches

FIGURE 8. - Overcore results, hole 2. 
Crescent mine

hole 3

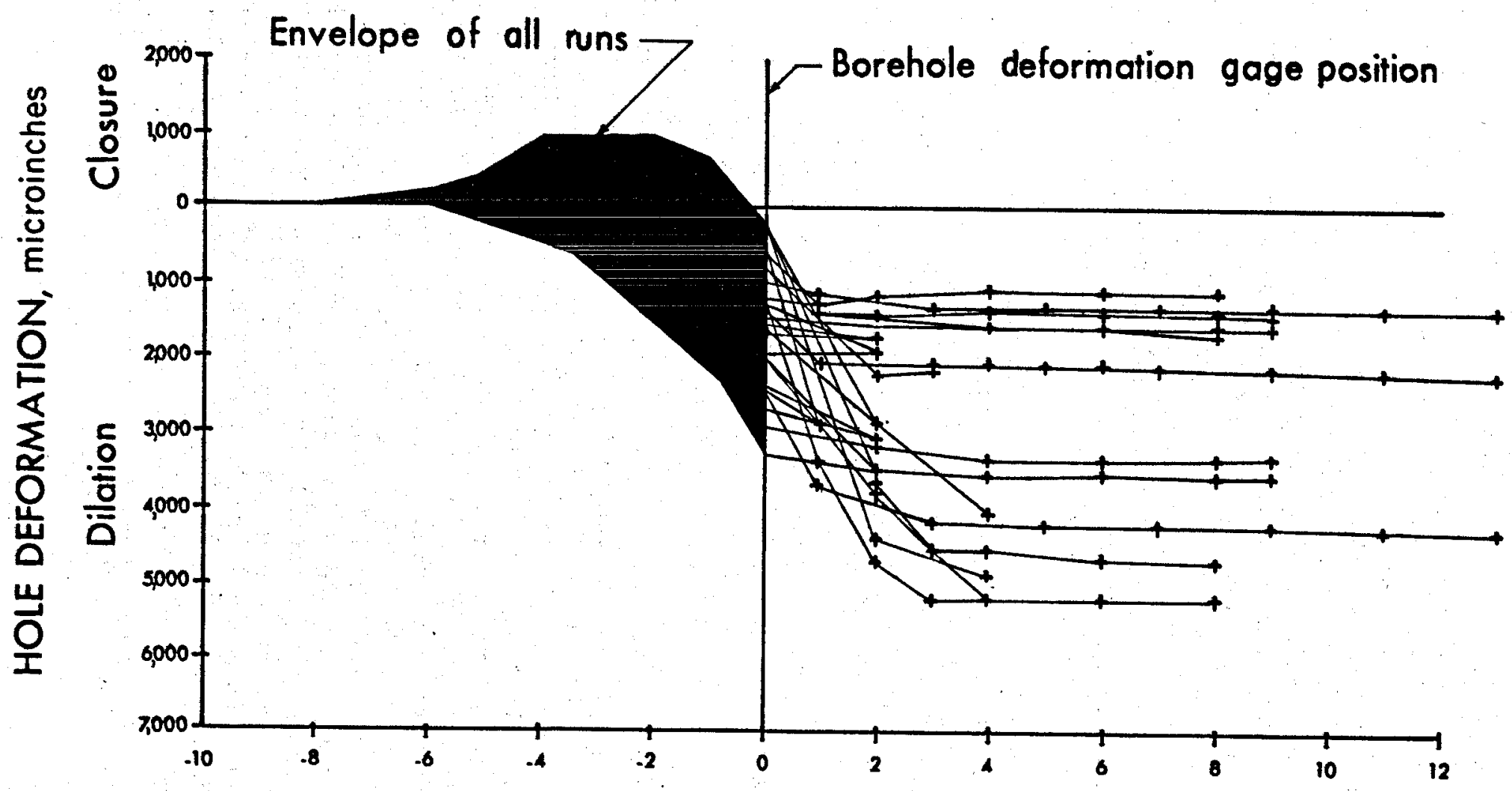

DISTANCE ALONG BOREHOLE, inches

FIGURE 9. - Overcore results, hole 3. 
and minimum strain, and the angle $e^{5}$ of principal axes with respect to the reference axis: Such graphs can, of course, also be used for shear stress and their properties are very similar to those for strain (Mohr's circle).

Initial strain analysis of Crescent overcore data followed the procedure in RI 6732 (41, p. 23) wherein the plot of individual measurements was first made. This identifies measurements that are inconsistent with the trend of al1 data. Any abnormal strain is indicative of stress concentration, residual strain, or incomplete overcore stress relief. Two additional objectives were desired from the strain study: (1) To determine the ratio of opening strain to diameter for an overcore size hole (1.5 inch diameter) for purposes of later projection to larger diameter holes, and (2) to study the nature of strain distribution surrounding the opening as an aid to understanding artificial support and rock interaction.

Overcore hole 2 (figs. 5, 8) is presented for reference as showing data nearly perpendicular to the horizontal axis of a typical mine drift. The maximum and minimum principal strain obtained from rosette analysis for overcore hole 2 from near the opening wall rock outward to a depth of about three access drift diameters is shown in figure 10. This view is a vertical elevation projection along the horizontal axis of overcore hole 2 .

As shown in figure 10, the percent overcore hole deformation (as defined by the measurement along the maximum-minimum principal axes of strain and expressed as the percent overcore hole deformation to hole diameter) ranges from a maximum of 0.378 percent near the region of assumed maximum stress concentration to a minimum of very nearly zero for the nearest surface overcore run at a depth of 13 inches. Also shown is the average strain, equal to $\left(U_{1}+U_{2}+U_{3}\right) / 3$, equivalent to the center of the strain rosette (the vertical line of figure 10 represents the strain rosette diameter of Mohr's circle and contours the envelope of all measured deformations). More theoretically, this point is the first strain invariant in two dimensions which is equal to $1 / 2\left(\varepsilon_{\max }+\epsilon_{\mathrm{min}}\right)$ and under a state of uniform stress must be a constant. For the assumed free field zone beyond the influence of the access drifts, the deformation strain invariant averages 0.129 percent with a maximum of 0.161 and a minimum of 0.101 percent for overcore runs 12-22. In infinitesimal strain theory, the first invariant of strain represents the expansion in area per unit area of surface under strain. Similarly, volumetric change of area per unit area may be computed from the first invariant of strain. This and many other relations beyond the scope of this report can be developed from such strain tensor considerations ( $21, \mathrm{ch} .2)$. In this analysis, the properties of the first strain invariant were used only as a theoretical check on field data.

The angular orientation for both principal strain and stress is the same being found $(\underline{37}, \mathrm{p} .415)$ for a $60^{\circ}$ rosette as

$$
\operatorname{Tan} 2 \theta=\frac{\sqrt{3}\left(U_{2}-U_{3}\right)}{2 U_{1}-\left(U_{2}+U_{3}\right)}
$$

where $\mathrm{U}_{1}, \mathrm{U}_{2}, \mathrm{U}_{3}$ are the diametral strain measurements. 


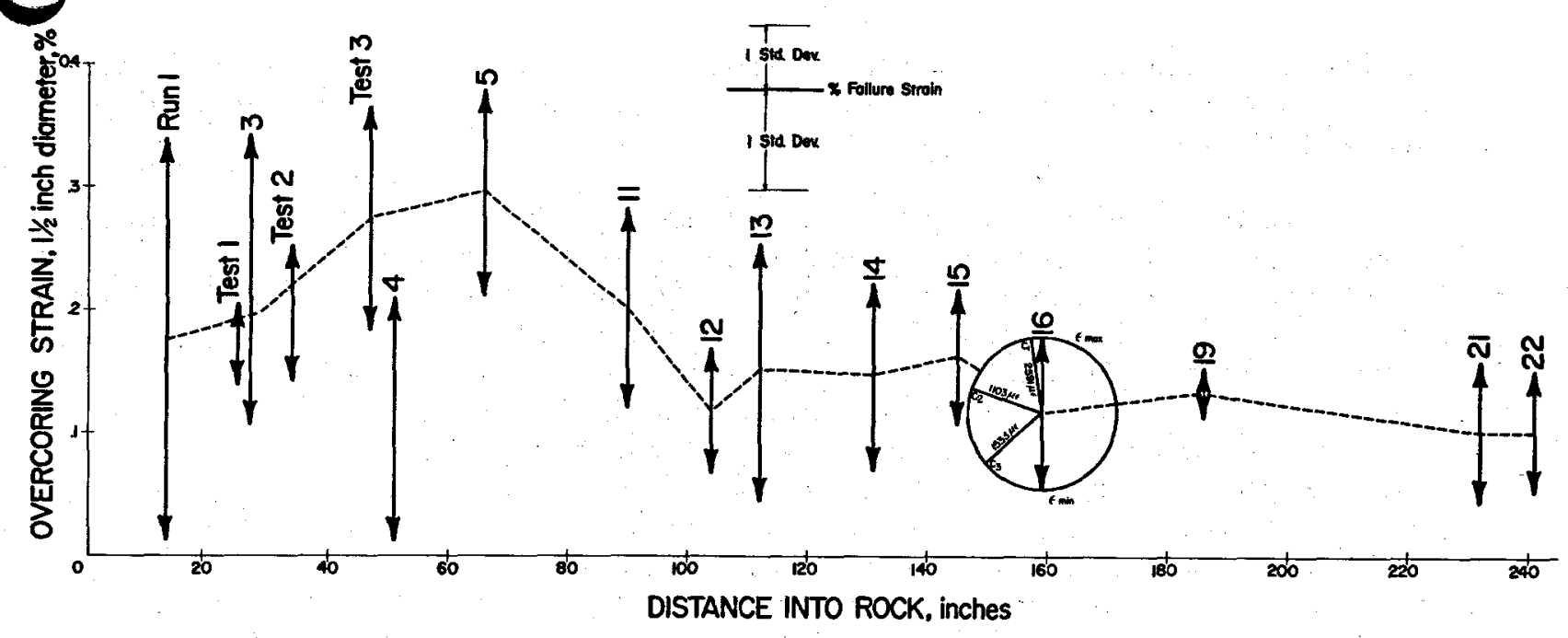

FIGURE 10. - Overcore strain analysis, hole 2.

A minimum principal strain of 190 and 205 microinches is shown for overcore run 1 and run 4, respectively. These are the lowest deformation strains for any overcore run from all four holes. It is probable that the near-surface rock had the opportunity to fully dissipate internal strain in the 2 years since driving of the access drift. Some work outside the Bureau has been done on residual strain in Revett Quartzite at this test site in the Crescent mine (10) by measuring deformations outside a hole perimeter by a method similar to the initial deformation method.

Overcore run 4 is noted to show a nearly complete stress relieved run. An interpretation for valid data can be made for this run by consideration of an average failure strain, $\epsilon$, as $\epsilon=\sigma / E$, where the average elastic modulus $(E)$ and the stress $(\sigma)$ from the average compressive strength are given in the physical property section of this report. Using these results and one standard deviation, the percent failure strain is plotted on figure 10 . It is thus seen that overcore run 4 possibly experienced failure during the overcore process yielding a maximum strain equal to the minimum strain from adjoining runs and a minimum strain of nearly zero, or complete stress relief. This demonstration also illustrates the existence of a highly strained zone surrounding the opening that has the potential of inducing self-fracturing. Overcore run 4 is also noted to lie within the zone of maximum stress concentration. Also note that no useful results were obtained between runs 5 and 11 with drilling records showing runs of 2 inches or less through this interval.6 Examples of rib failure will again be noted in the section of this report describing the initial deformation measurements. Superimposed on figure 10

${ }^{6}$ Core disking in this short interval between runs 5 and 11 could be used to substantiate stress conditions. Dure11i, Obert, and Parks (13) state that when the radially applied stress is larger than approximately one-half the uniaxial compressive strength of the rock--then core disking may occur. This argument is entirely consistent with the stress, physical properties, and observations made in this hole. 
are results from the three special overcoring runs for the initial deformation measurements taken in hole 4 (fig. 5). They are shown to be generally consistent with data from hole 2 .

In the free field region, the minimum deformation strain averages about 0.05 percent, or 750 microinches, while the maximum overcore deformation strain averages about 0.15 percent, or 2,250 microinches for hole 2 . The difference between free field minimum overcore deformation strain and the much less deformation strain. near the access drift surface is suggested to represent that potential deformation strain available as creep. Since the access drift is known to have been excavated about 2 years previously, it is postulated that at least 75 percent of the minimum available free field deformation strain is dissipated near the opening boundary within 2 years. If the Mohr circle for strain is expanded from the center point $1 / 2\left(\varepsilon_{\mathrm{max}}+\varepsilon_{\mathrm{m} \text { in }}\right)$ such that the minimum strain is reduced to zero (corresponding to complete stress relief for principal strain) then it is also seen that the increased maximum strain would correspond to a position certain1y in the failure strain range.

Both theoretical and experimental studies (photoelastic) for a pure biaxial loading condition have shown that at the opening boundary the maximum tangential stress concentration for plane stress is exactly 2.0 (37, p. 497). This evidence, noting that overcore measurements for hole 2 are tangential to the axis of the access drift, will be applied to strain and then to stress in this report. Averaging all overcore runs from run 12 and 22 , the average maximum strain is 0.187 percent and accepting the maximum value of deformation strain in the region of stress concentration as 0.378 percent, it is seen that the ratio of free field deformation strain to maximum deformation strain very slightly exceeds 2.0 at an $\mathrm{r} / \mathrm{a}$ of 2.25 (fig. 10). Elastic theory would predict the maximum occurs at the boundary of the opening or an $\mathrm{r} / \mathrm{a}$ of 1.0 ( $r$ is the radius of investigation and $a$ is the radius of the central hole). Other investigators have described various mechanisms such as plasticity, creep, and fracturing to account for this strain dissipation near the opening. However, it has been shown herein that the average deformation strain near the rock boundary is closely approximate to the maximum free field deformation strain. It is concluded from this analysis of strain that the Revett Quartzite surrounding this opening behaves as an elastic medium with respect to predicted theoretical analysis of opening behavior. Again to be noted is that all interpretation of strain results from overcore hole 2 measure tangential deformation with respect to geometry of the access drift.

7Stress is normally used when discussing stress concentration; however, stress from strain only involves multiplicative effect of the elastic modulus. Experimental stress concentration effects also begin with strain. 


\section{Secondary Principal Stresses}

Secondary principal stresses $\left(37\right.$, p. 26) ${ }^{8}$ were determined for all successful overcore runs. As for strain analysis, hand calculations and graphic methods were used. Calculation procedures are given in references 42 and $37, \mathrm{p} .41 .^{9}$ These are fairly straightforward algebraic forms and discussion of basic assumptions is found in these references. In addition, the computer program given in RI 7224 (18) for the isotropic case was used. In the following chapter on physical properties, an average elastic modulus of $7.10 \times 10^{6} \mathrm{psi}$ and a Poisson's ratio of 0.20 were determined, and these values were used for all overcore stress analysis.

Secondary principal stresses are useful for an understanding of stress distribution about underground openings. Besides the numerical magnitude of $P$ and $Q$, the sum and differences are related to the normal stresses and maximum shear stress, respectively, for the two-dimensional case. In maximum shear theory, $\tau_{\mathrm{max}}=\frac{\sigma_{\mathrm{max}}-\sigma_{\mathrm{m} 1 \mathrm{x}}}{2}$ is the maximum shear, and $\sigma=\frac{\sigma_{\mathrm{nax}}+\sigma_{\mathrm{n} \text { in }}}{2}$ is the mean normal stress representing hydrostatic loading in the two-dimensional case (neglecting $\sigma_{3}$ ) as in the normal Mohr-Coulomb theory. Each of these terms are elements of the maximum shear theory (37, p. 302). Regardless of the theoretical background, the sum and difference of secondary principal stresses are reoccuring in stress distribution calculations for an opening in an elastic medium.

Through such careful examination of $P$ and $Q$, opening geometry, and direction of drill hole orientation, valuable information on stress distribution can be obtained. Most important for this project is the case of a drill hole drilled outward nomal from the center line of the opening. Borehole measurements in this configuration will yield tangentially oriented secondary principal stresses (conversely, if a hole could be overcored parallel to the opening, radial secondary principal stresses would be determined). Again, as for strain analysis, hole 2 is presented as a typical example of horizontal secondary stress distribution normal to the opening and outward to the region of free field stress.

${ }^{8}$ Secondary principal stresses, $P$ and $Q$, are defined as the principal stresses resulting from stress components that lie in a plane normal to the given direction. The planes on which these stresses lie are the secondary principal planes, and these planes are free of shear stress.

${ }^{9}$ For reference herein, one form of these equations in plane stress may be written as:

$$
\begin{aligned}
& P+Q=\frac{E}{3 d}\left(U_{1}+U_{2}+U_{3}\right) \\
& P-Q=\frac{\sqrt{2} E}{6 d}\left[\left(U_{1}-U_{2}\right)^{2}+\left(U_{2}-U_{3}\right)^{2}+\left(U_{1}-U_{3}\right)^{2}\right]^{1 / 2}
\end{aligned}
$$


Figure 11 shows all successful overcore runs for hole 2 and tests 1,2 , and 3, from hole 4 plotted as depth of hole against the average or mean norma1 secondary principal stresses. This representation allows a common basis for orientation of the magnitude of $P$ and $Q$ since the secondary principal stress angle varies considerably along the hole length. The scaled secondary principal stresses are shown for each run and at their true angular orientation. (However, individual diagrams show secondary principal stresses in the plane of measurement normal to the borehole axis and with respect to hole 4, allowing comparison with later 3 - and 6-foot-diameter openings.) Only the $\frac{P+Q}{2}$ mean normal stress is plotted in figure 11 , and its profile is shown to closely confirm the theory of stress concentration for a biaxial loaded underground opening in an elastic medium. Noted is that the total of 16 values shown for 241 inches of depth represent about 1 measurement per 15 inches of depth. Some argument can be made that the mean normal stress more clearly shows the higher stress zone than a plot of $P$ or $Q$ by themselves.

No $p$ lot of $\frac{P-Q}{2}$ was made since for a nearly biaxial stress state, $P=Q$, and shear is essentially zero. However, the single measurement, run 1 , very near the surface where $Q$ is much less than $P$ gave a maximum shear stress of about 3,000 psi. The fact that shear stress should be a maximum at the boundary is also confirmed in theory ( $37, p .101)$. The implication of high shear stresses at the boundary will be described later in rib cracking of overcore hole 2. Using the first five overcoring points plotted in figure 11 and projecting the horizontal and vertical components to the surface boundary, a ratio of $\mathrm{H} / \mathrm{V}=0.25$ is projected. This plot is further shown by computer curve-fitting methods to be a linear plot, as the best fit equation form. Therefore, it is evident that zero stresses at the opening boundary cannot be admissible.

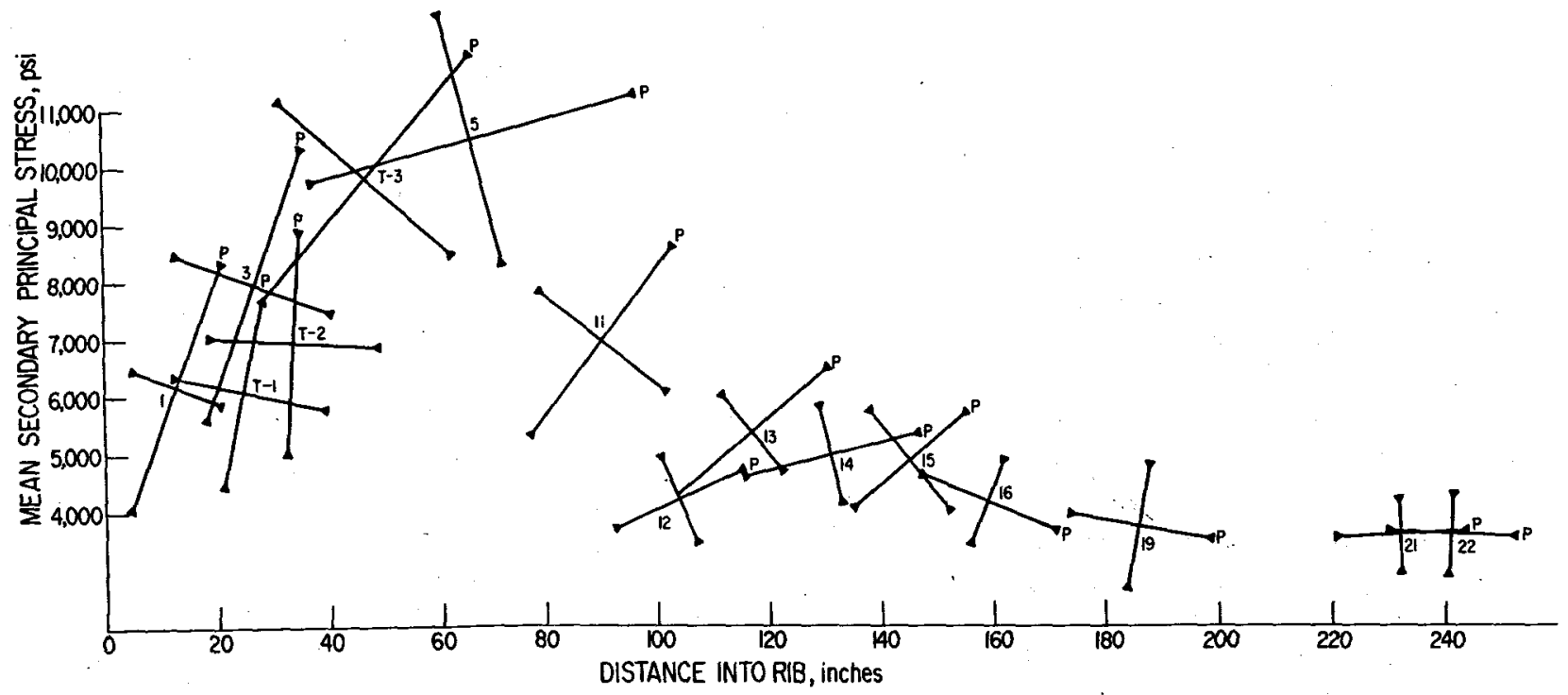

FIGURE 11. - Secondary principal stresses, hole 2. 
Although the near-surface data is limited, this conclusion is justified by correspondence between the residual stress measurements of reference 10 and overcore work described herein, by run 1, and extrapolation of a plot of the five near-surface runs. Therefore, both investigators, and by the use of different methods, obtained near-surface tangential rock stress in the range of 1,000 to 1,500 psi in the horizontal direction at the opening boundary.

The maximum secondary principal stress concentration in the tangential plane can be calculated for hole 2 using the vertically oriented stress of overcore run 5 and the vertical free field stress calculated from the stress ellipsoid. This gives a stress concentration of 1.91 for tangential stress in the vertical plane at a depth of about one opening diameter into the rock. Some difference can be attributed to rotation of the stress ellipsoid and the secondary principal stresses, as well as deviations in the true biaxial stress field. Again, the value of 1.91 is very near the theoretical 2.0 for a hole in a biaxial stress field, but the location is at depth into the rock and not at the opening boundary (these reasons were discussed previously).

\section{Stress Ellipsoid}

The three-dimensional, free field ${ }^{20}$ stress ellipsoid was determined using $\mathrm{U}_{1}, \mathrm{U}_{2}$, and $\mathrm{U}_{3}$ strain components from individual overcore measurements taken in each of the drill holes 1,2 , and 3 oriented at given azimuths (fig. 5). The stress ellipsoid calculation procedure is fully described in RI 6732 (41). Some simplified relations are restated as follows, for clarification.

Equations were developed in RI 6732 using three-element rosettes from drill hole diameter deformations, as a function of applied stresses, and in each of three differently oriented drill holes, to determine the threedimensional stress ellipsoid. An oriented, right-hand, rectangular coordinate system, common with respect to each drill hole orlentation, is used. The three-dimensional state-of-stress is defined by specifying the magnitude of the three components of normal stress and the three components of shearing stress. Stresses parallel to the axis of the drill hole are assumed to have negligible influence. A total of six such independent simultaneous stress equations are required to adequately define stress in the theory of 1 inear elasticity. Measurements of diametral change in a single drill hole provide a maximum of three independent conditions for solution of the above stress components. Therefore, a minimum of three holes is ordinarily required for solution of all stress equations. Precision of the resulting stress ellipsoid is optimized by a least-square solution applied to the overall set of measurements. Simultaneous solution of all equations, orientation of the direction cosine, and incorporation of a least-square procedure can be performed by desk calculator or computer. Transformation of the given system into any coordinate system of interest can be accomplished, that is, true vertical and horizontal. This project used the RI 6732 computer program with results shown herein.

Iofree field stress is herein defined as that stress beyond the influence of the opening. 
To approach a reasonably good balance of measurement, with respect to the determination of each of the six stress components, one must seek an appropriate combination of (1) direction of angular measurement within the holes and (2) hole directions with respect to the coordinate axes. Undue influence may be given principal stress orientation of the stress ellipsoid from strain measurements taken in one direction from more than one dri11 hole (41, $p .11)$. This was considered true for the $90^{\circ}$ strain measurements taken with the threeelement $\left(30^{\circ}, 90^{\circ}\right.$, and $\left.150^{\circ}\right)$ borehole deformation gage in holes 1,2 , and 3 . To lessen this influence, measurements were also taken with another threeelement gage $\left(0^{\circ}, 60^{\circ}\right.$, and $\left.120^{\circ}\right)$ in hole 3 . Thus, three drill holes, each with different azimuths and having a total of 15 angular measurement orientation components, provide significantly better balance with respect to the final stress ellipsoid determination.

A similar situation holds in the spatial geometry for the set of overcore holes. The best solution to the stress ellipsoid is obtained when data from a large number of measurements are taken in at least three nonparallel holes, two oriented at about $60^{\circ}$ with respect to each other, and the third hole either verticaliy upward or downward. ${ }^{12}$ This could not be achieved exactly on this project owing to limitations to which the drill could be elevated or depressed. Table 1 shows final geometry attained. Note that the Included angle from holes $1-3$ and 1-2 are satisfactory, but that the hole 2-3 angle is low. However, in view of the number of measurements, variety of angular orientations, and approximate goemetric configuration, an adequate threedimensional stress ellipsoid was belleved achieved.

TABLE 1. - Geometry of overcore holes

\begin{tabular}{|c|c|c|c|c|c|}
\hline \multirow[t]{2}{*}{ Hole } & \multirow[t]{2}{*}{ Bearing } & \multirow[t]{2}{*}{$\begin{array}{l}\text { Drilling } \\
\text { angle }\end{array}$} & \multicolumn{3}{|c|}{$\begin{array}{c}\text { Horizontal included angles } \\
\text { with holes, deg }\end{array}$} \\
\hline & & & 1 & 2 & 3 \\
\hline 1 & N $76^{\circ} \mathrm{E}$ & Horizontal & $\overline{-}$ & 49 & 106 \\
\hline 2 & $N 55^{\circ} \mathrm{W}$ & Horizontal & - & - & 25 \\
\hline 3 & S $30^{\circ} \mathrm{E}$ & $+17^{\circ}$ & - & - & - \\
\hline
\end{tabular}

Data shown in figures 7-9 were used as input to the three-dimensional stress ellipsoid computer program previously discussed. Results are shown in table 2.

The stress components for the rectangular coordinate system in table 2 have the $Z$ direction alined vertical, $X$ alined positive east, and $Y$ alined positive north. Principal stresses, $S_{1}, S_{2}$, and $S_{3}$, are referenced to true north azimuth with clockwise angles. Inclinations are referred to vertical downward as being $0^{\circ}$, horizontal as $90^{\circ}$, and upward as $180^{\circ}$.

12 Personal communication with Vern Hooker, Denver Mining Research Center, Denver, Colo. 
TABLE 2. - Crescent stress ellipsoid calculations from 57 deformation measurements

Average ground stress components with respect to the $\mathrm{X}, \mathrm{Y}, \mathrm{Z}$ coordinate system, $\mathrm{psI:}$

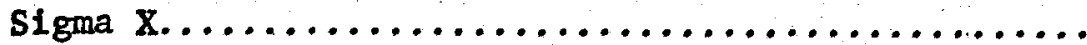

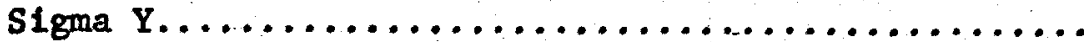

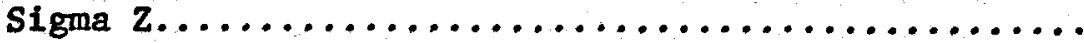

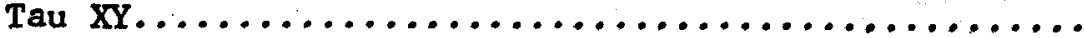

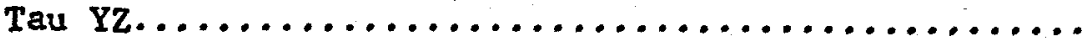

Tau ZX.....

Precision of the data:

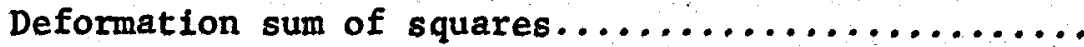
$B 1 * G 1+B 2 * G 2+\ldots+B 6 * G 6 \ldots \ldots \ldots \ldots \ldots \ldots \ldots$

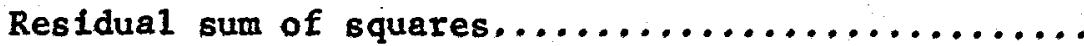
Multiple correlation coefficient squared............ Standard deviation of the fitted data.............

$7.7805 E-05$

$7.5652 \mathrm{E}-05$

$2.1529 \mathrm{E}-06$

.9723

$5.9902 \mathrm{E}-04$

Standard deviations (SD) of the ground stress components, psi:

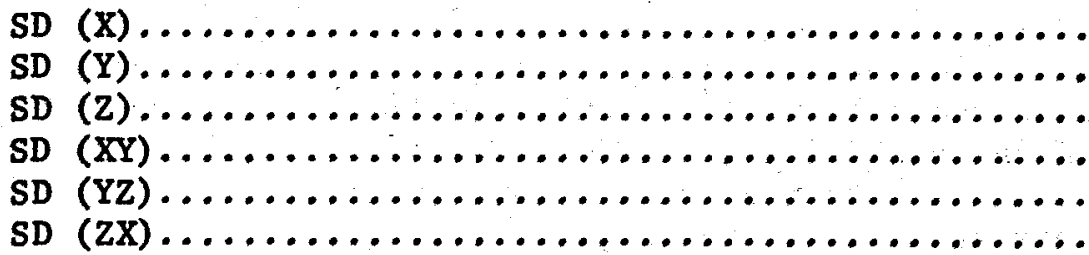

Principal stresses S1, S2, and S3 and their directions:

s1.................................pei..

s1 bearing.............................deg..

s1 Inclination......................... deg..

s2................................psi..

s2 bearing.............................deg..

s2 Inclination............................

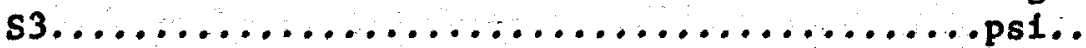

s3 bearing. ............................deg..

s3 Inclination..........................deg..

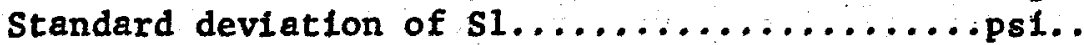

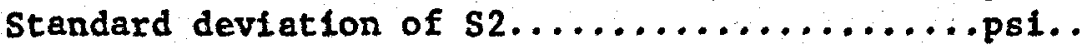

Standard deviation of $33 . . . \ldots \ldots \ldots \ldots \ldots \ldots$.
1,845

878

603

1,098

462

669

$-7,831$

153.0

88.0

$-6,255$

236.1

163.4

$-6,561$

63.6

106.5

1,387

571

977 
As an additional procedure, groups of borehole deformation data from the overcore holes used in the stress ellipsoid were F-tested to determine if borehole measurements were from the same populations. This would partially indicate a condition of hydrostatic stress. It was concluded from the F-test analysis that overcore measurements from each of the three holes were not from the same populations. Hence, rejection of the hypothesis for isostatic stress was given additional weight. (The F-test will be fully explained in the following section on physical properties.) Determination of the stress ellipsoid has neglected any total stress effects due to influence of the entire mine.

\section{Vertical Loading}

Conventional interpretation of the normal state of free field subsurface stress is that rock at depth, $z$, of density, $\rho$, and under the influence of gravity, $g$, will exert a vertical rock stress $\left(\sigma_{\nu}\right)$ equal to this incumbent overburden.

$$
\sigma_{\nu}=\rho \cdot g \cdot z
$$

This state of stress is commonly referred to as the lithostatic load. No similar theory exists for horizontal stresses $\left(\sigma_{H}\right)$ but the effect of Poisson's ratio $(\mu)$ is often assumed (that is, $\sigma_{H}=\frac{\mu}{1 \mu} \sigma_{\nu}$ ).

Thus, horizontal stresses are ordinarily assumed to be less than the vertical. The assumption that lithostatic stress at depth approaches hydrostatic conditions is known as Heim's rule (21, p. 355). As will be subsequently shown in this report, Heim's rule is more valid than the Poisson effect for free field stress at this test site.

The optional computer printout for the rotated stress ellipsoid into the true vertical and true horizontal components (both north-south and east-west) furnishes an excellent basis for determining gravity loading. First, the direct overburden depth at the test site is approximately 5,300 feet

(4,700 feet surface elevation, plus 600 feet below sea level at the 33001 eve1, see figure 2). Alternately, using the nearby elevation in the valley of the South Fork of the Coeur d'Alene river ( 2,400 feet elevation) and of Kellogg Peak (elevation 6,297 feet) the average overburden for the topographic slope is about 5,000 feet. The rock density obtained from 36 physical property determinations averaged $2.689 \mathrm{~g} / \mathrm{cm}^{3}$. Therefore, from equation 1 , the average vertical lithostatic load is at least and slightly in excess of 6,000 psi. This conforms well with less than 5 percent difference between the calculated value from the stress ellipsoid of about 6,300 psi. Using standard deviation of elevations, density, and stress, all error may be accounted for. Therefore, the normal vertical free field stress conforms with that of the normal

incumbent overburden.

The horizontal components of free field stress are remarkiably coincident with the orientation of Big Creek anticline and exceed the vertical stress. The north-south horizontal component exceeds the vertical stress by a factor of about 1.25. The north-south horizontal component is about normal to the 


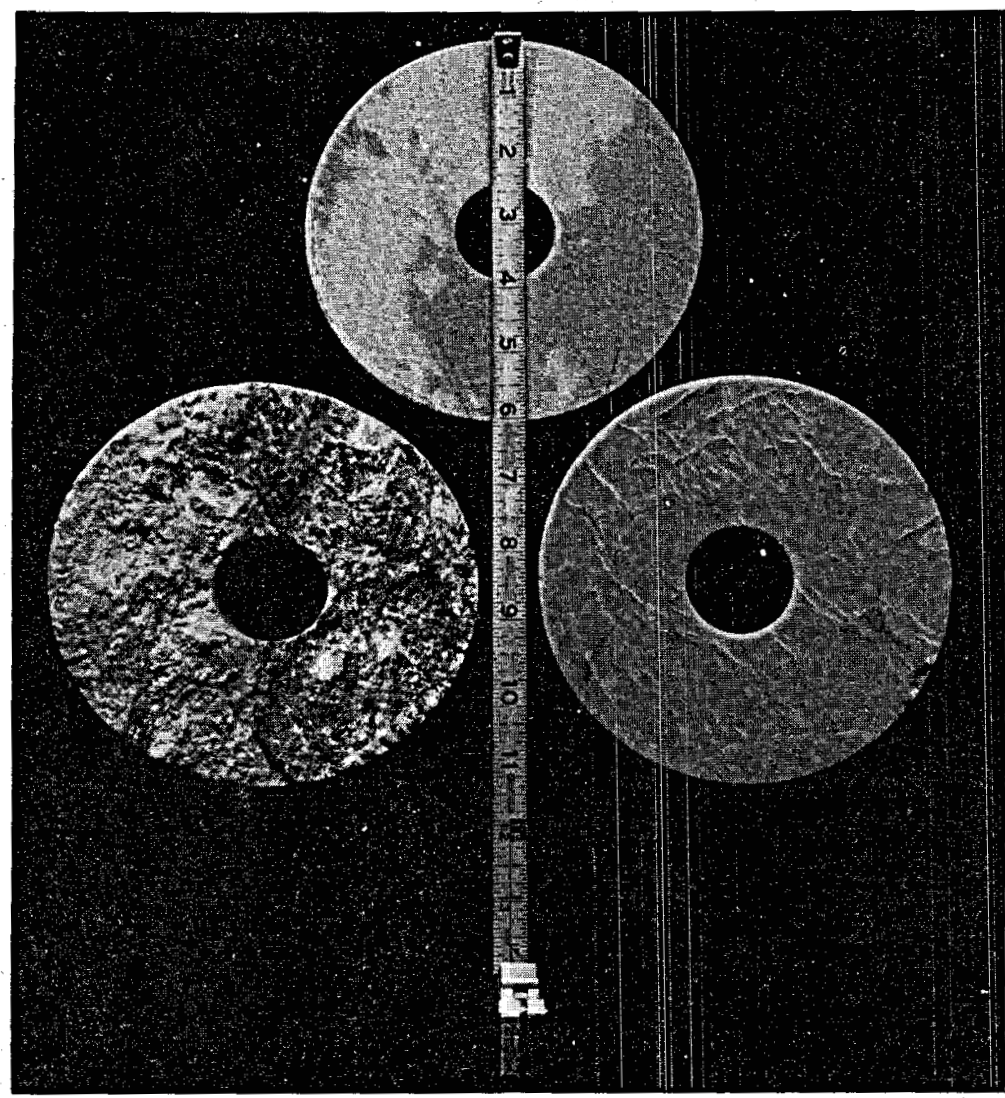

FIGURE 12. - Examples of overcore slices.

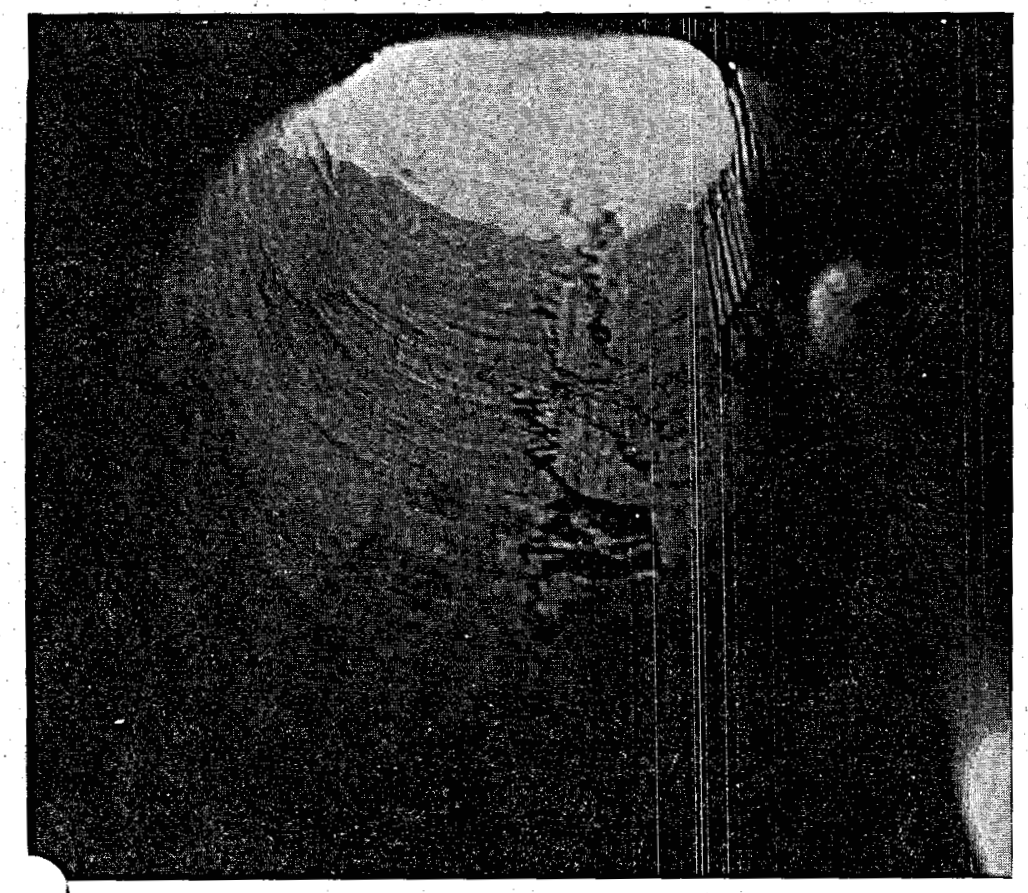

FIGURE 13. - Cracked rib of overcore hole 2. east-west major anticlinal axis. On the basis of results at this test site, it is concluded that Heim's rule of lithostatic loads is appropriate and that some relation of stress orientation to tectonic structure is evident.

\section{Rock Behavior}

The preceeding described overcore work revealed on1y four direct aspects of anomalous rock behavior:

1. The disking effect (36) observed only in hole 1 from 214 to 266 inches in depth; at least 15 percent of all overcore core could be classed as disked core, that is, lengths less than 2 inches long. No determination was made as to whether disking was caused either by a stress or drilling condition.

\section{Closely associated} with the disking effect was an assumed incipient stress condition that was internal1y noted on some pieces of unoriented sawed core. An example is shown in figure 12, right-hand core slice. A multitude of finely disseminated and interwoven cracks are shown. The top center core slice shows a normal unfractured sawed core slice. The left core slice shows a fractured core surface. Some evidence of rock fabric is noted on the fracture surface.

3. As a result of aspects 1 and 2 , some 
overcoring runs, notably through the expected zone of high stress concentration, apparently resulted in internal strain release that exceeded the local rock strength and caused rock failure concurrent with progress of the overcore run.

These runs suggest that sufficient potential strain is available to create propagation of self-fracturing mechanisms, particularly in the zone of stress concentration. Visual evidence of this in wall rock cracking will be described later in this report for overcore hole 4 . Figure 13 shows the left rib of overcore hole 2 with pronounced rib cracking. This failure was first noted about 6 months following completion of this hole (photo was taken nearly exactly 1 year after hole completion): The intensity of cracking appeared to be more severe in the zone of stress concentration althaugh the entire length of hole was cracked at the time of photography. The nature of cracking, as seen by the thin sheeting, suggests relation to rock fabric. Wall rock failure of this type is suggestive that rib failure rather than roof failure will be a ground support problem. Leeman (27, p. 77) presents borehole photography from South African mines nearly identical to figure 13.

4. Only for overcore hole 1 was the shape of the stress-relief record slightly different than the other records in that the dilation strain portion was longer. However, it alone was not sufficient evidence to be suggestive of any abnormal stress condition.

Character of certain overcore records was found to be somewhat indicative of stress conditions. Such unique records have been obtained in controlled laboratory tests by overcoring into strongly biaxially loaded blocks (4). This is a vital point in the initial deformation method, which has the thesis that initial deformation records can be used to indicate such conditions for ground support determination. As one such criteria, the ratio of final overcore strain (Indicating complete stress relief) to hole deformation measured at the position of gage placement was found to be correspondingly much higher in the region of high stress concentration. It would appear that the Induced stress concentration in this region inhibits the initial stress rellef at the beginning of an overcore run resulting in very low deformation at the point of gage placement. However, the orientation of the principal stress using these data does not appreciably differ from the orientation using complete stress-relief data.

Lesser evidence of rock behavior character, including a summary of some previously derived characteristics, includes the following: (1) The predominant orientation of secondary principal stress near the opening boundary and outward to the extremity of the stress concentration zone is vertical, beyond these areas the predominate stress direction changes to horizontal with nearly biaxial distribution; (2) the evidence from this test site is that the effective zone of stress concentration is about one opening diameter beyond the opening boundary and reaches a maximum value very near the theoretical value of twice the free field but which does not occur at the opening boundary as theoretically predicted; (3) residual stress is present at the opening boundary and with the average elastic modulus for this test site, a residuaf stress between 1,000 and 1,500 psi is probable; (4) the stress ellipsoid 
computation indicates a horizontal free field stress about 1.25 times the vertical stress and which conforms somewhat to local orfentation of Big Creek anticline; and (5) the vertical stress is in good agreement between the theoretical overburden stress and calculated vertical stress and apparently conforms to normal incumbent overburden loading.

\section{PHYSICAL PROPERTIES}

\section{General Data}

To establish definitive physical property ${ }^{12}$ data necessary for determination of the in situ stress field and for ground support prediction capability, a number of physical properties were required and extensive statistical analysis performed. These requirements were within the overall project effort to develop methods for predicting magnitude, direction, and nature of rock loads as a prerequisite for design of artificial supports in underground mines.

It was the project intent to provide physical property data comparisons at various depths in the hole, at various angular positions, and between the three different drill holes used for free field stress determination. Unfortunately, the ability to obtain sufficient core for complete testing purposes often proved a severe handicap to this objective. Nevertheless, sufficlent test data were obtained to validate, and with good statistical reliability, conclusions made in the following discussions on physical properties.

Selected 6-inch-diameter core samples of Revett Quartzite retrieved from the test site were provided by the Spokane Mining Research Center (SMRC) to the Twin Cities Mining Research Center (TCMRC), where testing was performed by the Rock Physics Laboratory of TCMRC. Only biaxial modulus tests were done at the Spokane Mining Research Center.

Data on 12 physical properties and related statistical analysis on 10 of these physical properties represent a cumulative 532 individual test results. Aggregate sample lots range from 29 to 85 with an average of 46 . Highest sample lots were for static elastic modulus and compressive strength because these tests provided replicated data obtained from dynamic specimens (see section on test procedures). Large numbers of samples were obtained on the advice of statistical consultants who recommend that hypothesis testing of population estimates that are derived from sample size near 30 will be approximately normally distributed (that is, there is little difference between the $t$ and $z$ statistic for sample size approaching 30 ).

Complete test data from overcore holes 1,2 , and 3 are summarized in table 3 . These data are without regard for angular position, depth, or hole reference. An entry-by-entry inspection of individual physical property data along the hole depth show surprising variations in physical properties. An examination of these data mostly point out extreme values compared with overall averages. Static properties have perhaps the greatest range. An example was hole 3, where one sample at 56 inches had the highest static elastic modulus value, $18.3 \times 10^{6} \mathrm{ps} 1$, as well as two others at $3.15 \times 10^{6}$ and $3.17 \times 10^{6}$. Al1 three were at different angles but the same depth. Hole 2 had the lowest static elastic modulus, $2.49 \times 10^{\circ}$. Throughout hole 1 , the static elastic modulus showed very little variation $\left(5.26 \times 10^{6}\right.$ to $\left.9.00 \times 10^{6}\right)$. For compressive strength, hole 1 shows variations of 9,050 and $53,400 \mathrm{psi}$ at 110 inches and 154 inches, respectively; both were at $150^{\circ}$ orientation. Holes 2 and 3 show similar variation from 13,000 to 48,000 psi and 5,700 to 32,400 psi, respectively. The compressive strength did show the greatest overall variation of 38.3 percent. 
TABLE 3. - Summary of physical properties, Crescent mine

\begin{tabular}{|c|c|c|c|c|c|c|c|c|c|}
\hline & 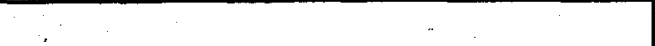 & & Low & Rar & 1ge & High & Arithmetic & Standard & Variation, 1 \\
\hline & Property & $\begin{array}{l}\text { of } \\
\text { samples }\end{array}$ & outlier & $\begin{array}{c}\text { Smallest } \\
\text { value }\end{array}$ & $\begin{array}{c}\text { Largest } \\
\text { value }\end{array}$ & out1ier & & deviation & percent \\
\hline 1. & Density $\ldots \ldots \ldots \ldots \ldots \ldots, g / \mathrm{cm}^{3} \ldots$ & 36 & 2.071 & 2.656 & 2.730 & - & 2.689 & 0.018 & $0: 669$ \\
\hline $\begin{aligned} \text { Dynam } \\
2 .\end{aligned}$ & $\begin{array}{l}\text { properties: } \\
\text { Longitudinal velocity.......fps... }\end{array}$ & 37 & - & 11,090 & 20,605 & - & 16,949 & 2,490 & 14.7 \\
\hline 3. & Bar velocity............... fps. & 36 & 6,824 & 9,705 & 19,761 & - & 14,485 & 3,153 & 21.8 \\
\hline 4. & Torsional velocity........... fps.. & 37 & - & 4,954 & 12,898 & - & 9,724 & 2,100 & 21.6 \\
\hline & $\begin{array}{l}\text { Dynamic elastic } \\
\text { modulus..........psi } \times 10^{6} \ldots\end{array}$ & 36 & 1.167 & 3.13 & 14.05 & - & 7.93 & 3.43 & 43.2 \\
\hline & $\begin{array}{l}\text { Dynamic shear } \\
\text { modulus...........psi } \times 10^{6} \ldots\end{array}$ & 37 & - & 0.878 & 6.021 & - & 3.539 & 1.328 & 37.5 \\
\hline 7. & $\begin{array}{l}\text { Dynamic Poisson's } \\
\text { ratio } \ldots \ldots \ldots \ldots \ldots \ldots \ldots \ldots \ldots \ldots\end{array}$ & 37 & - & 0.153 & 0.476 & - & 0.290 & 0.086 & 29.7 \\
\hline $\begin{aligned} & \text { Stati } \\
& 8 .\end{aligned}$ & $\begin{array}{l}\text { properties: } \\
\text { Uniaxial compressive } \\
\text { strength................. }\end{array}$ & 85 & - & 5,700 & 53,400 & - & 26,851 & 10,288 & 38.3 \\
\hline 9. & Elastic modulus.......psi $\times 10^{6} \ldots$ & 84 & - & 2.49 & 10.70 & 18.30 & 7.10 & 1.50 & 21.1 \\
\hline 10. & 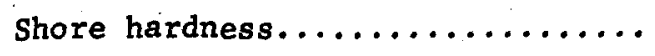 & 58 & - & 62.3 & 101.0 & - & 81.5 & 11.35 & 13.9 \\
\hline & $\begin{array}{l}\text { Brazilian tensile } \\
\text { strength................... }\end{array}$ & 16 & - & 2,390 & 5,270 & - & 3,798 & 859 & 22.6 \\
\hline 12. & Biaxial modulus.......psi $\times 10^{6} \ldots$ & 28 & 2.83 & 3.18 & 18.85 & 24.71 & 7.91 & 3.91 & 49.5 \\
\hline
\end{tabular}

\footnotetext{
${ }^{1}$ Variation calculated as $\frac{\text { Standard deviation }}{\text { Arithmetic mean }}(100)$.
} 
Dynamic properties are generally more consistent and within overall group averages. This is especially true for holes 2 and 3 . Hole 1 data has large variations within all velocity data; a factor of at least 2 is shown for longitudinal velocity, bar velocity, and shear velocity. Because of derived values, the dynamic elastic modulus and dynamic shear modulus have a range of $1.167 \times 10^{6}$ to $14.052 \times 10^{6}$ and $0.878 \times 10^{6}$ to $6.021 \times 10^{6} \mathrm{psi}$, respectively. Poisson's ratio ranges from 0.153 to 0.476 , caused by combinations of low shear velocity and high longitudinal velocity.

Biaxial test results were obtained from 6-inch-diameter cores recovered in holes 1,2 , and 3 but not at locations where the previously discussed physical property data was obtained with the exception of hole 1 where a few oriented biaxial elastic modulus values were obtained. One outlier biaxial modulus, $24.71 \times 10^{6} \mathrm{psi}$, was discarded in computing an average biaxial modulus. As indicated, large deviation in elastic modulus values are found between dynamic, static, and biaxial test methods from samples at the same location. However, the average elastic modulus from all samples obtained by dynamic, static, and biaxial methods, is $7.93 \times 10^{6}, 7.10 \times 10^{8}$, and $7.91 \times 10^{6}$ psi, respectively. Average elastic modulus values are the composite of all cores, irrespective of hole or orientation.

In summary, physical properties along individual hole lengths and between samples exhibit local variation of great contrast. A statistical treatment of data will be presented in the following sections.

\section{Histograms}

Original physical property data was complled into a series of histograms. Figure 14 lists those for static properties, and figure 1511 sts those for dynamic properties. These histograms were computer constructed based on prior Bureau of Mines programs having accepted statistical principles. The computer program has a fixed number of 10 class intervals. No attempt was made to alter the computer-produced histograms.

A histogram of density, based on 36 samples, illustrates a nearly uniform. distribution bounded by 2.656 and 2.730 . It is slightly skewed to the left peaking near the average, 2.689. Of all physical properties, density shows the smallest variation, 0.67 percent.

The static uniaxial compressive strength is completely bounded between 5,700 and 53,400 psi. A band between 10,470 and 39,090 psi contains 87 percent of data with nearly equal distribution throughout the range.

The static elastic modulus has a sharply definable band between $5.774 \times 10^{6}$ and $9.058 \times 10^{6}$ psi containing 82 percent of all values. However, a few high and low values create a large spread in the data. One outlier value, $18.3 \times 10^{6}$, is a valid modulus.

Shore scleroscope hardness contains a bimodal distribution peaked on the right near about 89. No explanation can be given for this, as well as other modal distributions more evident in the dynamic properties. Longitudinal 
Crescent mine physical properties - static

Density
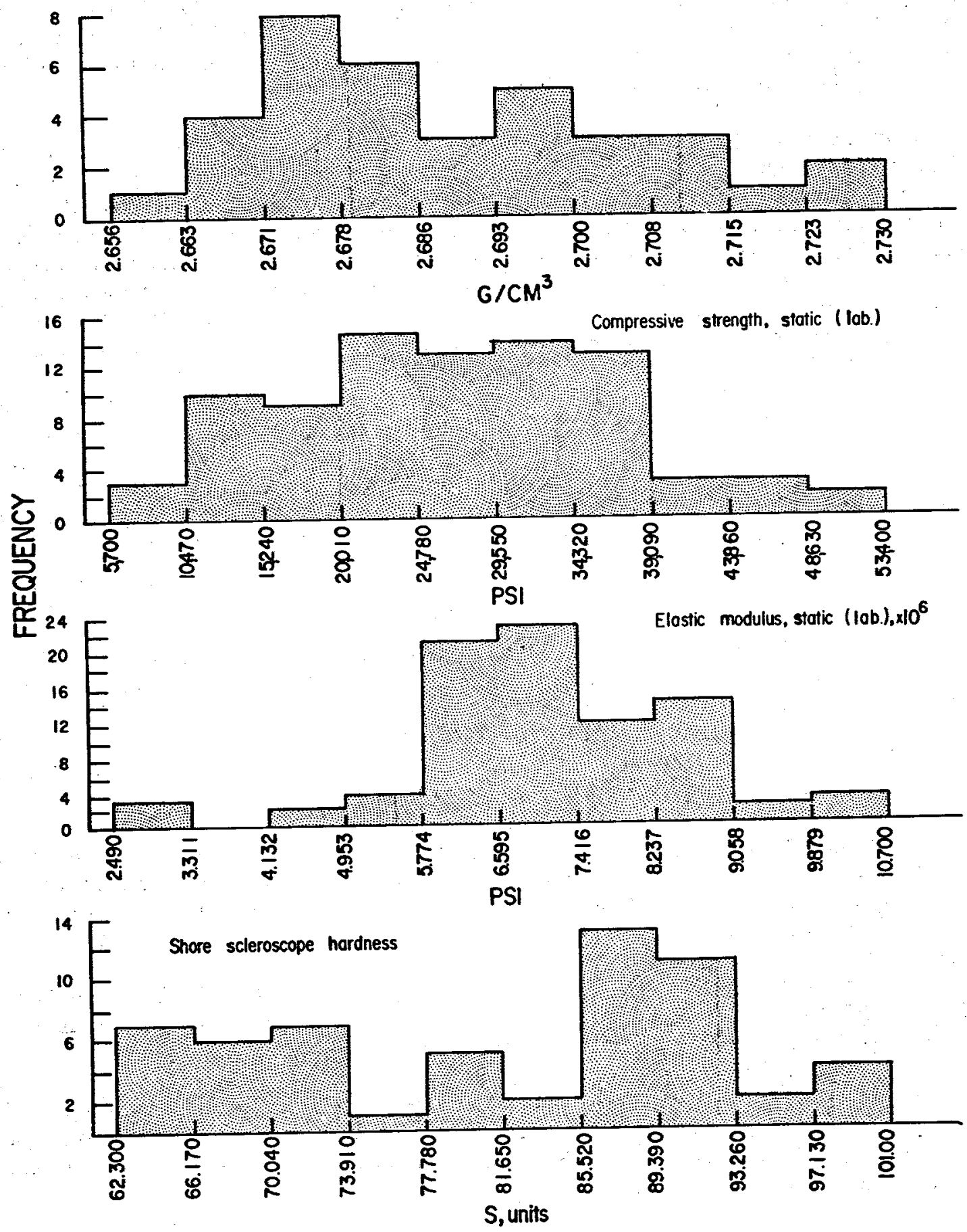

FIGURE 14. - Histograms of static properties. 
Crescent mine properties - dynamic

$\sqrt[8]{6}$

Longitudinal velocity (lab.)
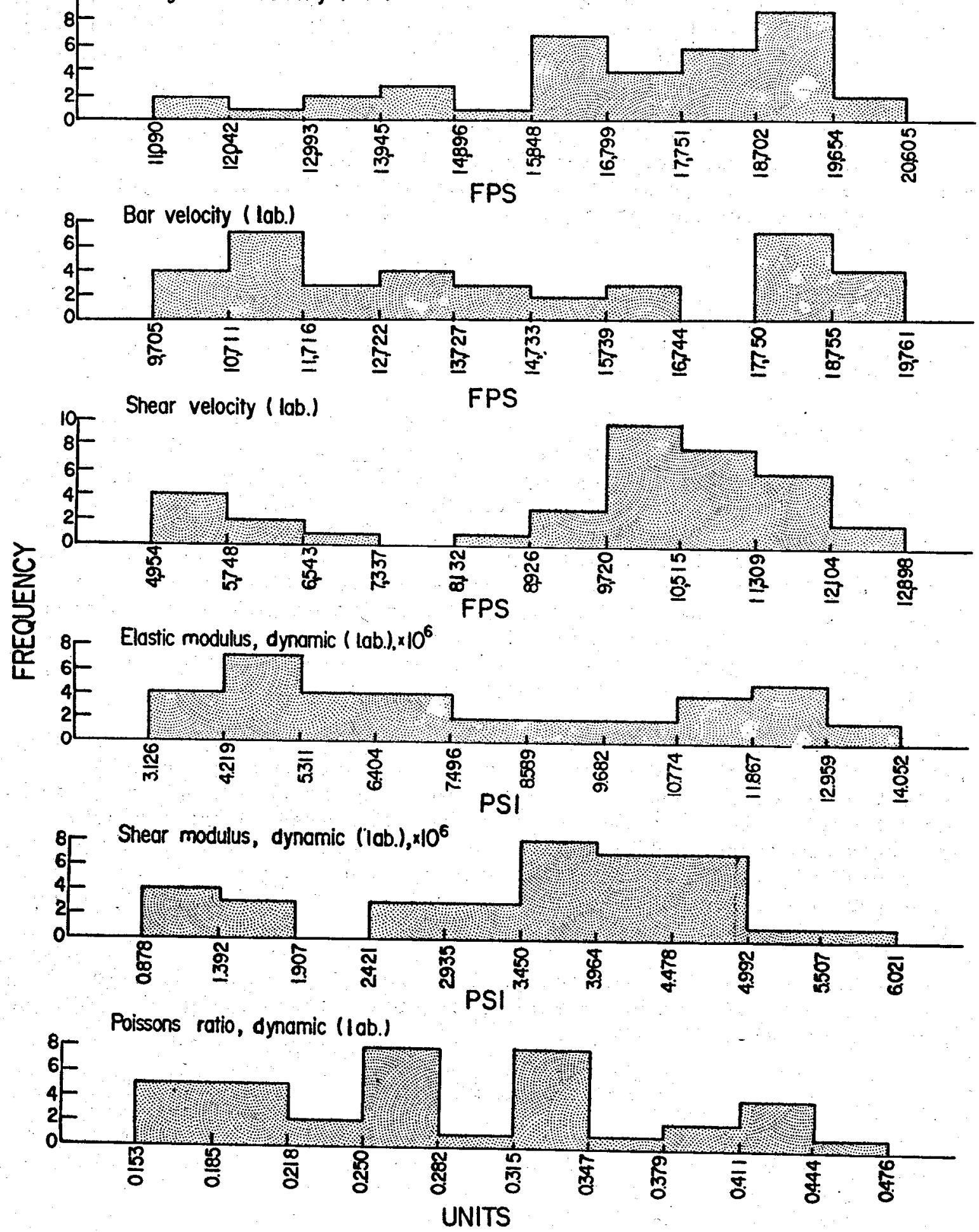

FIGURE 15. - Histograms of dynamic properties. 
velocity has a range between 11,090 and 20,605 fps, or a factor of nearly 2 . The data is skewed to the right having an average near 17,000. Bar velocity has a nearly uniform distribution throughout the range of 9,705 to 19,761 fps. A bimodal shape is apparent. The shear velocity is definitely skewed to the right with a mean of 9,724 fps. A bimodal distribution is again evident.

The derived dynamic elastic modulus exhibits a uniform distribution between $3.12 \times 10^{6}$ and $14.05 \times 10^{6}$ psi. Some bimodal shape is exhibited. This is in contrast to the static elastic modulus, which, as discussed previously, had a rather narrow band. The arithmetic mean, however, is $7.93 \times 10^{6}$ for the dynamic elastic modulus and $7.10 \times 10^{6}$ for the static elastic modulus.

Derived dynamic shear modulus exhibit a range and variability closely following the shear velocity. This is as expected since the velocity was used to calculate the modulus. The shear velocity and modulus are also the most bimodal shaped of any distribution.

Dynamic Poisson's ratio has a range of 0.153 to 0.476 with an unsymetrical bimodal distribution. The overall average is 0.290 . The histogram suggests two groups of data. One group between 0.153 and 0.282 has an average of 0.225 . The higher group between 0.315 and 0.476 has an average of 0.371. Owing to the brittle nature of the Revett Quartzite, only the lower value is accepted. Further assuming that the dynamically derived Poisson's ratio is higher than the static value in the same proportion as the elastic modulus previously discussed, the final static equivalent value for Poisson's ratio is 0.20 . No statically determined values are available for this project, except for a very few given in the finite element analysis section of this report, which confirms a static Poisson's ratio of less than 0.20 .

Figure 16 represents 28 elastic modulus values determined by the biaxial test procedure. A simplified class interval is shown. Analys is of all biaxial test data for the "best fit" of the load-deformation slope was done by computer methods. This extensive analysis (not discussed in this report) overwhelmingly demonstrated linear behavior for the biaxial load-deformation plot. The biaxial elastic modulus is presented as a loading secant modulus throughout the stress range based on this linearity of the "best fit" slope slope (37, pp. 293 and 339).

The biaxial test device and procedure are described in RI 6128 (15). Cores were tested at SMRC with hydraulic pressures between 1,200 and 2,600 psi, or concluded upon failure of the core.

\section{Analysis of Variance}

A fundamental statistical technique is called analysis of variance. It is utilized to determine if sets of data are from the same parent population or from different populations. Analysis of variance generates a test statistic, called the F-test, for which a given level of statistical significance is attached. The F-test hypothesis determines if data means taken from 
Biaxial plastic modulus, $\times 10^{6} \mathrm{psi}$

$n=28$

$\overline{\mathrm{X}}=7.91$

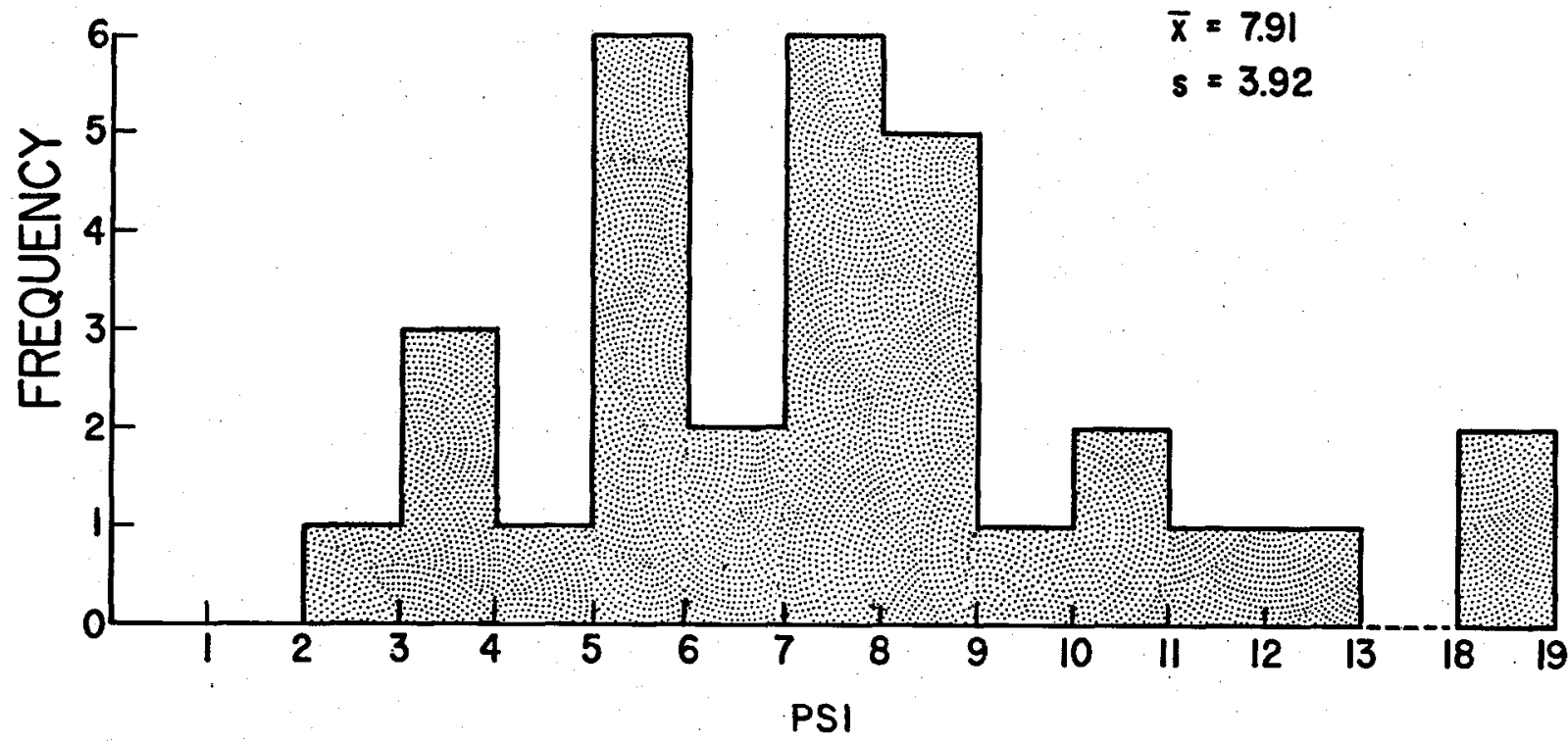

FIGURE 16. - Histogram of biaxial test results.

normally distributed populations, at the statistically significant level, are from the same or different populations. A detailed reference on the F-test method is by Guenther (17).

Two-way factorial analysis was first done to test for group differences between angular position and hole number, or location. Factolial runs were made for compressive strength and static elastic modulus. The term factorial identifies a type of experiment in which two or more independent variables are considered simultaneously. For both the compressive strength and static elastic modulus, there was found statistical significance between holes and angular position as follows:

Compressive Strength:

$F_{\text {Q at a }}$ (interaction) $=4.52, F_{95}$ percont $(4,117)=2.45$.

Static Elastic Modulus:

$F_{\text {data }}$ (interaction) $=12.16, F_{95}$ porcont $(4,117)=2.45$.

Since the interaction term is significant, individual one-way analysis of variance was then utilized to test for population differences. Therefore, further factorial analysis of compressive strength data, holding angular orientation fixed, found a critical difference between holes 1,2 , and 3 . $\left(F_{d a t a}=15.60, F_{95}\right.$ porcont $\left.(2,82)=3.06\right)$. Successive one-way analysis of variance tests between individual holes found significant differences between all paired hole combinations. 
Repeating the same factorial procedure for the static elastic modulus found no difference between the group of three holes. (Fata $=1.146$, F 95 percent $(2,84)=3.07)$. Successive one-way analysis of variance showed no significance between all paired hole combinations for static elastic modulus.

One-way analysis of variance was necessary to test for differences between angular orientation within holes. Results of the six runs are shown in table 4. It was found that there was no difference in angular position of sampling for either static elastic modulus or compressive strength at the 95 percent significance level except. for the compressive strength on hole 3 . This resolves the interaction effect found by the two-way factorial analysis.

TABLE 4. - One-way analysis of variance

\begin{tabular}{|c|c|c|c|}
\hline . & $\begin{array}{c}\text { Hole } 1 \\
\text { Test } 30,90, \\
150 \mathrm{deg}\end{array}$ & $\begin{array}{c}\text { Hole } 2 \\
\text { Test } 30,90, \\
150 \mathrm{deg}\end{array}$ & $\begin{array}{c}\text { Hole } 3 \\
\text { Test } 0,30,90, \\
120,150 \mathrm{deg} \\
\end{array}$ \\
\hline Elastic modulus...... & $\begin{array}{c}F_{\text {dat }}=3.15 \\
F_{95 \%}(2,40)=3.23 \\
\text { Not different }\end{array}$ & $\begin{array}{c}F_{d a t a}=0.46 \\
F_{85 \%}(2,16)=3.63 \\
\text { Not different }\end{array}$ & $\begin{array}{c}F_{\text {d } t}=1.72 \\
F_{95 \%}(4,18)=2.93 \\
\text { Not different }\end{array}$ \\
\hline Compressive strength. & $\begin{array}{c}F_{d a t}=2.28 \\
F_{\theta 5 \%}(2,40)=3.23 \\
\text { Not different }\end{array}$ & $\begin{array}{c}F_{d a t a}=1.04 \\
F_{95 \%}(2,16)=3.63 \\
\text { Not different }\end{array}$ & $\begin{array}{c}F_{d_{a} t_{a}}=3.73 \\
\mathrm{~F}_{85 \%}(4,18)=2.93 \\
\text { Significant }\end{array}$ \\
\hline
\end{tabular}

Intuitive relations to the preceeding analysis for significance in compressive strength but not for static elastic modulus are seen from the arithmetic means in table 5. Simple considerations of arithmetic means and standard deviation illustrate the difference in compressive strength but not in elastic modulus.

TABLE 5. - Means of compressive strength and elastic modulus

\begin{tabular}{c|c|c|c|c|c}
\hline \multirow{2}{*}{ Hole } & \multirow{2}{*}{$\begin{array}{c}\text { Number } \\
\text { of } \\
\text { samples }\end{array}$} & \multicolumn{2}{|c|}{ Compressive strength } & \multicolumn{2}{|c}{ Static elastic modulus } \\
\cline { 2 - 6 } & Mean, psi & $\begin{array}{c}\text { Standard } \\
\text { deviation, } \\
\text { psi }\end{array}$ & $\begin{array}{c}\text { Mean } \\
\text { psi } \times 10^{6}\end{array}$ & $\begin{array}{c}\text { Standard } \\
\text { deviation, } \\
\text { psi } \times 10^{6}\end{array}$ \\
\hline $1 \ldots \ldots \ldots \ldots \ldots \ldots$ & 43 & 32,790 & 8,561 & 7.10 & 1.04 \\
$2 \ldots \ldots \ldots \ldots \ldots$ & 19 & 24,395 & 8,394 & 7.81 & 1.84 \\
$3 \ldots \ldots \ldots \ldots \ldots$ & 23 & 17,778 & 6,812 & 7.00 & 2.99 \\
Overal1....... & 85 & 26,851 & 10,288 & 7.10 & 1.50 \\
\hline
\end{tabular}

This analysis is concluded by accepting the statement for compressive strength that some statistical significance exists between angular positions (hole 3 only) within the group of 3 holes and that there does exist a significant difference in mean compressive strength between holes on the basis of the given data. Or also stated--the Revett Quartzite is nearly isotropic in angular sample orientation but is inhomogeneous in sample location with respect to compressive strength. For static elastic modulus, the Revett appears to be isotropic with respect to both angular position and hole location (within this project's sampling). 
It is recalled that samples were more closely obtained along each hole length, than between holes, which were up to 30 feet apart. Also, note that the method of specimen preparation for compressive and elastic modulus values obtained from the core samples (see section on sample preparation) would consequently give oriented values normal to the borehole." From our geologic knowledge these values are therefore approximately in the dip plane of the rock (testing in the east-west plane of strike was not done). These considerations for the experimental procedures do not, however, appear sufficient to invalidate the conclusion for this project that there is a difference between hole location but not between angular orientation of sampling. In view of these conclusions, the authors are therefore justified in assuming an average value for the elastic modulus used for the in situ stress calculations. Use of compressive strength data will require more careful evaluation.

\section{Regression Analysis}

The use of computer facilities for stepwise regression analysis to correlate rock property data was done as the final step in physical property data analysis. This approach was prompted by the lack of an acceptable predictor for rock properties previously discussed in this investigation. The purpose of this study phase was to determine if it is possible to predict desired physical properties. In the manner of previous investigators $(\underline{9}, \underline{25}, \underline{35})$, the independent variable selected for correlation as a linear function of the remaining physical properties was the compressive strength and static elastic modulus. An additional analysis, to be described later, was made with selected combinations of physical property data to attempt a better correlation by assuming a curvilinear relationship.

As discussed previously, rock property measurements were made under uniform testing conditions at TCMRC and were collected from a single test site locality. This is considered essential for a meaningful regression analysis. Another important point made in this analysis is that each set of physical properties entered in the stepwise regression program are from the same rock core specimen. The rationale is to see how well all sample sets, in the aggregate, can be used to predict a particular rock property. The range of data and standard deviations have been compared previously in table 3. The histograms and data plots show distinct discrepancies between all rock properties. A resolution to the problem by stepwise regression was considered app1icable.

The computer program for this analysis was an SMRC in-house stepwise linear regression program developed along the format given in Draper and Smith (12, pp. 171-195). Method of computer solution is based on Efroymson (14). The program is run on a CDC $3200^{13}$ at SMRC. Ten physical properties were used; Brazilian data and biaxial results were not included because of limited test results. Brazilian tests were obtained only with respect to hole 1 , and biaxial tests were not obtained on the same rock core as the other

${ }^{13}$ Reference to specific brands, trade names, makes, or models of equipment does not imply endorsement by the Bureau of Mines. 
test data. All data were used in the regression analysis without regard for hole number or angular position.

It should be recalled, however, that dynamic properties are interrelated $^{14}$ and are expected to show good correlation, but static properties are determined independently. Also, dynamic properties, although showing seemingly linear relationships, should be cautiously used because dependent variables were known to have been derived from the independent variable. This predetermined the interdependence between the computed variables and the properties from which these were calculated. For example, the three velocities (longitudinal, shear, and bar) were increasingly correlated to dynamic properties. The average correlation between al1 three velocities was 0.66 ; the average correlation between velocities and dynamic properties was 0.79 ; and the average correlation between the derived dynamic properties was 0.81 . As expected, those velocities used to calculate dynamic properties had correlations exceeding 0.95 . The high correlation between derived properties is, however, interpreted as validating the accuracy of laboratory test procedures. Any resulting regression equation that yields a correlation coefficient approaching 0.80 is considered to be of the same order of confidence as interdependent laboratory derived properties. That correlation level is seen as test criteria for succeeding results of regression analysis.

A matrix presentation for all physical property correlation is shown in table 6 that lists simple correlation coefficients obtained from the stepwise regression computer program. This table illustrates the high correlation between interdependent dynamic properties discussed previously. Prediction equations and significant statistics for each of the 10 variables are shown in table 7. These equations collectively illustrate typical symmetry developed from regression equations for physical properties. As noted, final correlation coefficients for dynamic properties that are derived from interdependent properties show exceptionally high correlation coefficients. Also observed is that for some properties, little improvement in the correlation coefficient is achieved after the first few terms are introduced.

14 Interrelated and interdependent as used herein refer to properties in which one is derived from the other. 
TABLE 6. - Pairwise stepwise regression correlations

\begin{tabular}{|c|c|c|c|c|c|c|c|c|c|c|}
\hline & Density & $\begin{array}{l}\text { Longitu- } \\
\text { dinal } \\
\text { velocity }\end{array}$ & Bar & $\begin{array}{c}\text { Shear } \\
\text { velocity }\end{array}$ & $\begin{array}{l}\text { Dynamic } \\
\text { elastic } \\
\text { modulus }\end{array}$ & $\begin{array}{c}\text { Dynamic } \\
\text { shear } \\
\text { modulus }\end{array}$ & $\begin{array}{c}\text { Dynamic } \\
\text { Poisson's } \\
\text { ratio } \\
\end{array}$ & $\begin{array}{l}\text { Compres - } \\
\text { sive } \\
\text { strength }\end{array}$ & $\begin{array}{l}\text { Static } \\
\text { elastic } \\
\text { modulus }\end{array}$ & $\begin{array}{c}\text { Shore } \\
\text { hardness }\end{array}$ \\
\hline $\begin{array}{l}\text { Density ....... } \\
\text { Longitudinal }\end{array}$ & 1.000 & - & - & - & $\therefore$ & - & - & - & - & - \\
\hline velocity...... & .405 & 1.000 & - & - & - & - & - & - & - & - \\
\hline $\begin{array}{l}\text { Bar velocity... } \\
\text { Shear velocity. }\end{array}$ & $\begin{array}{l}287 \\
.058\end{array}$ & $\begin{array}{l}.712 \\
.461\end{array}$ & $\begin{array}{r}1.000 \\
.811\end{array}$ & 1.000 & - & - & - & - & - & - \\
\hline $\begin{array}{l}\text { Dynamic } \\
\text { elastic }\end{array}$ & 320 & $7 / 3$ & & 776 & 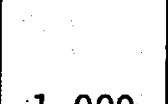 & & & & & \\
\hline $\begin{array}{l}\text { modulus } . . . . \\
\text { Dynamic shear }\end{array}$ & .320 & .743 & .995 & .776 & 1.000 & - & - & - & - & - \\
\hline$\underset{\text { Dynamic }}{\operatorname{modulus} . . . .}$ & .200 & .534 & .833 & .958 & .816 & 1.000 & - & - & - & - \\
\hline Poisson's & & & & & & & & & & \\
\hline $\begin{array}{l}\text { ratio......... } \\
\text { Compressive }\end{array}$ & -.058 & -.331 & -.862 & -.800 & -.850 & -.778 & 1.000 & - & - & - \\
\hline $\begin{array}{l}\text { strength...... } \\
\text { static elastic }\end{array}$ & -.211 & ${ }^{1}-.354$ & -.271 & -.140 & -.263 & -.210 & .017 & 1.000 & - & - \\
\hline $\begin{array}{l}\text { modulus....... } \\
\text { Shore }\end{array}$ & .066 & ${ }^{1} .252$ & .279 & .204 & ${ }^{1} .301$ & .220 & -.271 & 1.316 & 1.000 & - \\
\hline hardness..... & .206 & .046 & .247 & .323 & .214 & .321 & -.274 & -.415 & .015 & 1.000 \\
\hline
\end{tabular}

Pairwise correlations having the best pairwise correlation from independent physical properties. 
TABLE 7. - Stepwise regression predictor equation coefficient

\begin{tabular}{|c|c|c|c|c|c|c|c|c|c|c|c|c|c|c|}
\hline - & B & Dens ity & $\begin{array}{c}\text { Longltudinal } \\
\text { velocity }\end{array}$ & $\begin{array}{c}\text { Bar } \\
\text { veloctty }\end{array}$ & $\begin{array}{l}\text { Shear } \\
\text { velocity }\end{array}$ & $\mid \begin{array}{l}\text { Dynamic } \\
\text { elast } 1 \text { c } \\
\text { modulus }\end{array}$ & $\mid \begin{array}{c}\text { Dynamic } \\
\text { shear } \\
\text { modulus }\end{array}$ & $\begin{array}{c}\text { Dynamlc } \\
\text { Po1sson's } \\
\text { rat10 }\end{array}$ & $\begin{array}{c}\text { Shore } \\
\text { hardness }\end{array}$ & $\begin{array}{r}\text { Static } \\
\text { elastic } \\
\text { modulus }\end{array}$ & $\begin{array}{l}\text { Compressive } \\
\text { strength }\end{array}$ & $\begin{array}{c}\text { Standard } \\
\text { deviation } \\
\text { Sy }\end{array}$ & $\begin{array}{c}\text { fultiple } \\
\text { correlation } \\
\text { coef- } \\
\text { ficient, } \\
n\end{array}$ & $\begin{array}{c}\text { Residual } \\
\text { sum } \\
\text { squares } \\
\text { (RSS) }\end{array}$ \\
\hline Dens1ty..... & 2.50 & - & $\begin{array}{l}-3.956 \times 10^{-5} \\
0.405 \\
1\end{array}$ & $\begin{array}{l}0.000126 \\
0.715 \\
8\end{array}$ & $\begin{array}{l}-2.38 \times 10^{-5} \\
0.498 \\
3\end{array}$ & $\begin{array}{l}0.199 \\
0.622 \\
5\end{array}$ & $\begin{array}{l}0.0452 \\
0.612 \\
4\end{array}$ & $\begin{array}{l}2.64 \\
0.662 \\
6\end{array}$ & $\begin{array}{l}0.00480 \\
0.446 \\
2\end{array}$ & $\begin{array}{l}-0.0122 \\
0.733 \\
9\end{array}$ & $\begin{array}{l}4.502 \times 10^{-6} \\
0.699 \\
7\end{array}$ & 0.00862 & 0.733 & 0.520 \\
\hline $\begin{array}{r}\text { Longltudinal } \\
\text { velocity... }\end{array}$ & 11,397 & $\begin{array}{l}-2,532 \\
0.963 \\
6\end{array}$ & - & $\begin{array}{l}-2.455 \\
0.942 \\
3\end{array}$ & $\begin{array}{l}1.042 \\
0.952 \\
4\end{array}$ & $\begin{array}{l}3,497 \\
0.743 \\
1\end{array}$ & $\begin{array}{l}-1,059 \\
0.962 \\
5\end{array}$ & $\begin{array}{l}40,115 \\
0.937 \\
2\end{array}$ & $\begin{array}{l}26.525 \\
0.966 \\
7\end{array}$ & $\begin{array}{l}-59.554 \\
0.968 \\
9\end{array}$ & $\begin{array}{l}0.0223 \\
0.967 \\
8\end{array}$ & 690 & 0.968 & $3.33 \times 10^{7}$ \\
\hline $\begin{array}{l}\text { Bar } \\
\text { velocity... }\end{array}$ & 5,140 & $\begin{array}{l}-515 \\
0.999 \\
8\end{array}$ & $\begin{array}{l}-0.157 \\
0.998 \\
5\end{array}$ & - & $\begin{array}{l}0.388 \\
0.997 \\
2\end{array}$ & $\begin{array}{l}1,098 \\
0.995 \\
1\end{array}$ & $\begin{array}{l}-413 \\
0.998 \\
3\end{array}$ & $\begin{array}{l}6402 \\
0.999 \\
6\end{array}$ & $\begin{array}{l}7.90 \\
0.999 \\
7\end{array}$ & $\begin{array}{l}-25.42 \\
0.999 \\
9\end{array}$ & $\begin{array}{l}0.00176 \\
0.998 \\
4\end{array}$ & 174 & 0.999 & $2.13 \times 10^{6}$ \\
\hline $\begin{array}{l}\text { Shear } \\
\text { velocity... }\end{array}$ & $-2,349$ & $\begin{array}{l}-344 \\
0.968 \\
2\end{array}$ & $\begin{array}{l}0.235 \\
0.987 \\
8\end{array}$ & $\begin{array}{l}1.369 \\
0.973 \\
6\end{array}$ & - & $\begin{array}{l}-1.51 \\
0.983 \\
7\end{array}$ & $\begin{array}{l}1,212 \\
0: 958 \\
1\end{array}$ & $\begin{array}{l}-9,919 \\
0.970 \\
3\end{array}$ & $\begin{array}{l}-5.39 \\
0.971 \\
4\end{array}$ & $\begin{array}{l}13.29 \\
0.987 \\
9\end{array}$ & $\begin{array}{l}0.00452 \\
0.972 \\
5\end{array}$ & 328 & 0.987 & $7.51 \times 10^{6}$ \\
\hline $\begin{array}{l}\text { Dynamic } \\
\text { elastic } \\
\text { modulus, }\end{array}$ & -4.284 & $\left\{\begin{array}{l}0.630 \\
0.999 \\
7\end{array}\right.$ & $\begin{array}{l}0.000173 \\
0.998 \\
4\end{array}$ & $\begin{array}{l}0.000849 \\
0.995 \\
1\end{array}$ & $\begin{array}{l}-0.000331 \\
0.996 \\
2\end{array}$ & - & $\begin{array}{l}0.358 \\
0.997 \\
3\end{array}$ & $\begin{array}{l}-7.470 \\
0.999 \\
5\end{array}$ & $\begin{array}{l}-0.00824 \\
0.999 \\
6\end{array}$ & $\begin{array}{l}0.0261 \\
0.999 \\
8\end{array}$ & $\begin{array}{l}-4.380 \times 10^{-3} \\
0.999 \\
9\end{array}$ & 0.153 & 0.999 & 1.65 \\
\hline $\begin{array}{l}\text { Dynamic } \\
\text { shear } \\
\text { modulus. }\end{array}$ & 0.949 & $\begin{array}{l}0.385 \\
0.969 \\
2\end{array}$ & $\begin{array}{l}-0.000141 \\
0.980 \\
6\end{array}$ & $\begin{array}{l}-0.000859 \\
0.977 \\
4\end{array}$ & $\begin{array}{l}0.000714 \\
0.958 \\
1\end{array}$ & $\begin{array}{l}0.961 \\
0.971 \\
3\end{array}$ & - & $\begin{array}{l}5.65 \\
0.982 \\
7\end{array}$ & $\begin{array}{l}0.00410 \\
0.982 \\
8\end{array}$ & $\begin{array}{l}-0.00705 \\
0.982 \\
9\end{array}$ & $\begin{array}{l}-4.09 \times 10^{-6} \\
0.979 \\
5\end{array}$ & 0.251 & 0.982 & 4.43 \\
\hline $\begin{array}{l}\text { Dynamic } \\
\text { Poisson's } \\
\text { ratio. }\end{array}$ & -0.173 & $\begin{array}{l}0.0821 \\
0.980 \\
6\end{array}$ & $\begin{array}{l}1.952 \times 10^{-5} \\
0.952 \\
2\end{array}$ & $\left\{\begin{array}{l}4.875 \times 10^{-5} \\
0.862 \\
1\end{array}\right.$ & $\mid \begin{array}{l}-2.140 \times 10^{-6} \\
0.971 \\
4\end{array}$ & $\begin{array}{l}-0.0736 \\
0.962 \\
3\end{array}$ & $\begin{array}{l}0.0207 \\
0.978 \\
5\end{array}$ & - & $\begin{array}{l}-0.000870 \\
0.982 \\
7\end{array}$ & $\begin{array}{l}0.00225 \\
0.985 \\
9\end{array}$ & $\begin{array}{l}-1.001 \times 10^{-6} \\
0.985 \\
8\end{array}$ & 0.0152 & 0.985 & 0.0162 \\
\hline $\begin{array}{l}\text { Shore } \\
\text { hardness... }\end{array}$ & -80.0 & $\begin{array}{l}45.66 \\
0.601 \\
4\end{array}$ & $\begin{array}{l}0.00394 \\
0.555 \\
3\end{array}$ & $\begin{array}{l}0.0184 \\
0.746 \\
9\end{array}$ & $\begin{array}{l}-0.00355 \\
0.494 \\
2\end{array}$ & $\begin{array}{l}-24.79 \\
0.639 \\
7\end{array}$ & $\begin{array}{l}4.587 \\
0.637 \\
6\end{array}$ & $\begin{array}{l}-266 \\
0.694 \\
8\end{array}$ & - & $\begin{array}{l}1.753 \\
0.627 \\
5\end{array}$ & $\begin{array}{l}-0.000721 \\
0.415 \\
1\end{array}$ & 8.410 & 0.746 & 4951 \\
\hline $\begin{array}{l}\text { Static } \\
\text { elastic } \\
\text { modulus. }\end{array}$ & 15.48 & $\left\{\begin{array}{l}-4.435 \\
0.611 \\
6\end{array}\right.$ & $\begin{array}{l}-0.000339 \\
0.618 \\
7\end{array}$ & $\begin{array}{l}-0.00227 \\
0.536 \\
3\end{array}$ & $\begin{array}{l}0.000336 \\
0.620 \\
8\end{array}$ & $\begin{array}{l}3.01 \\
0.509 \\
2\end{array}$ & $\begin{array}{l}-0.302 \\
0.621 \\
9\end{array}$ & $\begin{array}{l}26.39 \\
0.587 \\
5\end{array}$ & $\begin{array}{l}0.0672 \\
0.566 \\
4\end{array}$ & - & $\begin{array}{l}0.000125 \\
0.316 \\
1\end{array}$ & 1.647 & 0.621 & 190 \\
\hline $\begin{array}{c}\text { Compressive } \\
\text { strength... }\end{array}$ & 14,406 & $\begin{array}{l}27,354 \\
0.783 \\
6\end{array}$ & $\begin{array}{l}2.12 \\
0.533 \\
2\end{array}$ & $\begin{array}{l}2.62 \\
0.792 \\
7\end{array}$ & $\begin{array}{l}1.90 \\
0.795 \\
9\end{array}$ & $\begin{array}{l}-8,413 \\
0.760 \\
5\end{array}$ & $\begin{array}{l}-2,921 \\
0.793 \\
8\end{array}$ & $\begin{array}{l}-195,304 \\
0.693 \\
4\end{array}$ & $\begin{array}{l}-461 \\
0.415 \\
1\end{array}$ & $\begin{array}{l}2,085 \\
0.679 \\
3\end{array}$ & - & 6721 & 0.795 & $3.16 \times 10^{9}$ \\
\hline
\end{tabular}

NOTE. - Wherever three numbers in a column refer to one physical property, the first numeral is $\beta_{n}$ coefficlent at step (n), the 8 econd numeral is coefficient of correletion (n) at that step, and the third numeral is order of stepwise regression selection. 


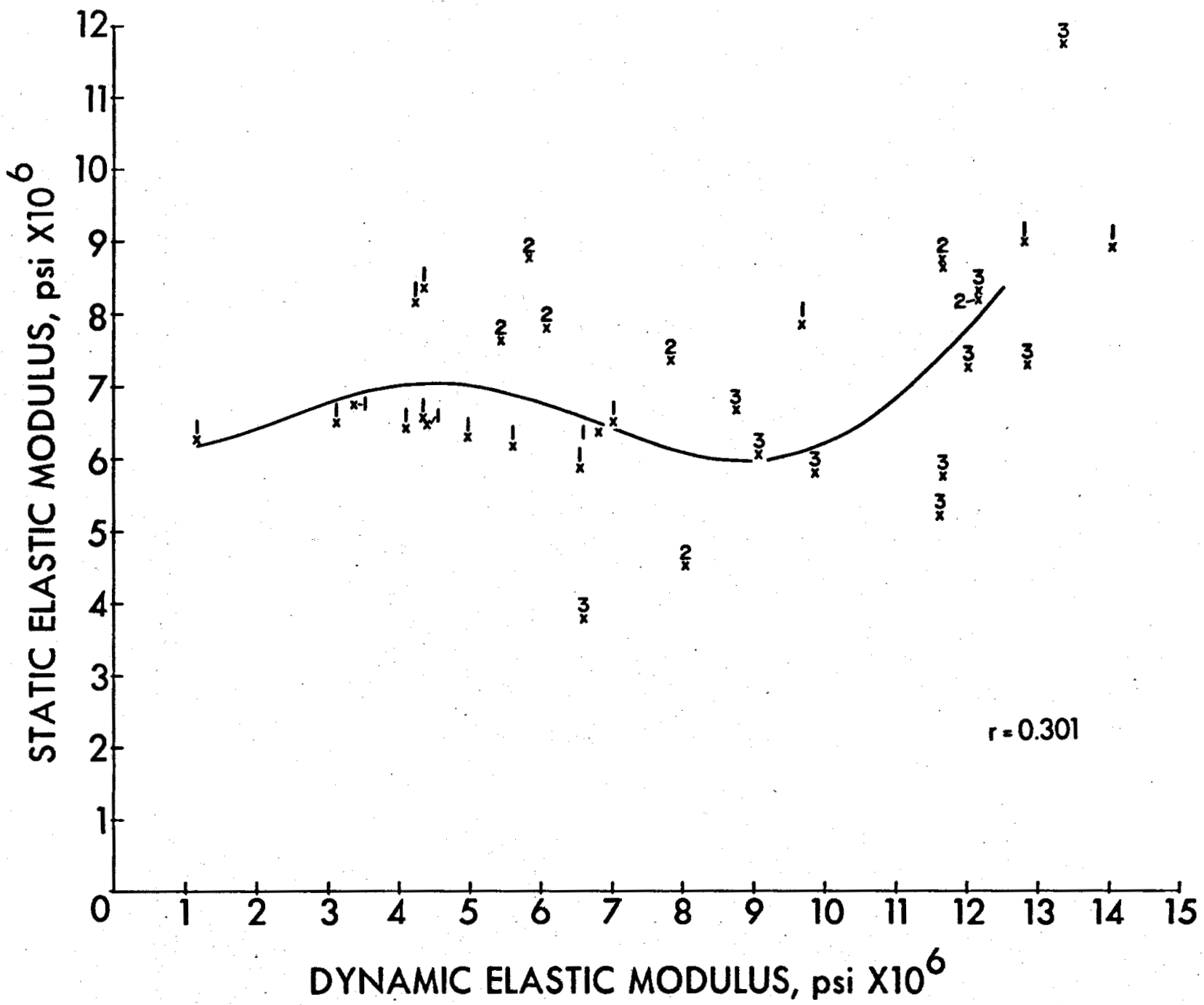

FIGURE 17. - Static elastic modulus versus dynamic elastic modulus.

Four pairwise correlations in table 6 having the best pairwise correlation from independent physical properties have been plotted as scattergram ${ }^{15}$ figures 17-20. Visual comparison of these plots readily points out difficulties in correlating rock properties. Noted is that plots with static elastic modulus commonly have "bands" of data, but the plots containing compressive strength show "bunching" of data.

Particularily significant is figure 18 wherein a few values of exceptionally high compressive strength and low longitudinal velocity from hole 1 have created a negative correlation. (This is completely the inverse of

${ }^{15}$ In these figures the curves are al1 computer-drawn best-fit fifth-degree curves, except for figure 20 , which also has a superimposed computer-drawn linear fit. Numbers $1-3$ refer to overcore hole numbers. 


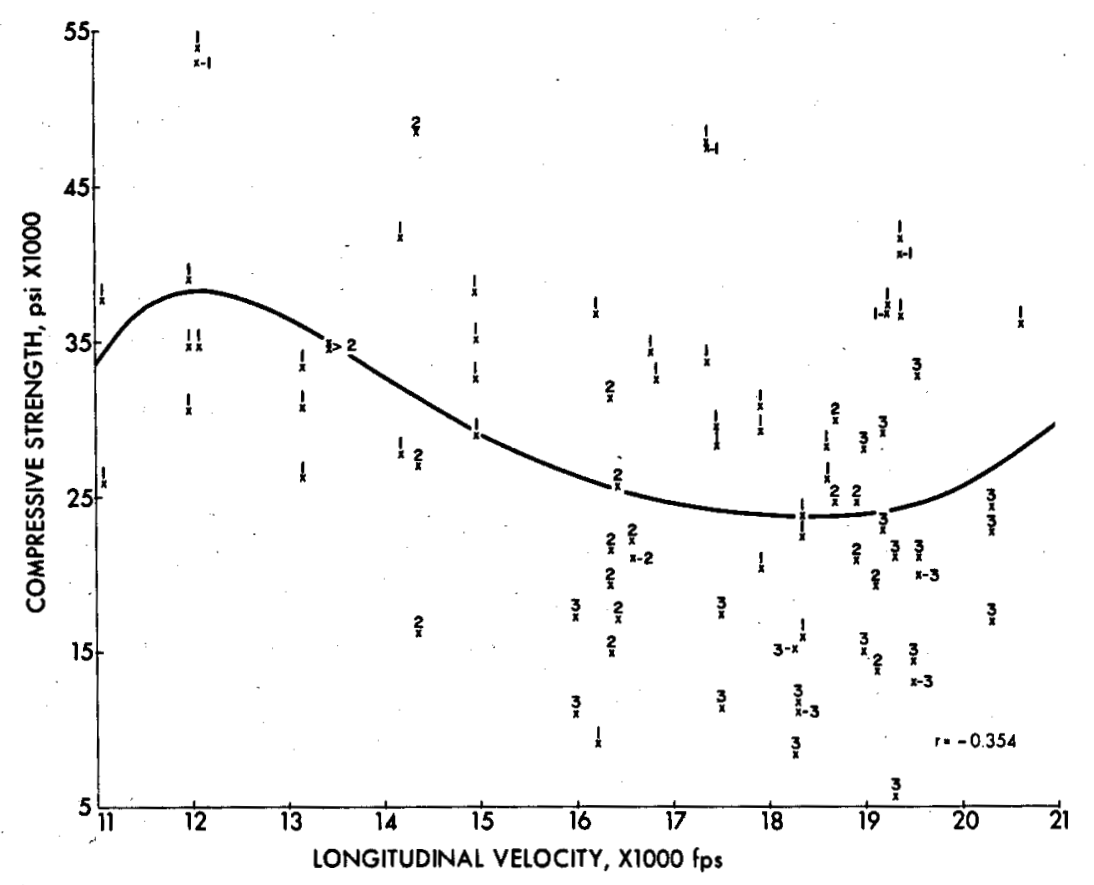

FIGURE 18. - Compressive strength versus longitudinal velocity.

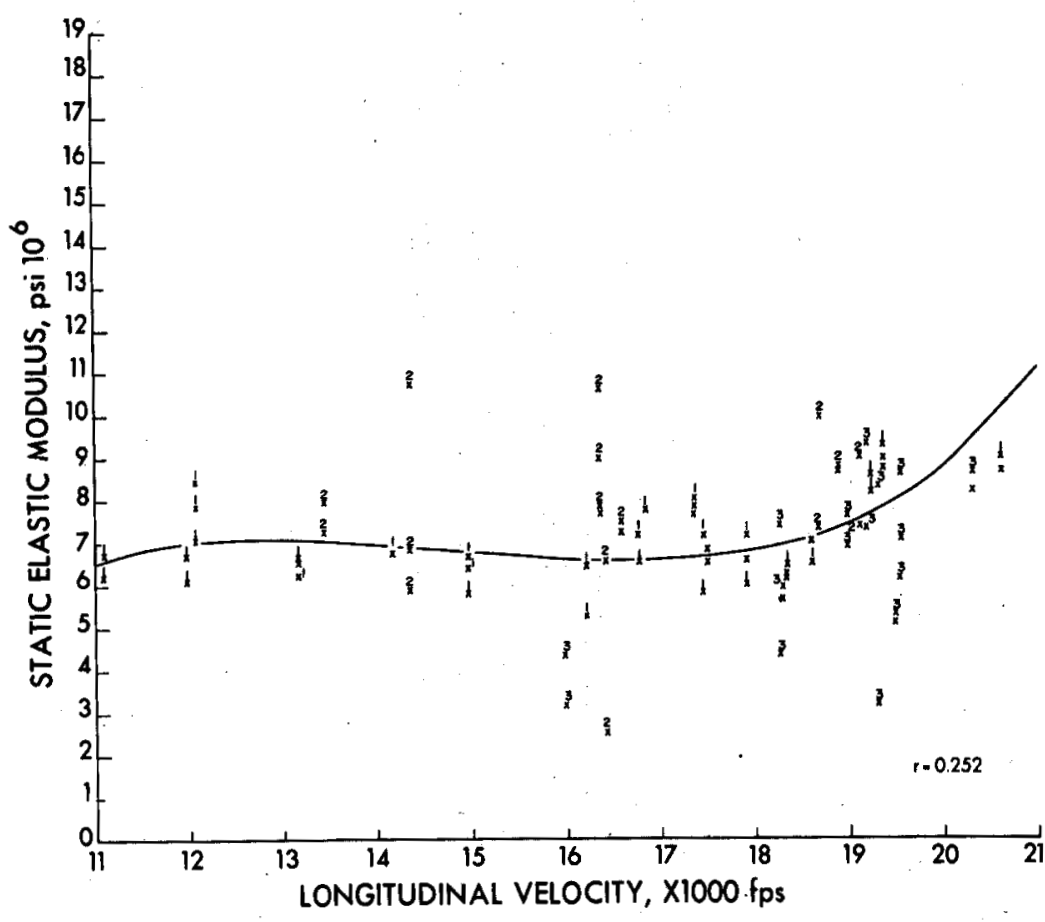

FIGURE 19. - Static elastic modulus versus longitudinal velocity. 


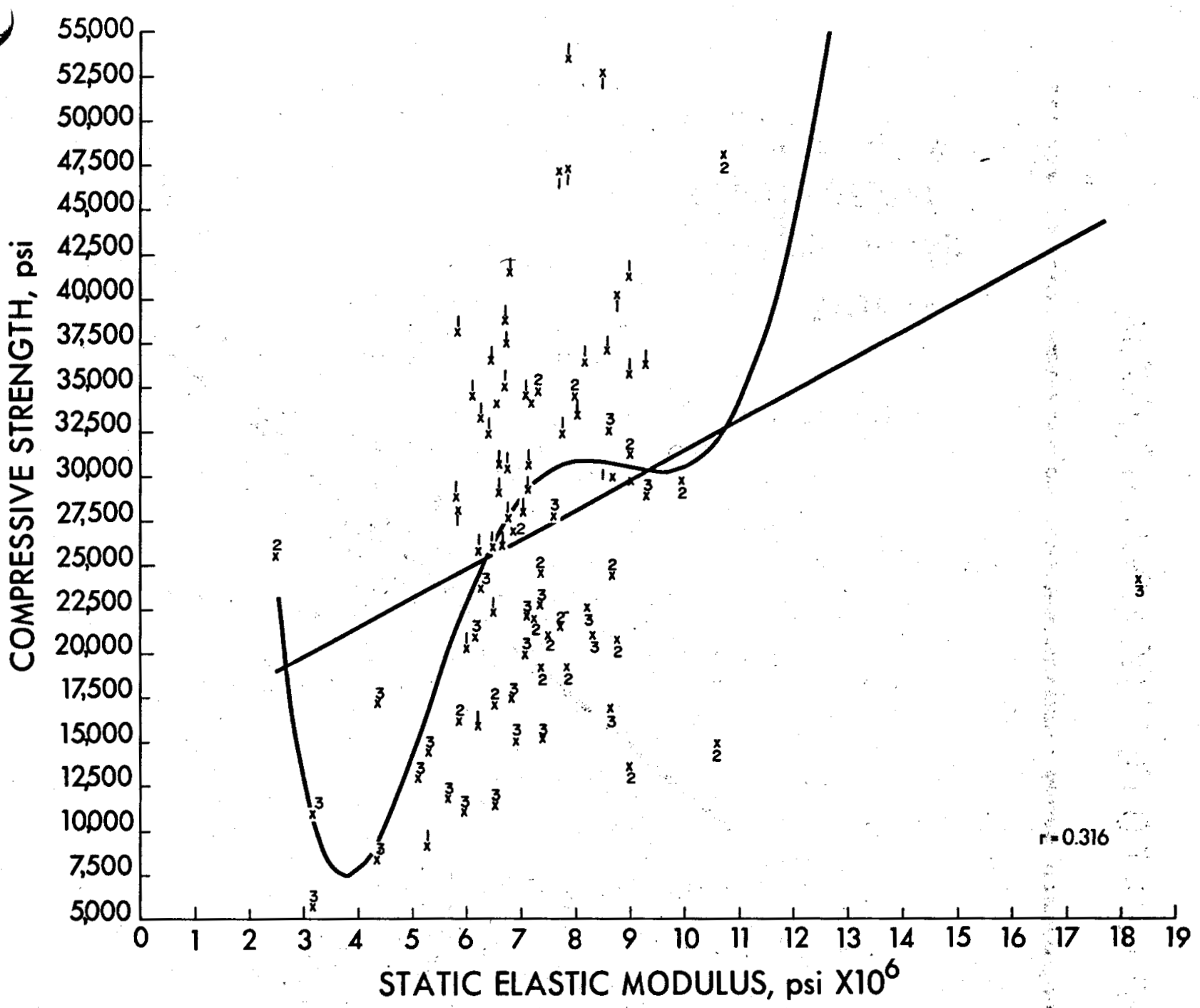

FIGURE 20. - Compressive strength versus static elastic modulus.

results from all other investigators.) Noted, however, is that the range of longitudinal velocity is only from 11,090 to $20,605 \mathrm{fps}$, but compressive strengths range from 5,700 to 53,400 psi.

Prediction equations from table 7 for static elastic modulus and compressive strength are plotted in figures 21-22. These plots show that acceptable estimates of physical properties can be obtained from simple functions of other rock properties (and which are considered herein as a suite of standard physical properties). A simple linear fit is shown on each figure with the standard deviation and correlation coefficient.

As noted throughout the overcoring and physical property testing, correspondence between angular orientation of borehole deformation and sample location was maintained. Therefore, an excellent opportunity was provided to jemplace numerical values of oriented in situ borehole deformation as another 


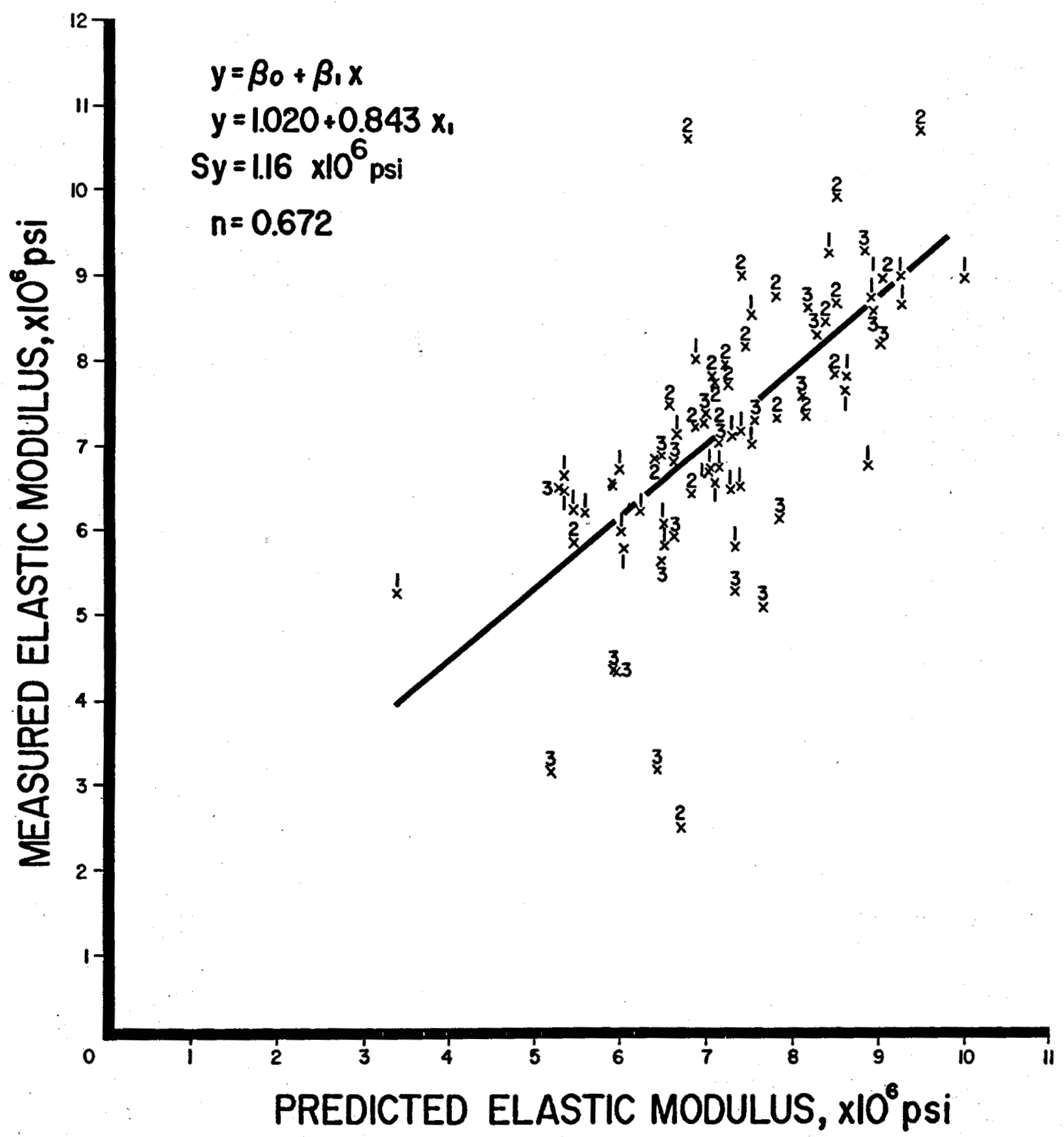

FIGURE 21. - Predicted and measured elastic modulus.

physical property into stepwise regression. Computer runs were therefore made for this problem using 37 values of corresponding borehole deformation with the static elastic modulus and compressive strength as independent variables.

With static elastic modulus as the independent variable, the ordering of variables was compressive strength, dynamic elastic modulus, and velocity 


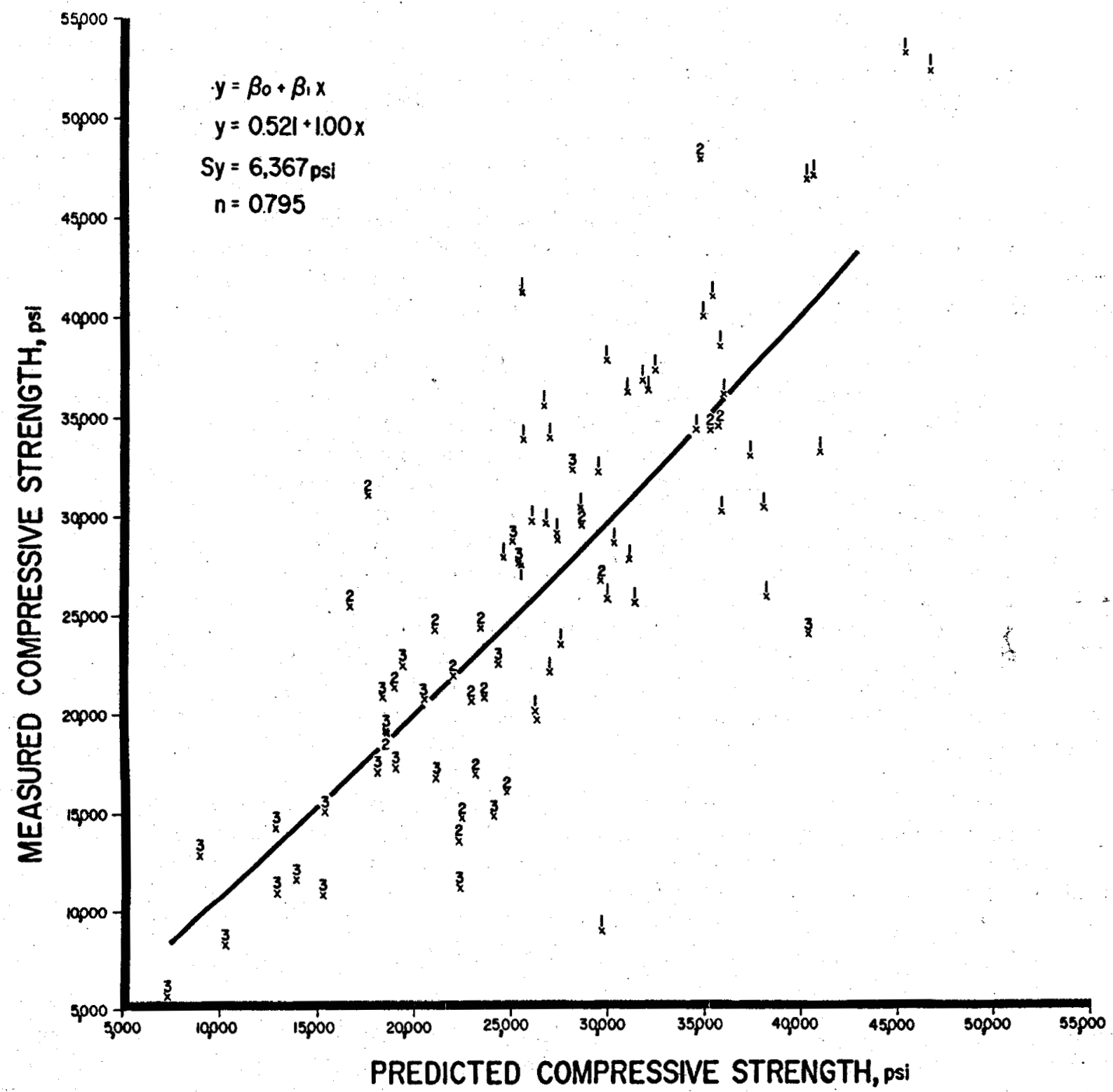

FIGURE 22. - Predicted and measured compressive strength.

with the remaining varlables following. Borehole deformation was the last variable selected. For compressive strength, the ordering of variables was Shore hardness, velocity, static elastic modulus, and borehole deformation. The remaining variables followed. Pairwise correlation shows that borehole deformation correlates highest with compressive strength $(r=0.345)$, density $(r=-0.234)$, static elastic modulus $(r=0.241)$, and very poorly with all others. Regression with borehole deformation as the independent variable shows the ordering of dependent variables as compressive strength, density, and static elastic modulus. The remaining variables follow. 
The interpretation of this physical property correlation including borehole deformation is that in situ deformation is best correlated with compressive strength and about equally well with static elastic modulus and velocity. Very poor correlation is obtained with all other properties, and these are judged to be insignificant with respect to in situ deformation by the overcore process. To be noted is that borehole deformations are strongly dependent upon direction and magnitude of the load; as well as being under the influence of localized stress concentration about the opening. Therefore, these results may contain unfair and biased correlations. They do, however, demonstrate the uniqueness of in situ deformation records and their dependency upon other than solely elastic modulus considerations.

As mentioned previously, depth of sample could not be conveniently constructed into a multilevel analysis of variance. An alternative procedure was to insert sample depth as a variable into stepwise regression. This resulted in a surprising demonstration of the importance of sample depth. For compressive strength, the ordering of variables was longitudinal velocity, static elastic modulus, Shore hardness, and depth of sample, with the remaining variables following. For static elastic modulus, the ordering of variables was similar with compressive strength, dynamic elastic modulus, longitudinal velocity, and depth of sample. Thus, in each case, depth of sample was the fourth most important variable selected and is interpreted as showing that the value of each independent variable depends very strongly upon its sample location. This information, coupled with the F-test results, illustrates the vital importance of obtaining oriented samples for the Revett Quartzite.

In conclusion, a summary of all statistical test procedures suggests that for the two independent variables examined, the compressive strength is more sensitive than the static elastic modulus with respect to hole location, angular orientation, and depth of sample.

\section{Curvilinear Analysis}

Analyses of this type are called curvilinear because the regression equation is represented as a warped surface. The degree of warp depends on the number and nonlinearity of the entering variables. Based on previous results of linear regression, a curvilinear trend has been suggested as a more accurate form of predictor. A random selection of sum terms of velocities, of product terms, squared terms of the previous variables, and logarithmic transformations were used. Such curvilinear relationship between variables has been indicated previously $(\underline{9}$, p. $9 ; \underline{23}, \mathrm{p}: 25)$.

The results, however, were rather disappointing. Although the curvilinear regression analysis selected a sequence of variables in much the same order as before in the linear analysis, it proceeded to use nonlinear variables before using linear terms in much the same ordering sequence as in the strictly linear analysis. However, the final multiple correlation coefficient (r) reached at the last step was only about 15 percent better, in total, than the linear stepwise regression. 
An alternate procedure was to select the highest pairwise correlations and form product terms. Two simple terms from these variables were able to account for nearly half the correlation. For compressive strength: longitudinal velocity times Shore hardness has a correlation coefficient, $r=0.464$. For static elastic modulus, compressive strength times dynamic elastic modulus has an $r=0.497$. Note that these $r$ 's are derived from individual $r$ 's from 0.30 to 0.35 .

Although curvilinear analysis, if pursued extensively, may happen upon very successful correlation terms--it was not explored further in this project. However, promise is shown that a moderately successful prediction equation for compressive strength and static elastic modulus can be developed from only a few physical properties and product terms of these properties. Curvilinear analysis does suggest the possibility of predicting static elastic modulus by regression with combined compressive strength and dynamic elastic modulus.

\section{Thermal Measurements}

In situ rock temperature and heat-flow determination data are included with these physical property data to complete all available data to date pertaining to this test site in the Crescent mine. Characteristics of in situ rock thermal behavior are described in RI 7589 (19). No thermal stress analysis was made for this report. However, the presence of large horizontal stresses can be theoretically attributed to an above-normal geothermal gradient.

\section{Rock Temperatures}

Soon after experimental work began at the test site, temperature measurements were taken in the ambient air and at the end of an NX hole (HL-4) that was drilled to a depth of 4 feet near overcore hole 4 . All temperatures were taken with the same Taylor thermometer (6-inch-1ength, mode1 6111). These temperature measurements were actively continued for the following 6 months and intermittently for the following year. During this time no change in air temperature was noted either in the air exiting from the fan line or in the drift air itself. The constant air temperature was $88^{\circ} \mathrm{F}$. Wet bulb temperatures of $86^{\circ}$ to $87^{\circ} \mathrm{F}$ indicated relative humidity in excess of 90 percent. At a depth of 4 feet into the $\mathrm{rib}$ of the access drift, the rock temperature was $92^{\circ}$ F. A 3-inch-thick polyurethane plug was placed at the collar of the drill hole to remove possible air temperature effects. Regular drift readings for a 6 -month interval were taken, but no observable change from $90^{\circ} \mathrm{F}$ was noted. A constant temperature environment was assumed for this report.

\section{Heat-F1ow Determinations}

In a previous investigation in the Crescent mine reported by Blackwel1 (6), heat-flow determinations were measured in two downward inclined dril1 holes on the 3300 level (DDH-841 and $\mathrm{DDH}-845)$. These holes are about 275 feet southeast from the test site along the access drift and were previously used for mineral exploration (fig. 4). Heat-flow measurements were made within month after the drill holes were completed. Average heat flow was 
calculated as $2.22 \times 10^{-6} \mathrm{cal} / \mathrm{cm}^{2} \mathrm{sec}$ for both holes. Thermal conductivity ranged from 7.80 to 14.70 and averaged $11.71 \times 10^{-3} \mathrm{cal} / \mathrm{cm} \mathrm{sec}{ }^{\circ} \mathrm{C}$ from 40 measurements in both holes. Blackwell's data from the northwestern United States indicate that the Coeur d'Alene mining region appears to be an area of higher than normal heat flow, but several anomolous zones are present, and present lack of data prevents exact definition throughout the region.

\section{Testing Procedures}

As mentioned previously, all testing was done at TCMR under uniform testing conditions and procedures. A detailed description of these test procedures will be contained in a forthcoming Bureau of Mines publication (28). Only such discussion of testing procedure is presented herein as are relevant to sample collection and specimen dimension. Deviations from standard test procedures are also noted.

Exact location of in situ overcore borehole deformation measurements made in the field were marked on overcore samples provided to TCMRC by SMRC (hole number and depth were also noted). Only one core specimen could be obtained by TCMRC from each such marking. Additional samples as necessary were obtained from the 6-inch-diameter cores by longitudinally parallel coring. Up to five corings were required to complete a suite of physical property data for each marked location. Completed cores of $3 / 4$ inch diameter and 1.5 to 4.5 inches in length were lapped for end parallelism. After visual inspection, samples were dried for 5 days in an evacuated oven at $150^{\circ} \mathrm{F}$. All laboratory tests were conducted at $72^{\circ} \mathrm{F}$. It should be noted that inherent rock defects frequently limited the number of representative specimens that could be obtained from each cored location. Fractures within the specimens further introduced unavoidable large variation in the data.

Dynamic properties were obtained on 4:1 length-to-diameter cores. The density and all dynamic elastic constants were determined from these specimens. Individual specimens were weighed, pulsed, and resonated according to accoustical testing procedures described in RI 6188 (22).

Replicated compression tests were performed on 2:1 length-to-diameter cores obtained from 4:1 cores. The static compressive strength and static elastic modulus were obtained from these cores. Test loading rate was applied to maintain constant deformation of $1.0 \times 10^{-5}$ inch/inch/second. Observations by TCMRC ${ }^{16}$ pertaining to compressive tests of Revett Quartzite indicates it is a very brittle rock that tends to exhibit chip defoliation under test. As discussed previously on specimen preparation, oriented cores were taken at marked points of in situ stress determination on the overcore. Therefore, the direction of compressive test is in a plane normal to the axis of the drill hole and oriented in the same angular position as the overcore borehole deformation.

${ }^{16}$ Personal communication with Peter Chamberlain, Twin Cities Mining Research Center, Twin Cities, Minn., Mar. 6, 1970. 
The Brazilian test method (indirect tensile) was used for all tensile testing. Test disk dimensions were prepared to length-to-diameter ratio of 1:2. Proper directionality became apparent during the course of testing in order to develop a tensile strength value having meaningful direction. Loading the Brazilian test specimen in the direction corresponding to the orlented overcore axial direction produces a tensile strength value in the tangential direction. Loading a specimen normal to the overcore axial direction produces a tensile strength corresponding to the axial direction of the overcore. Even with this problem resolved, an infinite number of loading directions are possible depending upon location of in situ deformation measurements as marked on the overcore. These difficulties were recognized and oriented Brazilian tests were made. However, since Brazilian tests were made only in hole 1 at six locations of depth (and at three orientations with two to four determinations each) it is recommended that the limited Brazilian tests presented herein (see physical property table 3 ) be interpreted as nonoriented data. ${ }^{17}$ Also, Brazilian test disks tend to break at random angles, lending support to a nonoriented situation.

Rock hardness (on the ends of prepared core specimens) was determined by the Shore scleroscope method. For hole 1, 10 measurements were made on each end of each specimen prepared in the laboratory and the average value for all cores at each depth presented. For core specimens from holes 2-3, the procedure was changed so that the average of 10 Shore hardness determinations on each end of each core specimen was presented.

\section{Summary}

This exhaustive analysis of physical properties--all from a test site sampling area enclosing a sphere of little more than 50 feet in diameter--has abundantly shown the variability of rock properties through histograms, selected plots, and extensive mathematical correlation analysis. Further, varlability was shown between samples taken at various depths in the hole, between various angular positions, and between three different drill holes from which core samples were obtained.

Overall results of this study indicate general correspondence with the works of Judd (23-24). The scatter of these investigator's data and combinations of data are evident from every aspect. Likewise, for this study, no single independent variable was found that would give a substantially high pairwise correlation. Report of investigations 6702 found that compressive strength and point load tensile strength were exceptionally highly correlated $(r=0.947)$. When at least one variable may be highly correlated, then a statistically accurate prediction equation may be formulated. This was found especially true for dynamic physical properties of this investigation. As discussed in RI 6702 ( 9 , p, 15) where one value is not derived from another, only limited relationship between data can be satisfactorily formulated to obtain an estimate of one property from the measurement of another property.

${ }^{17}$ Personal communication with Peter Chamberlain, Twin Cities Mining Research Center, Twin Cities, Minn., Mar. 6, 1970. 
Likewise, for the Revett Quartzite of this study, the best pairwise correlations for static elastic modulus and compressive strength range from $r=0.25$ to $r=0.35$.

Selected product terms of high pairwise correlations have $r$ 's not greater than $r=0.50$. Using data from all 10 physical properties, and a linear regression equation of the form $Y=\beta_{0}+\beta_{1} X_{1}+\beta_{2} X_{2}+\ldots \ldots \beta_{n} X_{1}$, the final correlation coefficient for static elastic modulus is $r=0.621$, and for compressive strength, $r=0.795$. These values, 0.621 and 0.795 , are about 25 percent less than, and nearly equal to, respectively, the lowest correlation between interdependent properties. Correlation between interdependently derived dynamic tests will show $r^{\prime}$ s greater than 0.80 . Selected interdependent properties will have, exceeding or nearly, $r=0.95$. Regression analysis suggests two prediction possibilities: (1) A moderately successful prediction equation for compressive strength and static elastic modulus can be developed from only a few physical properties, and (2) by combining compressive strength predictions from field data using longitudinal velocity and shore hardness with dynamic elastic modulus obtained from laboratory tests, a fairly complete physical property spectrum is generated. Note that a suite of field and laboratory properties will result with some properties suitable for cross correlation. The compressive strength and hardness properties, in addition to being useful for opening design, are useful drillability indices.

The elastic modulus and compressive strength data, when statistically treated (F-test methods), resulted in the statement that the Revett Quartzite is nearly isotropic with respect to static elastic modulus but inhomogeneous with respect to compressive strength. Several types of analysis were performed to explain this causation, which demonstrated that compressive strength is more sensitive to sample hole location, angular orientation, and depth of sample than is the static elastic modulus. The importance of obtaining correctly oriented samples cannot be overemphasized.

INITIAL DEFORMATION MEASUREMENTS

\section{Theory}

Previous portions of this report have extensively described borehole deformation behavior measured at the wall of the opening for the particular case, $r=a$. The overcore thesis was that when the surrounding stress field $\left(p_{0}\right)$ is totally relieved by means of a concentrically drilled larger diameter hole, borehole deformations measured across the diameter of a smaller central hole are related to that stress field both physically and mathematically. A corresponding thesis for the condition $r>a$ can also be applied very much in the same manner as the overcore technique with the same identical mathematical formulation, that is, Lame's thick wall cylinder theory and the Kirsh equations: To demonstrate this theory, three tests were conducted in a horizontal hole, overcore hole 4, drilled into the drift rib opposite hole 2 (fig. 5). The first test of the three validated the aforementioned concept by digital strain-gage readings taken in the manner similar to the overcore procedure with strip chart recordings used to verify the trend of data. Test 2 fully documented wall rock behavior with rock deformation monitored by strip chart 
recorders supplemented with digital readings. Test 3 attempted to duplicate the effort of test 2 . However, it did not yield results as expected owing to the presence of a localized high stress field resulting in wall rock failure. This stress was probably due to stress concentration effects about the access drift. Other valuable information was obtained and will be discussed later in this section.

\section{Experimenta1 Procedure}

An experimental program was developed using the experience of overcoring previously performed. The three field experiments used the basic 6-1/2-inchdiameter overcoring hole that was drilled to simulate the driving of a typical mine heading (ordinary overcore borehole deformation data was taken coincident to each of these three field tests during this simulation). To obtain deformation outside the hole boundary, it was necessary to drill two smaller holes in the horizontal plane on each side of the overcore hole (fig. 23). Distances into the rib were selected as one hole radius beyond the hole wall. A hole area ratio of about 10:1 was also selected as minimizing interaction effects. In subsequent analysis, the effect of the smaller hole was neglected.

Procedures for drilling this sequence of holes was to drill the EX hole for the overcore gage to completion. Then the 6-1/2-inch-diameter hole was collared concentrically over it and drilled to a depth of about. 8 inches. The drill was then moved 2 inches to the left side of the larger hole and a BX

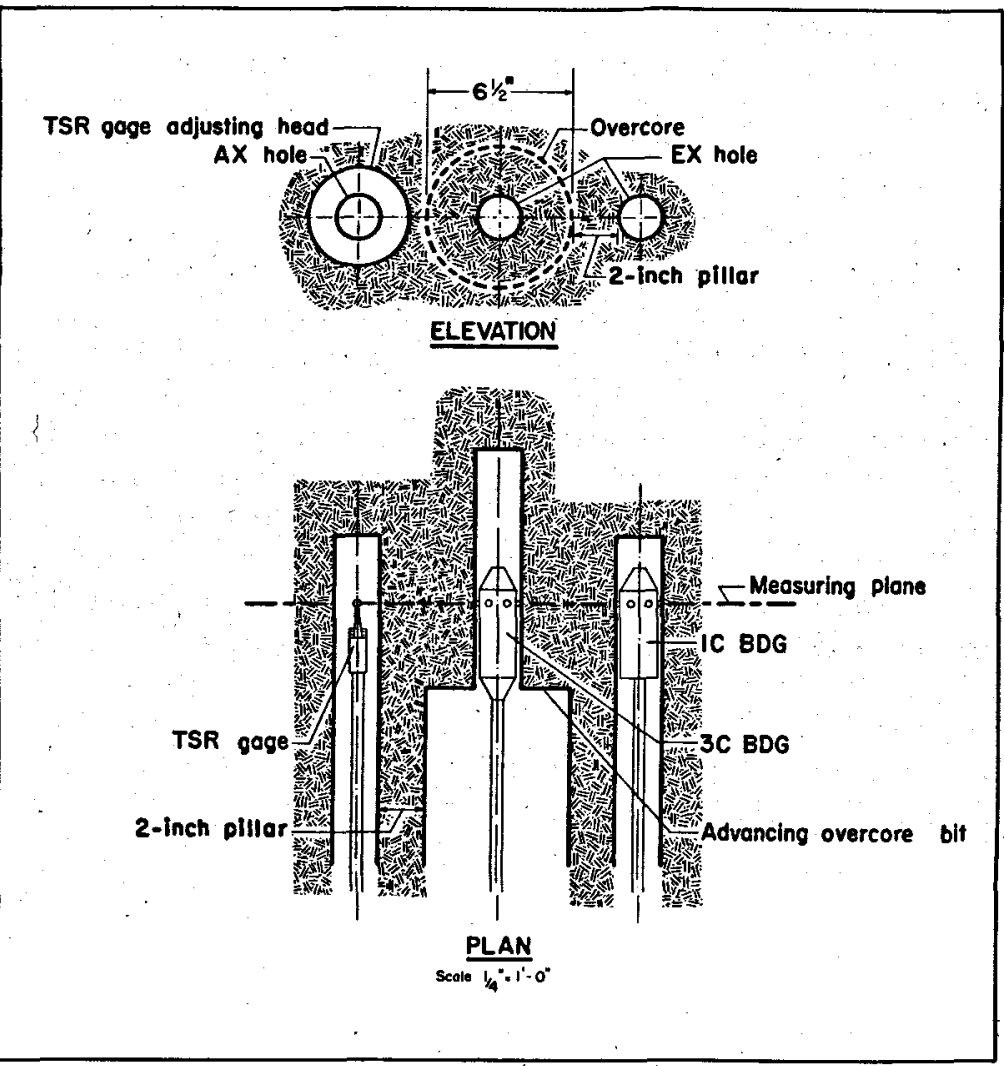

FIGURE 23. - Three-hole experimental procedure. hole drilled 18 inches deep and parallel to the overcore hole. The BX bit size, was then reduced, and the hole was completed to a total depth of 60 inches with an AX bit. This size difference allowed for more downhole clearance near the adjustment head. During the three tests, the tunnel stress relaxation (TSR) gage operated from this hole to monitor horizontal wall rock deformation. The TSR probe was rigidly held by an additional anchor arm grouted into overcore hole 3 and which extended to the vicinity of this $\mathrm{BX} / \mathrm{AX}$ hole (appendix B).

The drill was moved 2 inches to the right side of the overcore hole to drill a parallel EX hole to a depth of 60 inches. A 
single-component borehole deformation gage (1C BDG) monitored horizontal diameter change in this hole during all three tests. No attaching hardware was necessary for this gage. Figure 24 shows operations just after collaring all holes, and figure 25 shows operations during drilling with all gages operating.

\section{Test 1}

Test 1 was begun 21 inches from the collar with the TSR gage, 3-comonent overcore borehole deformation gage (3C BDG), and single-component borehole deformation gage all set at 25 inches. The test was carried to completion at a depth of 28 inches. This depth, based on previous overcore experience, was sufficient to effect an overcore run. Overcore drilling was done in the same manner as previous overcoring technique with no change from any procedures used previously in holes 1, 2, and 3 (appendix A).

Results from all three channels of the borehole deformation gage show the characteristic shape of an overcoring run as recorded by deformation on the walls of the central EX hole. The beginning part of the run shows an initial deformation excursion in the closure direction as the bit advances towards the gage. This closure reached a maximum at about one $\mathrm{EX}$ hole diameter before the point of gage placement, corresponding to results obtained from individual overcore runs in each of the previous three holes. Shortly after passing this point, normal relief of the overcore is apparent as the central EX hole deformation shows rapid expansion (dilation) until completion of the run when maximum overcore relief is indicated. Continuous records from all three channels are shown in figure 26 along with initial and final digital strain gage readings.

The EX hole on the right side, containing the single-component borehole deformation gage and using only digital readings at intervals, showed a horizontal hole expansion of 40 and 155 microinches near the gage and at completion of the run, respectively. These data were simply used to confirm the event, and no real interpretation of rock behavior was expected. However, it is evident that since the single-component borehole deformation gage records only total diameter change, the nearby larger diameter overcore hole must only have experienced closure (when oriented with respect to the large hole in the horizontal radial direction). Closure of the smaller EX hole is not admissible from these data. Also, it confirms that during the overcore process there occurs an initial closure deformation on the edge of the larger diameter (6-1/2-inch) overcore drill hole that is opposite to the expansion of the central EX hole within the core stub. (This fact also substantiates another aspect of stress-relief theory.) A complete record of the single-component borehole gage was obtained on test 2 and will be discussed later. 


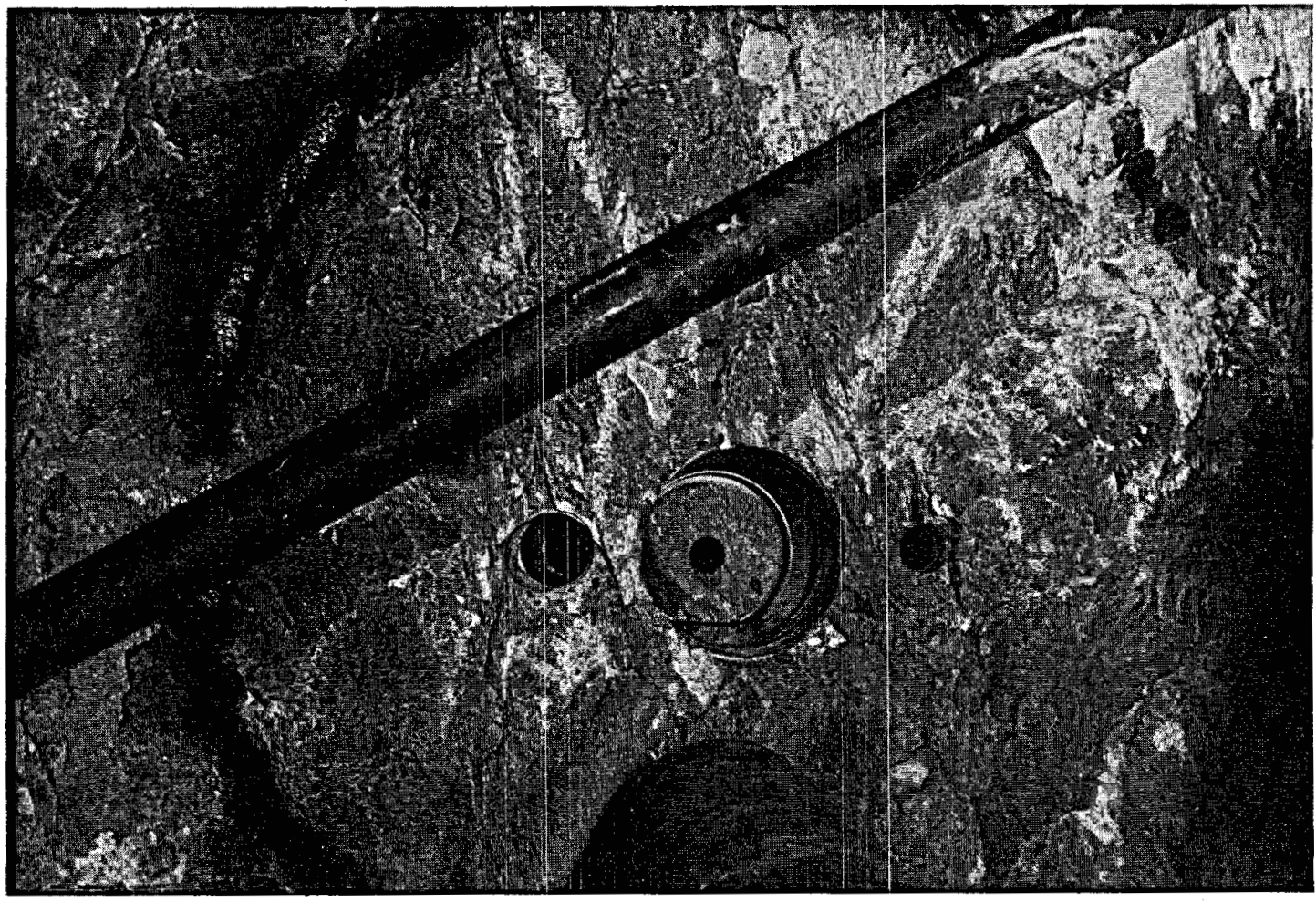

FIGURE 24. - Drill hole layout at collar.

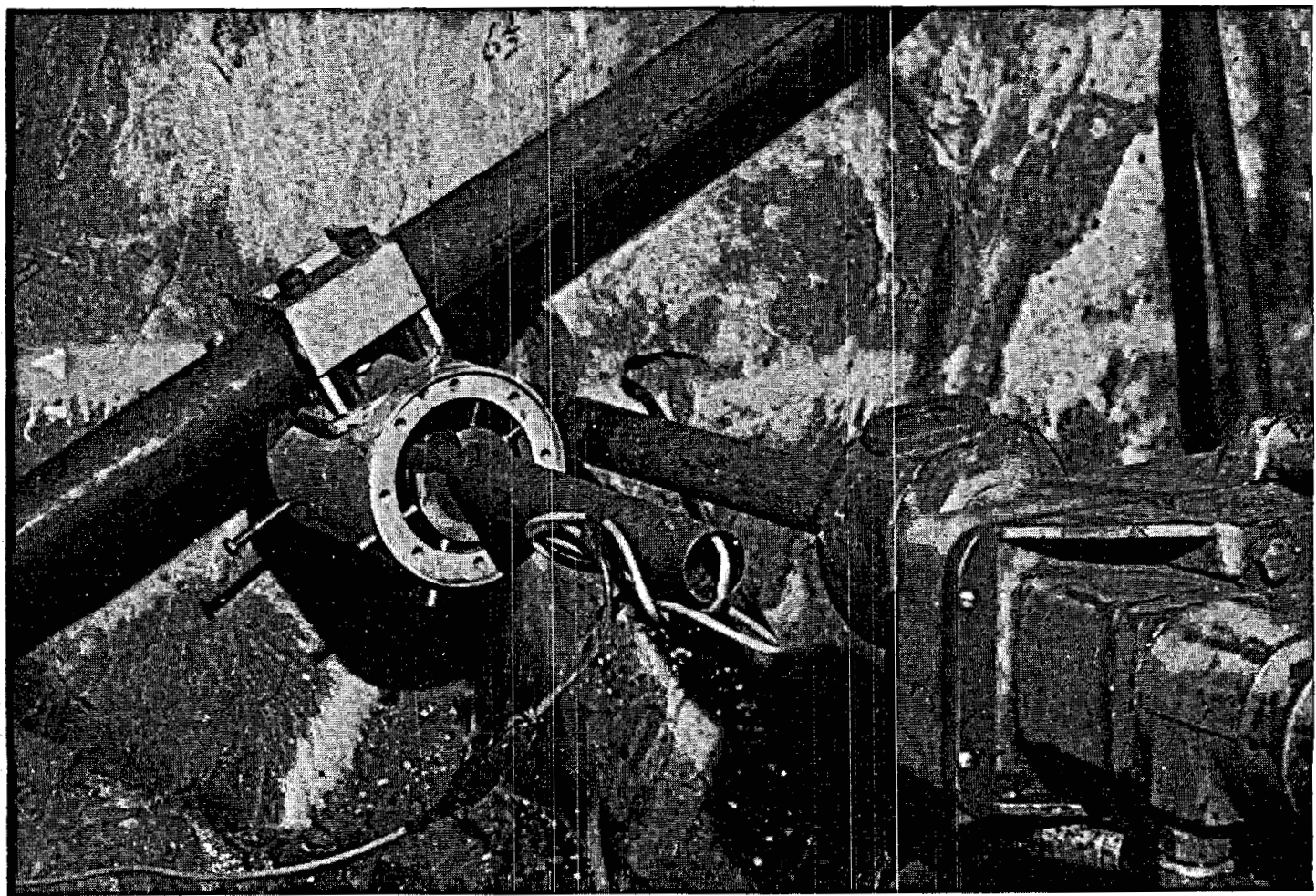

FIGURE 25. - Three-hole experiment during field tests. 

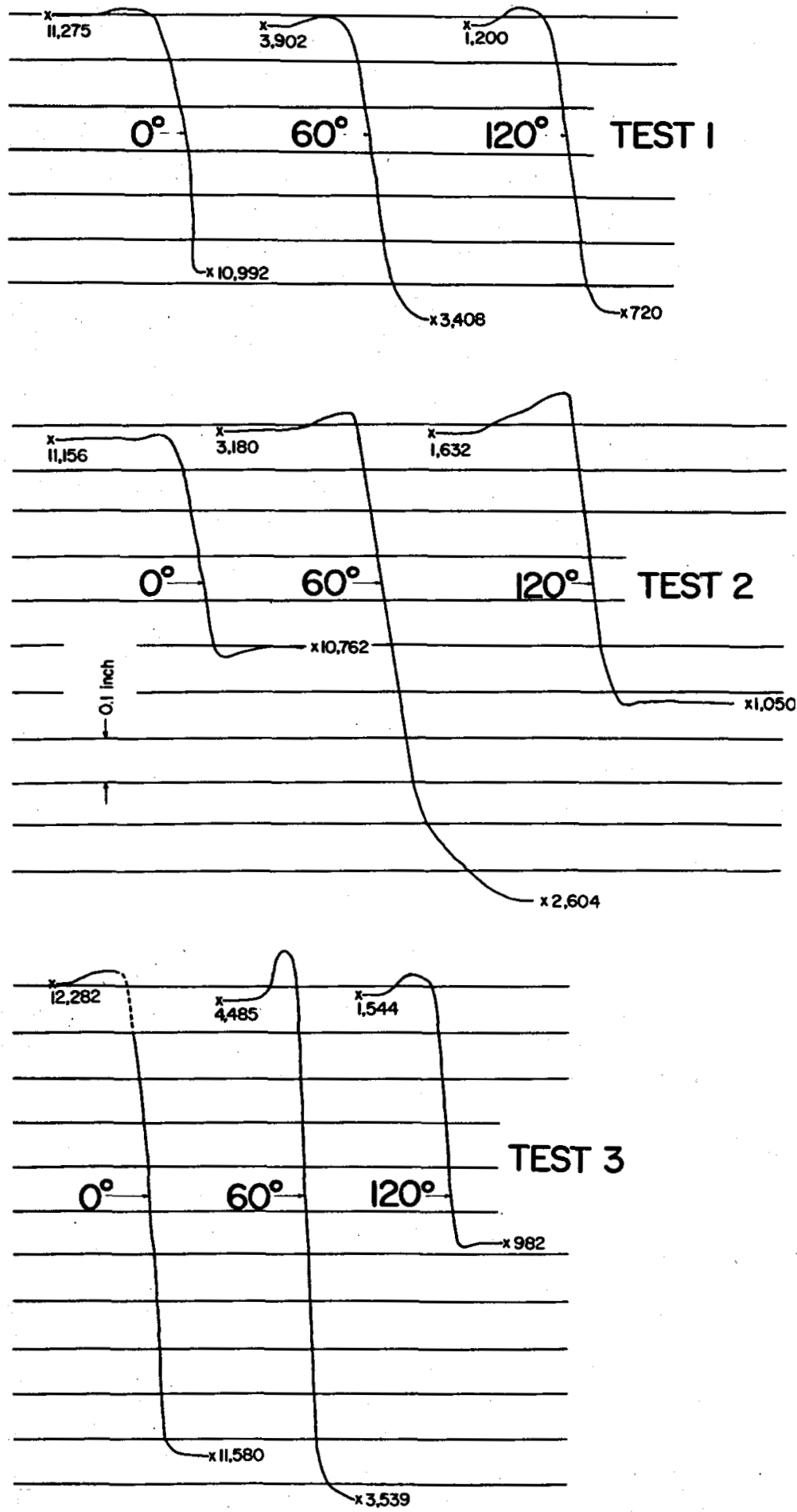

FIGURE 26. - Overcore record, tests 1, 2, 3.
The tunnel stress relaxation gage (TSR) placed in the left side AX hole was better able to define actual direction of rock movement at depth in the rib rock adjacent to the overcore hole. Figure 27 shows TSR deformation recorded in test 1. As shown, deformation initially has a barely perceptable closure direction. This was corroborated with a digital gage reading that indicated approximate1y 60 microinches closure. This movement, although slight, appears to be valid data (the same occurrence was observed in tests 2 and 3 ). Thereafter, as overcore drilling continued, rib rock deformation began a dilation excursion that reached a maximum of about 500 microinches near 1-1/2 inches before the point of gage placement. Beyond the maximum dilation excursion, rib rock deformation experienced

reversal going toward the overcore hole, or closure deformation. Increased closure continued until completion of the overcore run, which was terminated 


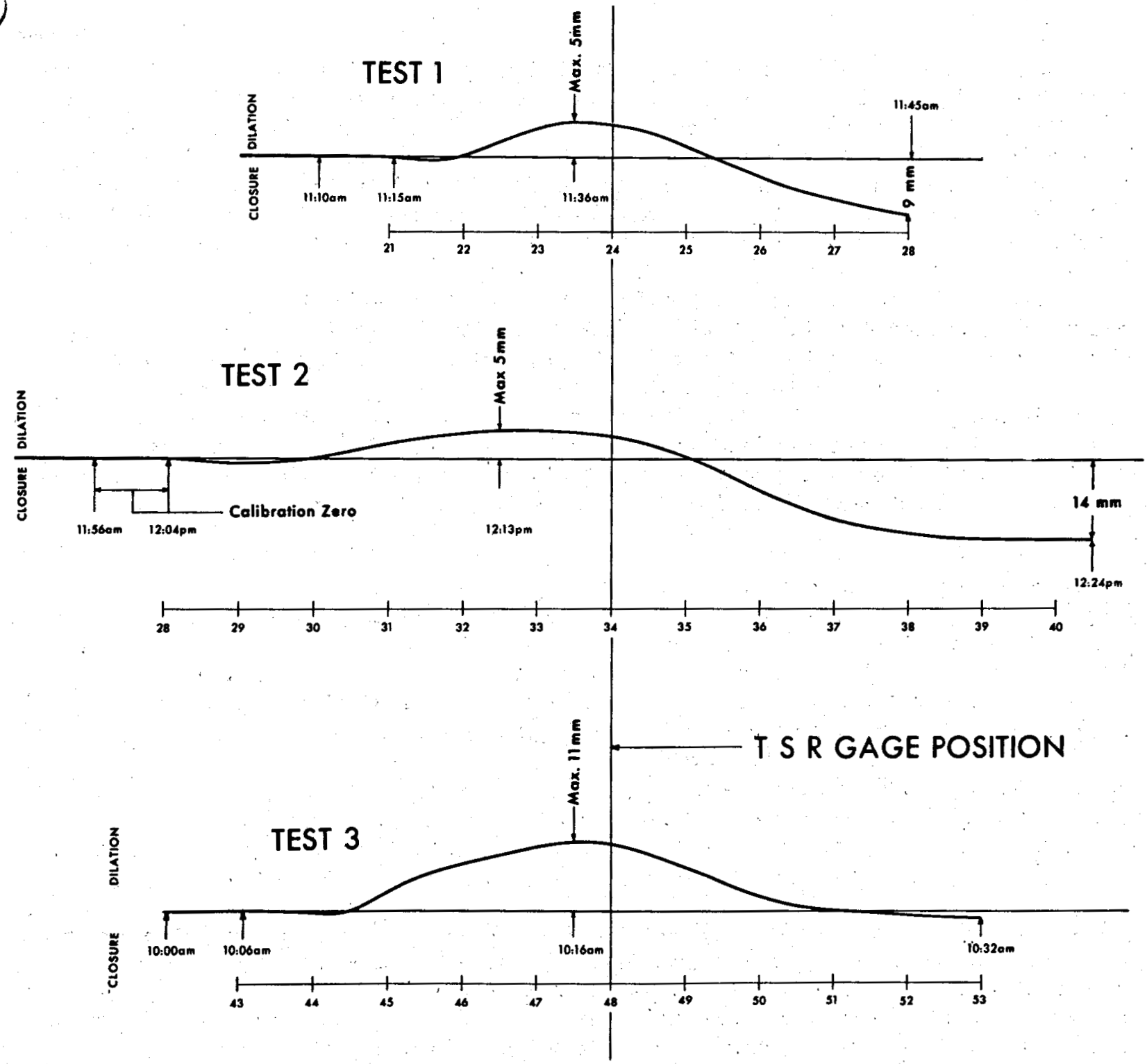

FIGURE 27. - Tunnel stress relaxation deformation, tests $1,2,3$.

when closure recorded on the strip chart indicated a plateau of about 900 microinches had been reached. These features described are shown on figure 27.

\section{Test 2}

Test 2 was begun at completion depth for test 1 , or 28 inches. Al1 three gages, the three-component borehole deformation gage, single-component borehole deformation gage, and tunnel stress relaxation gage, were set at a depth of 34 inches with overcore results showing essentially complete relief at about 39 inches. Drilling operations were conducted identical to previous work. 
As in test 1, all three channels of the three-element borehole deformation gage in test 2 show the characteristic stress relief pattern (fig. 26). The initial few inches of overcore run show a slight excursion into hole closure with peak closure about one EX hole diameter before the point of gage placement. Thereafter, the record shows rapid hole dilation that continued until complete stress relief was achieved. Borehole deformation records were otherwise uneventful.

The single-component borehole deformation gage (on the right side) was operated throughout test 2 with a strip chart recorder (fig. 28). This record shows a most dramatic hole dilation shortly after drilling beyond the point of gage placement. The dilation excursion reached a maximum at a depth of approximately 40 inches. This behavior would be very comparable with gage placement-depth relations previously found in overcoring, that is, maximum relief is completed about three EX hole diameters beyond the borehole deformation gage. Total gage dilation at this point, as indicated on the chart

\section{BDG TEST 2}

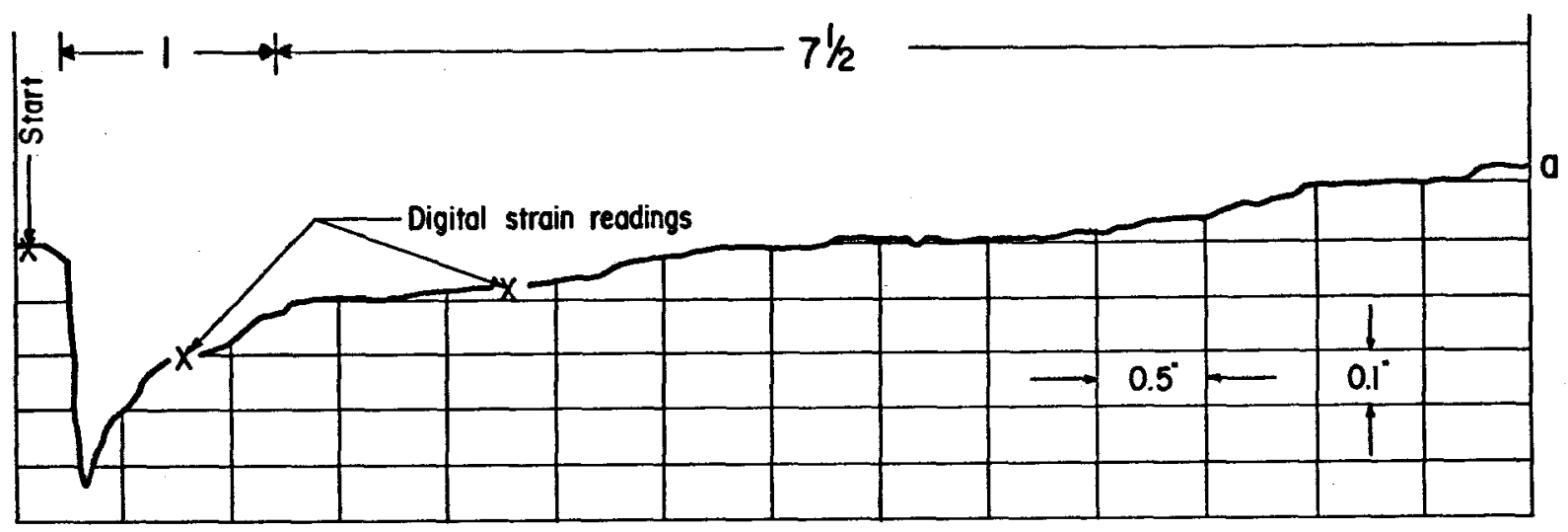

TIME, hours

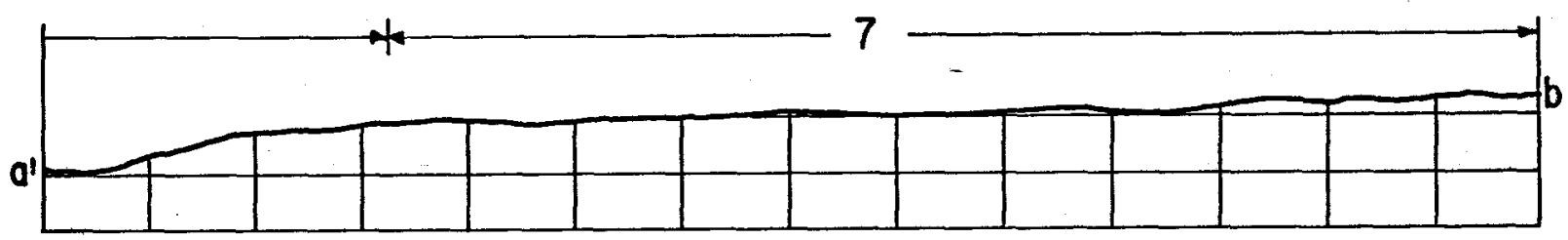

TIME, hours

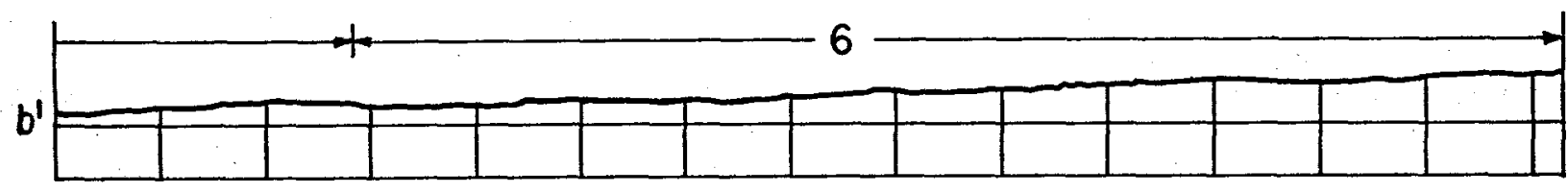

TIME, hours

FIGURE 28. - Single-component borehole deformation gage, test 2. 
record, was about 430 microinches. However, overcore drilling was continued to 44 inches during which time hole closure in the outer EX gage hole began to occur. A digital strain reading of 245 microinches was recorded at the end of drilling on test 2 (44 inches). From the point of maximum dilation, after which hole closure began, the record shows an approximate exponential shaped closure rate for the next 1 hour only. Thereafter and for the next 7 hours, a very nearly linear closure rate occurs that is calculated to be approximately 23 microinches per hour. A gradual change in slope then follows with curvature completed in about 1 hour. Reduced linear hole closure occurred for the next 7 hours and is calculated as about 7 microinches per hour. At this point and for the next 6 hours until the following morning when this portion of the test was terminated, the closure rate appears insignificant. Total closure up to test termination ( 21 hours) was approximately 690 microinches, which is 1.6 times the dilation deformation.

The tunnel stress relaxation gage (TSR) operated in the left side hole and provided the record shown in figure 27, test 2 . As described in test 1 , initially a small perceptible deformation in the closure direction also occurred on test 2. Continued overcore drilling indicates that wall rock movement slowly proceeds towards dilation with that excursion for test 2 reaching a maximum of 1,250 microinches $1-1 / 2$ inches before the point of gage measurement. Thereafter, wall rock dilation decreases and returned to zero deformation at about 1-1/2 inches beyond the point of gage measurement. Continued overcore drilling to about 6 inches, or four EX hole diameter, beyond the point of gage placement recorded hole closure before a recognizable plateau at 3,500 microinches closure is evident in the record.

At this stage of test 2 ( 12 inches total drilling), which was 6 inches beyond the measuring point position of the borehole deformation gage, and when the left side hole having the TSR gage had indicated stable closure movement toward the overcore hole for over 1 inch of drilling progress, a sudden fallure of the rock wall between the overcore hole and TSR hole was believed to have occurred. This was first observed on the continuous records and was confirmed with visual inspection of the hole at the conclusion of test 2 . However, at the time of occurrence, its cause was not known, and drilling was continued in the previous manner throughout the test. The direction of this and subsequent such movement was all away from the overcore hole (closure of the TSR recording hole).

Interestingly, this excursion had almost instantaneous rise time and a magnitude approximately equal to the maximum secondary principal strain. Corrective procedures were then taken to bring the recorder onto midscale. At approximately 2 inches of further drilling ( 14 inches total), another excursion occurred that was identically similar to that described previously. 


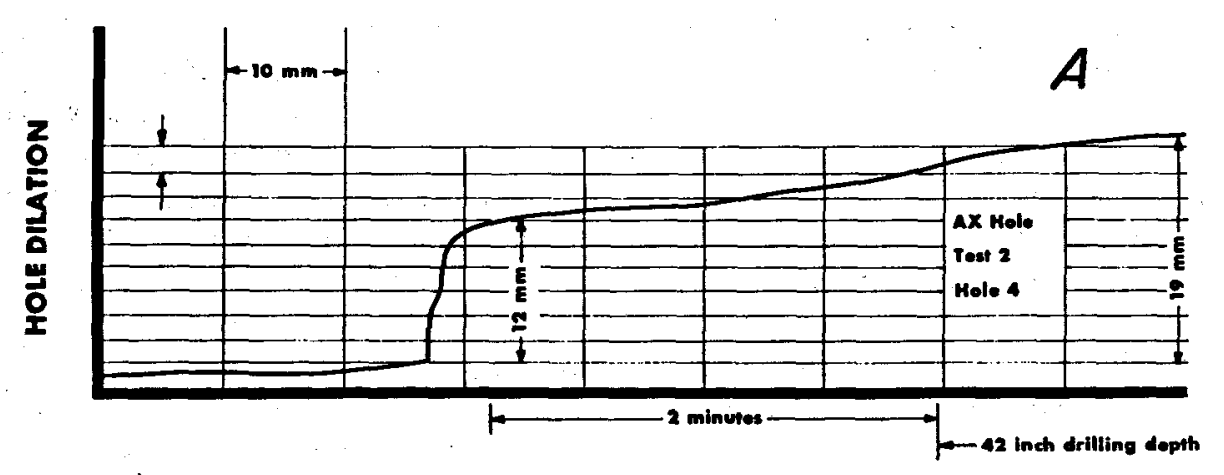

TIME

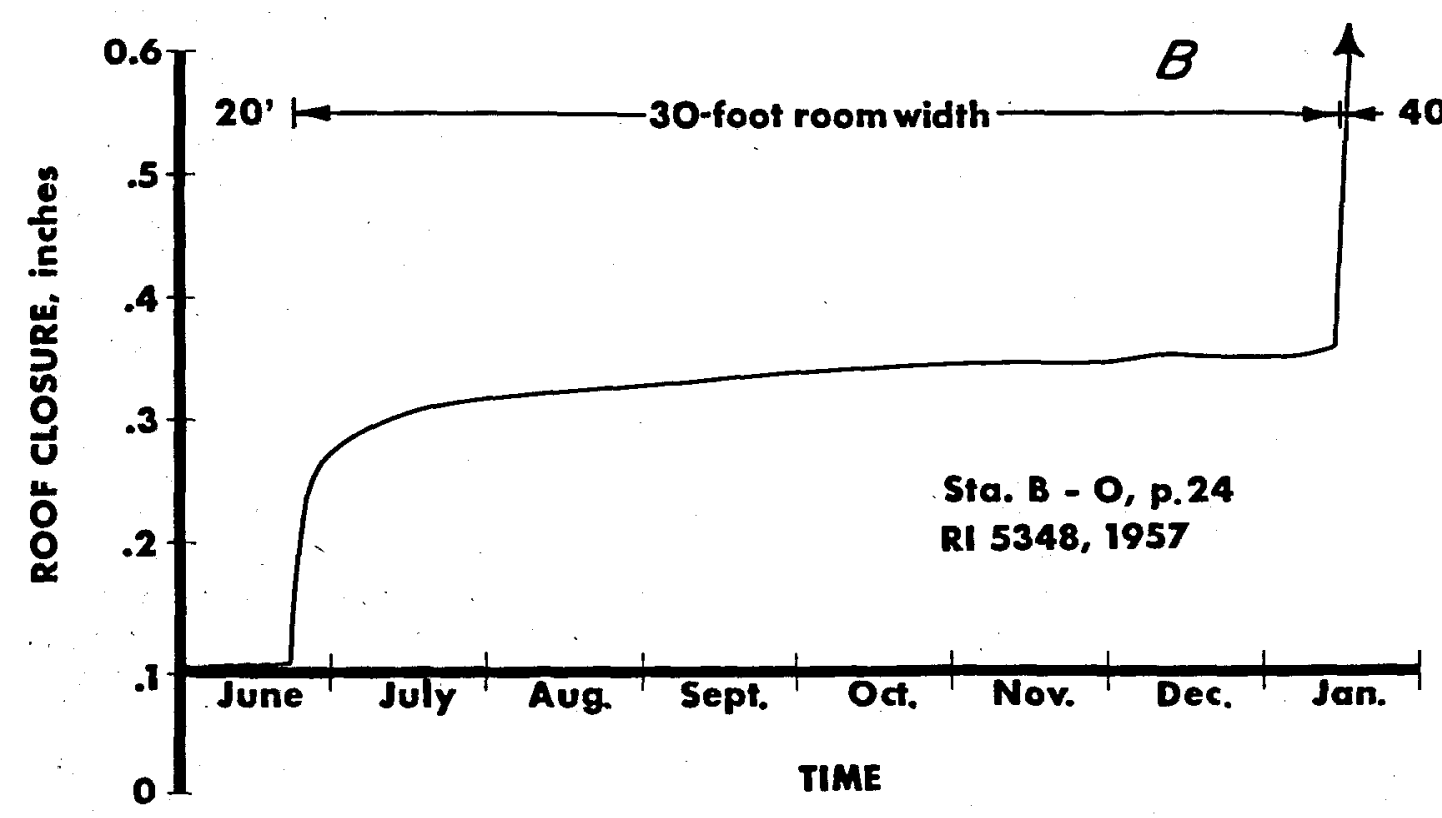

FIGURE 29. - Example of wall rock failure during drilling.

Its trace is reproduced in figure $29 \mathrm{~A} .{ }^{18}$ Drilling was continued during this failure occurrence, and the magnitude of the excursion was approximately equal to the maximum secondary principal strain for test 3 . This particular type of wall rock failure was much more prevalent in test 3 and will be further described for that test. At 2 inches beyond the second occurrence

${ }^{18}$ Along with this figure, a reproduction of record B-0, p. 24 from $\mathrm{RI} 5348$ (33) is shown in figure $29 \mathrm{~B}$. This figure shows a nearly exactly similar deformation record that occurred upon widening a room in a limestone mine. By analogy with this overcore drilling experiment, it is believed that the roof span probably experienced an undetected failure. The time scale, however, is seconds for the drill hole and days for the roof span. However, the two records are nearly identical in cause and effect relationship. 


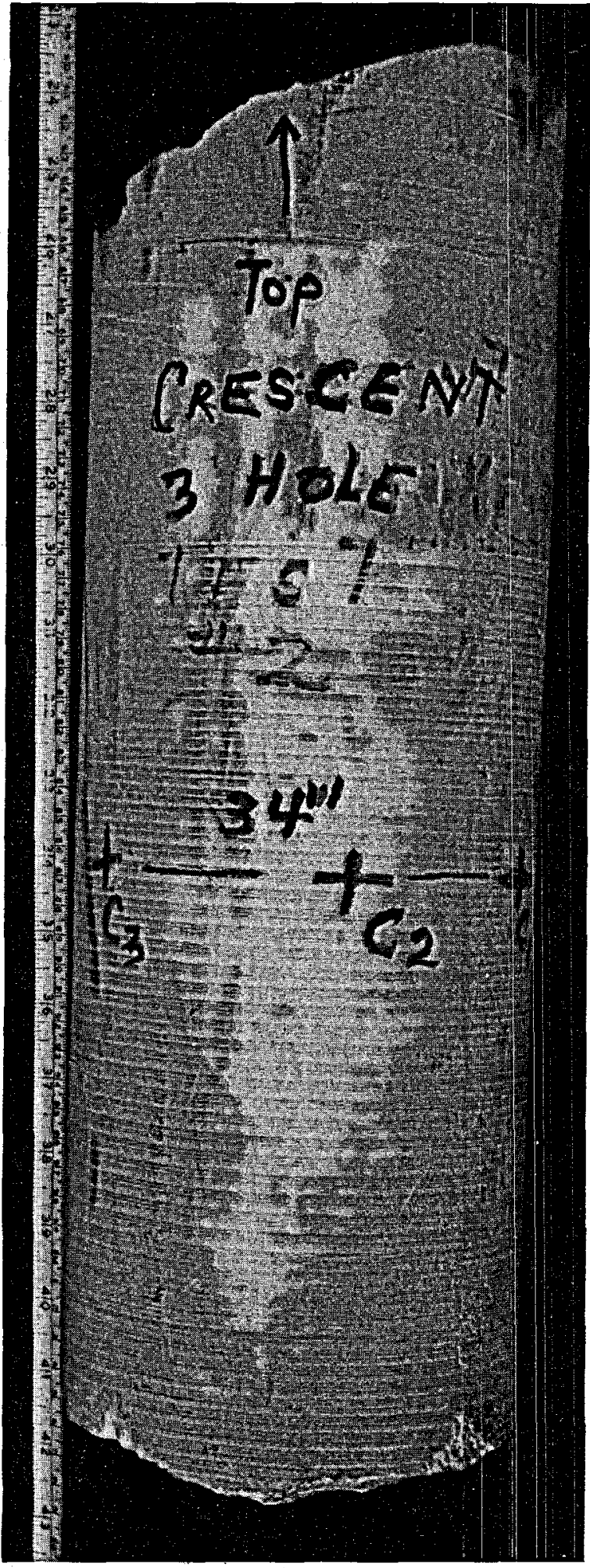

FIGURE 30. - Overcore recovered from test 2.
(16 inches total) test 2 was terminated (at a total depth from the collar of 44 inches) and the 16-inch core pulled (fig. 30).

Nowhere on the overcore specimen was evidence of rock failure found. However, the 6-1/2-inch-diameter hole did have an 18-inch-long visible crack between 26 inches and the end of the hole. No cracking could be observed in the right side EX hole containing the single-component borehole deformation gage. The left side hole containing the TSR gage was visibly cracked between 23 inches from the collar to within 3 inches of the end of the hole, which was drilled to a depth of 5 feet with an AX bit. The continuous recorder was set for overnight operation, but mechanicalelectrical difficulties caused termination of the record after about 4 hours. Direction of the record during this time indicated hole closure. This work concluded test 2 .

\section{Test 3}

Test 3 was begun at the conclusion of test 2 , or 44 inches. Gage p1acement was identical to the previous two tests, the single-component borehole deformation gage was placed on the right side hole and the tunnel stress relaxation gage placed on the left side hole, and the three-component borehole gage was placed in the central EX hole. All gages were placed at a depth of 48 inches prior to commencing drilling. No changes were made from previous tests in drilling operations for test 3.

Records of the three channels from the three-component borehole deformation gage in test 3 again show the characteristic stress relief patterns typical of tests 1 and 2 (fig. 26).

However, in contrast to the previous two tests, the derived maximum and minimum secondary principal stresses 
show very high values, approximately 11,400 and $8,150 \mathrm{psi}$, respectively. At a depth of 48 inches into the wall of the drift rib, it is believed that the zone of maximum stress surrounding the drift was nearly reached (fig. 11) and was responsible for rock fracturing between holes as this stress level exceeded the lower standard deviation for rock compressive strength.

The single-component borehole deformation gage was operated throughout test 3 using a strip chart recorder. As in test 2, the record showed maximum EX hole dilation amounting to approximately 800 microinches after drilling reached approximately 6 inches beyond gage placement. This portion of the record was very similar to that of test 2 and is not reproduced. Continued drilling to a final depth of 77 inches with complete recording of the event indicated a very erratic pattern on the record that could not be interpreted. This was later attributed to various degrees of fracturing of the wall rock between the holes. However, behavior of this portion of the record displayed the same trends as the TSR record, and this deformation will be more adequately described on that record. No further information was obtained on the borehole deformation record upon termination of drilling for test 3 .

Detectable wall rock deformation in the left side hole recorded by the TSR gage began about 3 inches before gage position at 48 inches. As in test 2, a perceptable closure movement occurred first. Peak dilation deformation of 2,700 microinches was recorded about 1 inch before TSR gage position. Drilling beyond the gage position resulted in rock deformation in the closure direction and which reached zero displacement at approximately 3 inches beyond the point of gage measurement. Continued drilling produced a closure plateau in the record at 6 inches, and beyond the point of gage placement (fig. 27 ).

At a depth of 54 inches, a sharp dilation break in the record occurred; an instrument check was then made and it was determined that wall rock fracturing probably had occurred similar to that experienced in test 2 . Drilling between 55 inches and the conclusion of test 3 at 77 inches provided much anomalous data (recalling that the measurement position was at 48 inches). However, attempts were made during this portion of test 3 to ascertain the origin of some aspects of this behavior. Figure 31 reproduces the trace of certain features and accompanying self-explanatory notes on recorded TSR data while drilling operations were underway during test 3 .

It is seen that the overall trend of data after the initial peak dilation excursion is in the closure direction that can be substantially modified by control of drilling water. Overnight operation monitored by digital readings showed continued closure deformation. At conclusion of test 3 , evidence of wall rock cracking was visually observed. As in test 2, the left side AX hole was observed cracked completely to the final hole depth of 5 feet. It appeared to be more cracked at the end of test 3 , especially within the last foot of depth. The wall of the 6-1/2-inch hole was observed cracked with an apparent single failure line that extended to completion depth ( 77 inches) of test 3. The smaller EX hole on the right side was not observed to be cracked. The hypothesis is advanced that as drilling proceeded into the highly stressed rock surrounding test 3 , the wall rock sustained nearly simultaneous and 


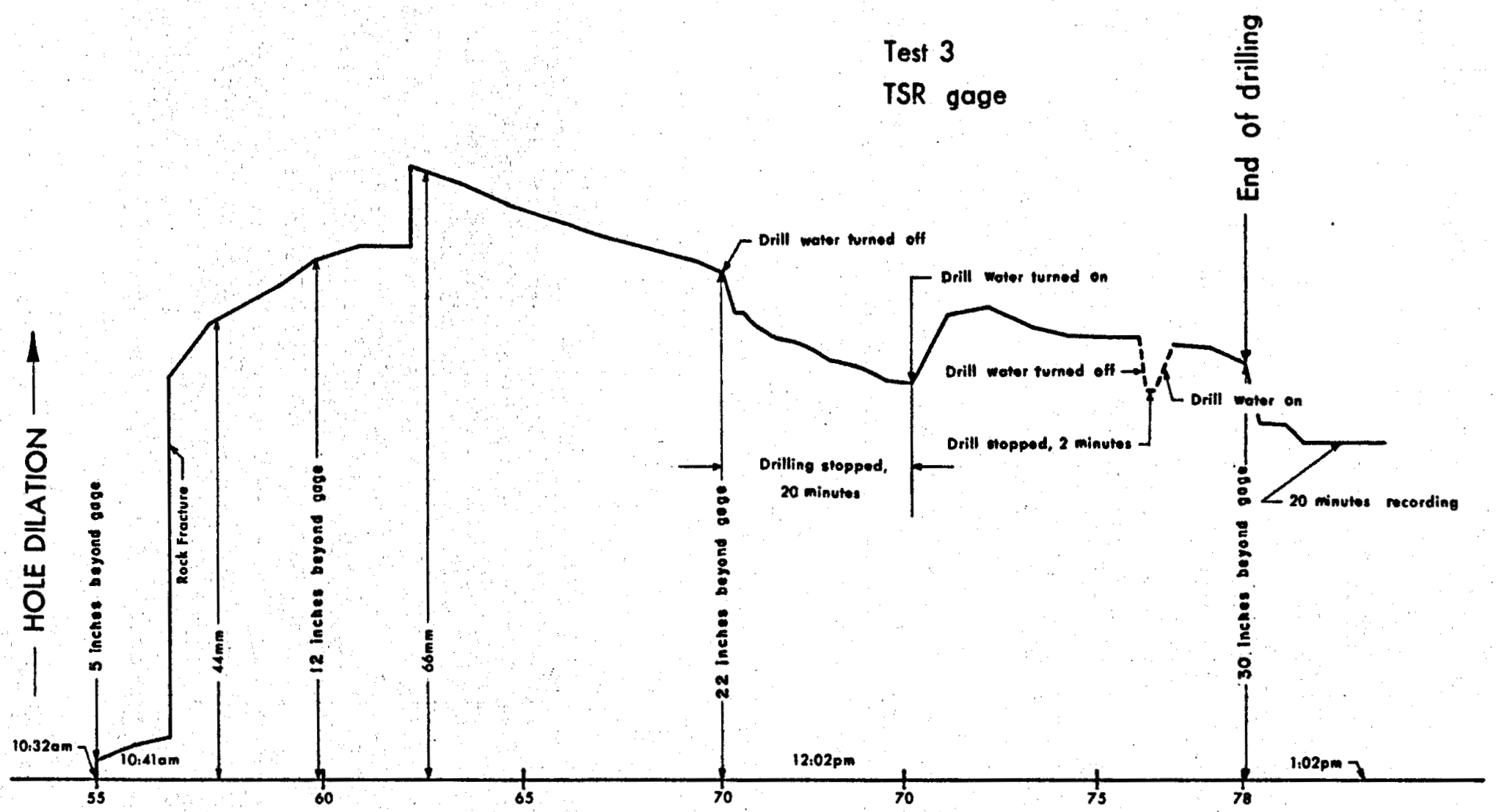

COLLAR DISTANCE ALONG BOREHOLE, inches

FIGURE 31. - Anomalous portion of record from test 3. 
progressive failure concurrent with drilling. of course, the fact that these events were recorded up to 30 inches beyond the point of measurement is certainly interesting.

\section{Jacking Tests}

Upon completion of the three special overcoring tests in hole 4, as described previously, a series of jacking tests were then conducted to determine the in situ elastic modulus at depths corresponding to the special overcore test depths $(28,34$, and 48 inches). Sixteen jacking runs were made, 11 runs with the jack thrust oriented horizontally and 5 runs with the jack thrust oriented vertically. Most of the unsuccessful horizontal runs were on test 1 but were expended to confirm equipment operation. This resulted in a total of 12 runs considered successful. A schedule of two horizontal runs and two vertical runs were attempted for each of the three overcoring depths. Elastic modulus values were calculated for seven horizontal runs.

The purpose of these jacking tests was to demonstrate feasibility of method, to show that deformation of wall rock at a depth of one radius into the rib could be accomplished by simple jacking, to support the hypothesis that rock behavior conforms to an elastic medium, and to show application of overcoring stress equations.

Two types of jacks were used. A simplex jack manufactured by Blackhawk Industrial Products Co., Butler, Wis., was selected for size and load capability in these tests. The other jeck used was the Roc-Jak, model 9, manufactured by K. O. Duncan Co., Boulder, Colo. This jack has 9 pistons, each 1-1/8-inch diameter, distributed along 15-inch axial length. These two types of jacks were tried for comparison purposes; the Simplex jack giving near point loads while the Roc-Jac loads an axial length of hole. The jacks were chosen after a cursory review of the state-of-the-art for jacking equipment intended for downhole installation, and with dimensions and pressure desired, indicated this particular equipment to be suitable at the time. A much better jacking installation could have been designed had time permitted.

The Simplex jack was fitted with bearing shoes having 4 square inches total surface area and curved to fit the inside radius of the 6-1/2-inchdiameter overcore hole. The Roc-Jak required special machined steel feathers having a total shoe surface area of 12 square inches to distribute the load axially along the curved inside edge of the hole. Hydraulic systems of each were similar, with common hydraulic lines, fluid reservoir, gages, and handactivated pump. Peak pressure in the hydraulic system during the jacking tests was 10,000 psi. This peak pressure, and considering the bearing area, ${ }^{19}$ gave a rock bearing pressure of $5,000 \mathrm{psi}$ for the Simplex jack and $5,840 \mathrm{psi}$ for the Duncan Roc-Jak. A typical loading cycle was 2,000-psi increments of

19 Shoe sizes approximates Tranter's (48) criteria that the length of bearing surface should be equal or greater than the hole radius. However, this does not apply to area of hole circumference loaded. The central angle loaded was $35^{\circ}$, or about $\pi / 5$. This was compared with similar data in RI 6812 (40). 
hydraulic pressure except for the first horizontal runs in test 1 , when 1,000-psi increments were used. A loading cycle along with readings to complete a jacking test could be done in less than 30 minutes. No readings were taken on the return cycle except at the zero return position. Digital readings taken at return zero pressure indicated a permanent "set" occurred in the rock. This is to be expected in jacking tests $(51 ; 11, p .22)$. The term "inelastic set" is used to indicate that upon release of jacking pressure, rock deformation did not return to its preloading position (37, p. 278). For those runs with the jack oriented horizontally, most inelastic set occurred on the first jacking run, especially in tests 2 and 3 , which were conducted in rock known to be fractured. Little inelastic set occurred in all 3 tests for those runs with the jack thrust oriented vertically.

Two graphs of field data showing load-deformation relationships are reproduced in figure 32. These were typical of all 12 successful jacking runs. The one graph, figure 32A, is from the TSR gage, test 3 , second horizontal run, and figure $32 B$, is from the single-component borehole deformation gage on test 2 , second horizontal run. Digital reading from a strain indicator and a strip chart recorder were both used for data interpretation. The strip chart recorder was mostly used to monitor the trend and direction of deformation and to detect any unusual events during a jacking run. No anomalous behavior was shown on any record from any jacking run. Reduced results for six jacking tests are shown on figures 33-37. Computer plot-programs concurrently print out "best fit" equations for data. These predictive equations indicate that simple linear fit is acceptable and that higher order equations will reduce the standard deviation of predicted displacement resulting from horizontal
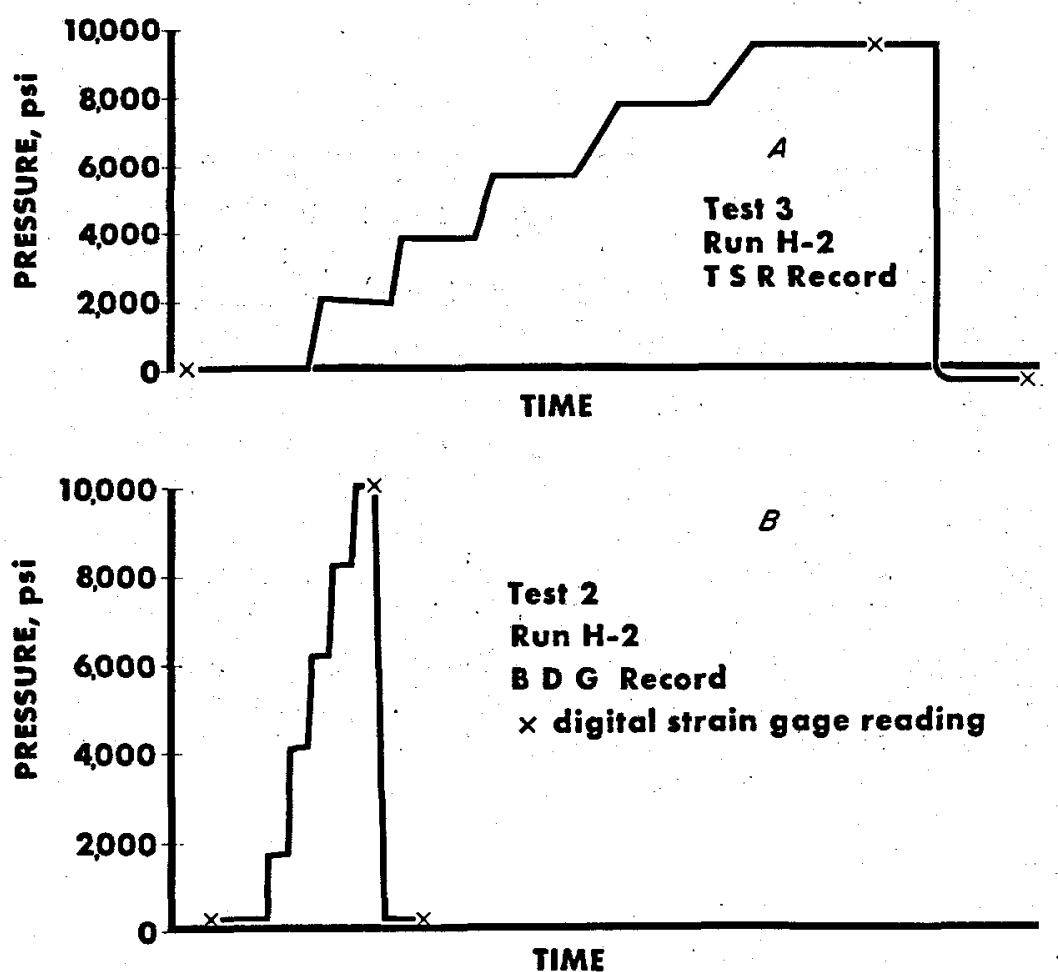

FIGURE 32. - Typical field jacking records. jacking thrust by at least one order of magnitude. For jacking runs in cracked rock, tests 2 and 3 , higher order (with a fourth degree being a best fit) equations decided1y demonstrate this nonlinear rock behavior. In summary, these curve fit equations suggest that rock deformation is linear if unfractured but nonlinear when rock is known to be fractured.

It should be recalled from the previous drilling discussion that wall rock fracturing definitely occurred on tests 2 and 3. Jacking runs in test 1 did not encounter fractured rock. Uniquely, rock fracturing was oriented parallel to the direction of jacking thrust. 


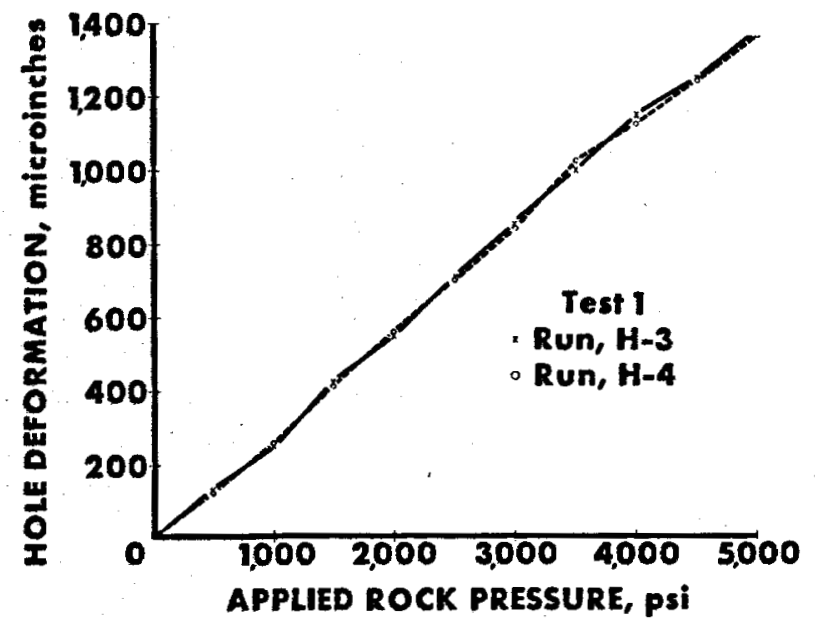

FIGURE 33. - Reduced jacking record, test 1, run $\mathrm{H}-3, \mathrm{H}-4$.

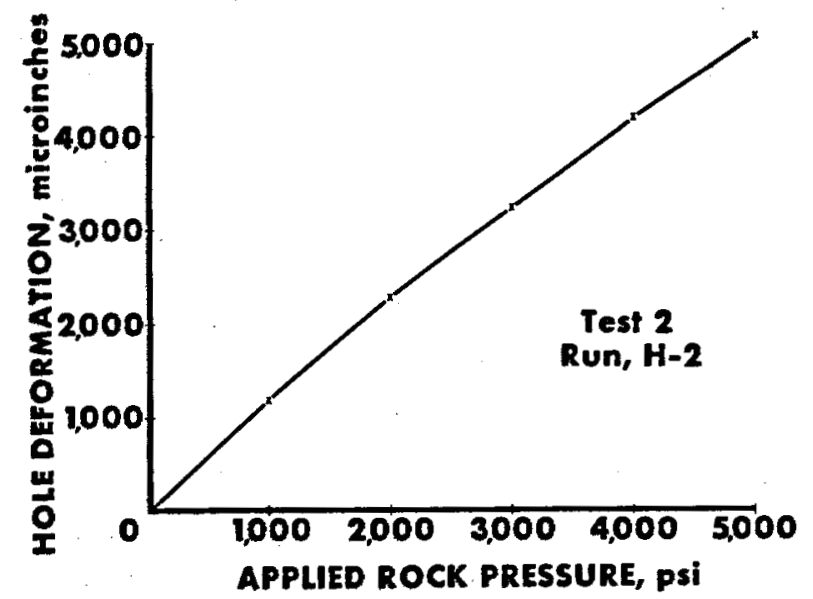

FIGURE 35, - Reduced jacking record, test 2, run $\mathrm{H}-2$.

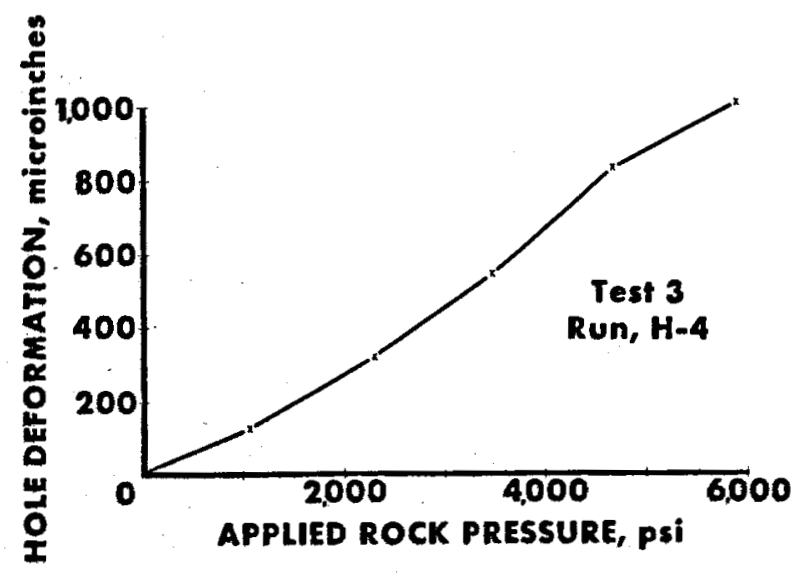

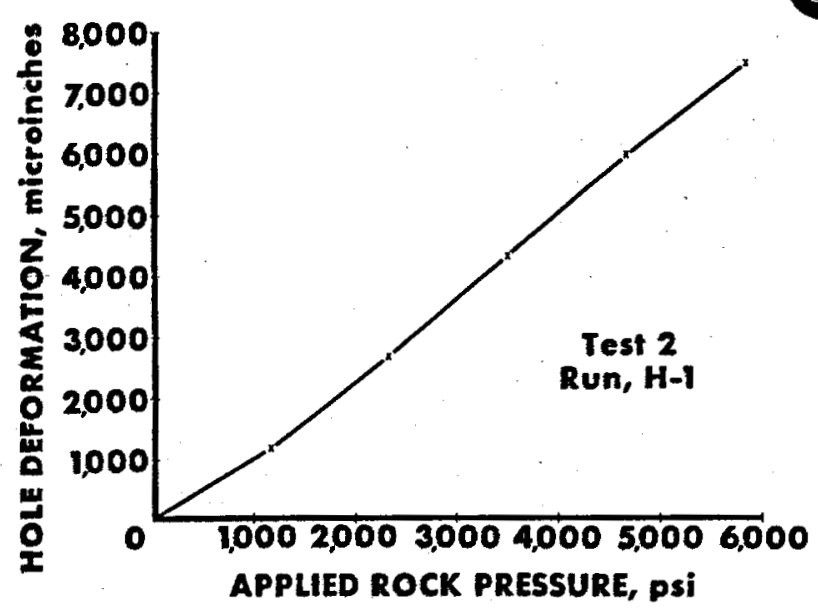

FIGURE 34. - Reduced jacking record, test 2, run $\mathrm{H}-1$.

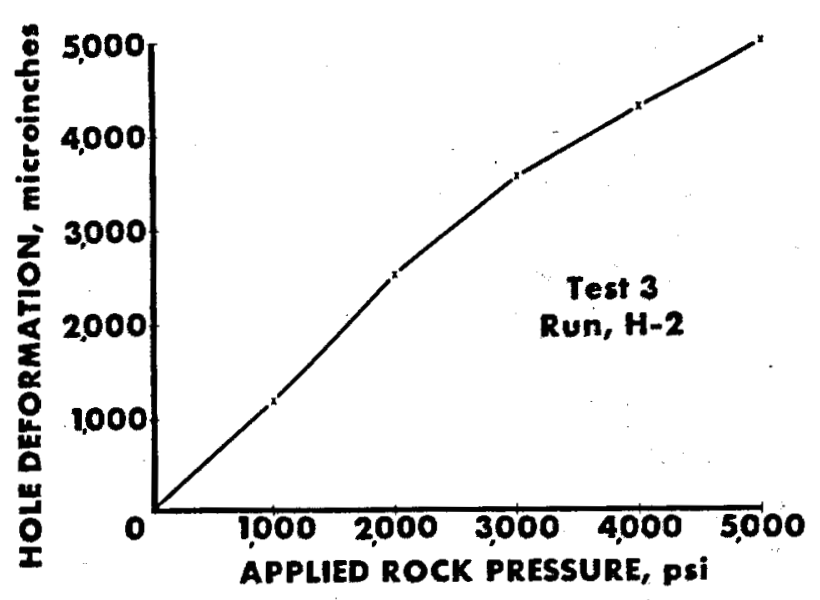

FIGURE 36. - Reduced jacking record, test 3, run $\mathrm{H}-2$.

FIGURE 37. - Reduced jacking record, test 3, run $\mathrm{H}-4$. 
To be compatible with the concept of overcoring, elastic modulus calculations with equations previously used from the overcore stress determination were made using borehole deformations. It is realized that a variety of computational methods are available that could be used (11). The secondary principal stress field was previously known at each test depth as a result of the three prior special overcoring tests. Some previous data from this work is shown in table 8 .

TABLE 8. - Input data for jacking analysis

\begin{tabular}{c|c|c|c|c|c}
\hline Test & $\mathrm{U},{ }^{1}$ microinches & $\theta,{ }^{2}$ deg & $\mathrm{S}^{3}$ psi & $\mathrm{T},{ }^{3}$ psi & $\sigma_{\mathrm{x}},^{4}$ psi \\
\hline 1 & 1,577 & $83^{\circ} 07^{1}$ & 6,652 & 4,667 & 4,696 \\
2 & 2,176 & $86^{\circ} 39^{\prime}$ & 7,826 & 6,033 & 6,040 \\
3 & 3,923 & $49^{\circ} 18^{\prime}$ & 11,372 & 8,160 & 9,524 \\
\hline
\end{tabular}

Overcore borehole deformation at horizontal orientation, microinches.

${ }^{2}$ Angle of secondary principal stress, $\theta$, degrees.

${ }^{3}$ Stress values presented are all for $E=7.10 \times 10^{6}$ psi.

${ }^{4}$ Calculated stress in the horizontal direction, psi.

Secondary principal stress values were applied as an external pressure source in the horizontal plane and used in thick walled cylinder theory for the stress ${ }^{20}$ in the rib rock corresponding to the horizontal gage position at the $\mathrm{AX}$ hole location. Stress caused by jacking can be similarily computed at the AX hole position. Upon jacking, actual hole deformation resulting from the net effect of the external stress and the outward jacking thrust is obtained on the TSR and borehole deformation gage records. ${ }^{21}$

When all stresses are known or calculated, along with recorded hole deformations, the in situ elastic modulus can be calculated from conventional borehole deformation equations. Generally, methods of calculation follow a class of problems theoretically based on corresponding elastic solution of the form

$$
E=\Psi \frac{\mathrm{Pa}^{2}}{\mathrm{Ur}}(1+\mu)
$$

where $\Psi$ is an analytical function usually expressed in elliptical integrals based on the loading situation, $P$ is applied pressure, $U$ is radial deformation, $a$ is the hole radius, $r$ is the point of interest beyond the wall rock, and $\mu$ is Poisson's ratio. The function $\psi$ is equal to 1.0 for uniform internal loading completely about the circumference of an elastic medium and with infinite length of axial loading. Deformations of wall rock at peak applied jacking load as recorded in the AX and EX gage holes are shown in table 9.

${ }_{21}^{20} \sigma_{\mathrm{p}}=\mathrm{P}_{0}\left(1-\frac{\mathrm{a}^{2}}{\mathrm{r}^{2}}\right)$.

A popular interpretation of such deformation is termed "annuliment stress," but as indicated in table 8 , this could only be done on test 1 . Because all gages were at depth into the rock, annullment stresses were not experimentally determined. 
TABLE 9. - Borehole deformation and jacking results

\begin{tabular}{|c|c|c|c|c|c|c|}
\hline \multirow[t]{2}{*}{ Test } & \multirow[t]{2}{*}{ Orientation } & \multirow[t]{2}{*}{$\operatorname{Run}^{I}$} & \multicolumn{2}{|c|}{ Horizonta1 ${ }^{2}$} & \multicolumn{2}{|c|}{ Vertical ${ }^{3}$} \\
\hline & & & TSR & IC-BDG & TSR & $I C-B D G$ \\
\hline 1 & 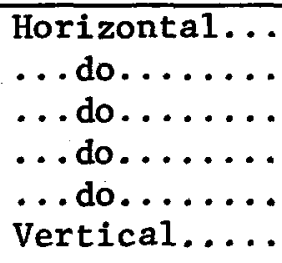 & $\begin{array}{l}1 \\
2 \\
3 \\
4 \\
5 \\
1\end{array}$ & $\begin{array}{r}\text { Void } \\
621 \\
1,375 \\
1,365 \\
113\end{array}$ & Void & 198 & 10 \\
\hline 2 & 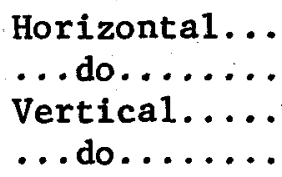 & $\begin{array}{l}1 \\
2 \\
1 \\
2\end{array}$ & $\begin{array}{l}7,475 \\
5,070\end{array}$ & $\begin{array}{l}1,088 \\
1,049\end{array}$ & $\begin{array}{l}244 \\
284\end{array}$ & $\begin{array}{l}57 \\
69\end{array}$ \\
\hline 3 & $\begin{array}{l}\text { Horizontal... } \\
\ldots \text { do........ } \\
\ldots \text { do....... } \\
\ldots \text { do....... } \\
\text { Vertical.... } \\
\ldots \text {. do....... }\end{array}$ & $\begin{array}{l}1 \\
2 \\
3 \\
4 \\
1 \\
2 \\
\end{array}$ & $\begin{array}{l}\text { Void } \\
5,025 \\
473 \\
1,420\end{array}$ & $\begin{array}{r}\text { Void } \\
136 \\
51 \\
891\end{array}$ & $\begin{array}{l}830 \\
830\end{array}$ & $\begin{array}{l}152 \\
458\end{array}$ \\
\hline
\end{tabular}

At peak applied rock pressure.

${ }^{2}$ Horizontal deformations are all closure, microinches.

${ }^{3}$ Vertical deformations are all dilation, microinches.

${ }^{4}$ Very small deformations were recorded.

Much data was not utilized; however, the data used confirm expected rock behavior patterns. For example, the fact that AX hole deformation was closure at all loading levels with jacking runs having horizontal oriented thrust is simple confirmation of the state of radial stress surrounding the overcore hole. This is especially true of the one-component borehole deformation gage records (not utilized in calculations) that showed little net ${ }^{22}$ borehole $^{2}$ deformation for unfractured rock but significantly large deformations for fractured rock. - The fact that these net hole deformations are comparatively smal1 and somewhat uniform in magnitude indicated that the deformation interaction effect measured between opposing sides of the hole is not large.

Jacking runs with the thrust oriented vertically very effectively demonstrated hole closure as measured in the horizontal direction (a prediction from elastic theory):

Assumptions necessary for these overcore-jacking tests are (1) overcore borehole deformation relations are valid, (2) rock behavior conforms to a linear elastic material at the loads applied, (3) effect of hole interaction is negligible, (4) jacking forces are perfectly applied, and (5) friction effects during jacking are neglected. Application of equipment in the field revealed difficulty in precise orientation and alinement of the jack; obtaining pressure distribution on the jacking pad required extraordinary care

22 Recall that construction of the borehole deformation gage permits recording only total hole deformation irrespective of which side of the hole actually moved. 
to insure uniform rock contact; and use of a hydraulic system constructed of only ordinary materials made for slow installation time. Insufficient data was available to evaluate the two types of jacks. An additional unexpected field condition mentioned previously was the presence of rock fracturing on tests 2 and 3 .

Nevertheless, the results are gratifying in that elastic modulus values for test 1 are in the range for intact rock (see section on physical properties), and for tests 2 and 3 elastic modulus values are on the order of magnitude-expected for fractured rock. No doubt the symmetry of forces in the horizontal direction (that is, the direction of minor secondary principal stress was nearly in the same direction as jacking thrust) contributed to more representative calculated modulus values. The use of this jacking technique also suggests a new approach to field jacking wherein the overcore borehole deformation equations can be utilized. This method was not explored further than described previously in this project.

\section{FINITE ELEMENT MODELING}

\section{Theory}

The purpose of finite element modeling was to show that correlation between experimental and theoretical modeling methods could be achieved. In addition, an opportunity was presented to utilize values of elastic modulus, overcore deformation, and computed free-field stress in calculations as an excellent check between displacements obtained from field tests and calculated from the theoretical model.

Finite element methods have, within the past decade, and as a direct result of high-speed computers, risen from mathematical concepts to perhaps the largest scope of present activity within the field of numerical analysis. Advances have been swift, and the experimental fieldwork described herein was completed before finite element programs were fully operational at SMRC. The term "finite element method" as presently evolved indicates a type of idealization used to reduce a structural continuum to a system of discrete bodies. In reality, idealization must allow either physical or mathematical simplification of the structure. However, finite element methods have been successfully used to obtain good approximate solutions to a wide class of problems. A variety of mining problems have also been successfully investigated by this method $(\underline{7}, \underline{49}, \underline{52})$.

The finite element idealization of a two-dimensional structure of any complexity produces a highly indeterminate system that consequently introduces a tremendous number of numerical operations necessary for solution. With present computer technology and use of matrix notation, a general solution to such problems can be obtained. The digital computer performs three major tasks in the complete analysis of this system of equations: (1). The equilibrium equations are formulated; (2) the system of equations is solved for nodal point displacements; and (3) the internal stress distribution throughout the lement geometry is then determined. A more complete and recent treatment of he finite element method is given by Zienkiewicz ( $\underline{56}$ ). 


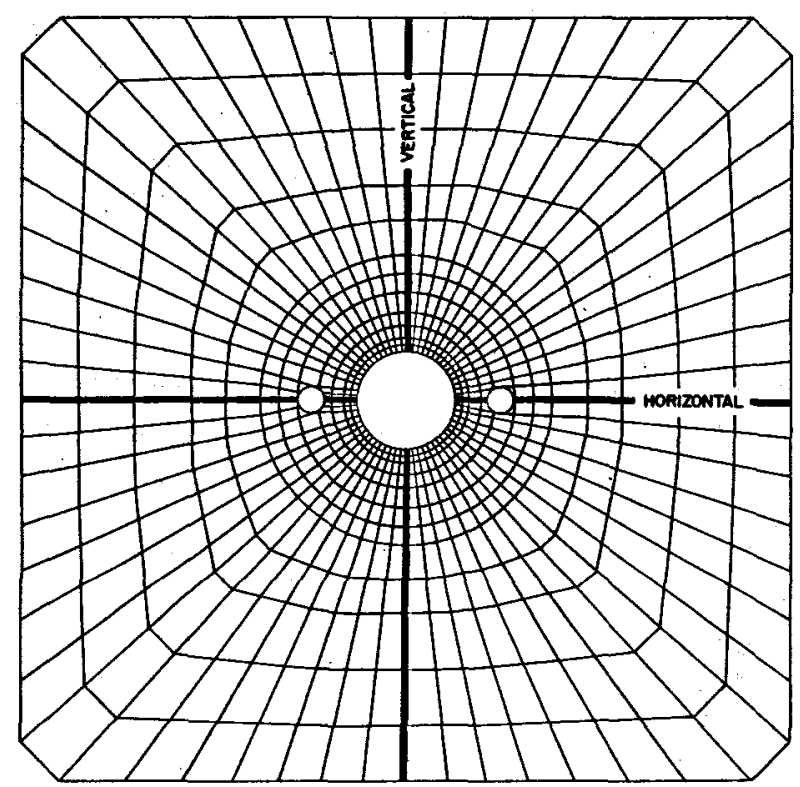

FIGURE 38. - Mesh element model.

\section{Modeling}

The finite element models selected for this analysis utilized 720 elements with 780 nodal points. The geometric size and shape of the total model was about 7.70 times the diameter of the 6-1/2-inch overcore hole (in order to obtain a boundary area that was not affected by the overcore hole). Geometry of the mesh elements are shown in figure 38.

This basic mesh mode1 was used for all subsequent overcore finite element solutions in this report. The size of element band nearest the overcore hole was represented by a radial width of $1 / 2$ inch. This radial element width was geometrically enlarged to 1-inch elements out to one overcore hole diameter from the overcore hole edge.

Tangential elements were spaced every $6^{\circ}$ about the overcore hole perimeter. Geometry of the smaller holes was not exactly defined, but mesh geometry was designed such that nodal points corresponding to the smaller hole perimeter coincided with actual hole diameter positions.

Material properties of elements within coincident nodal points corresponding to these smaller holes were assigned zero values. Average material model properties of $E=7.10 \times 10^{6} \mathrm{psi}$, and Poisson's ratio of $\mu=0.20$ were based on physical property determinations previously discussed. Principal stresses from the overcore procedure were modeled into the boundary conditions for each of the three initializing computer runs. (These initial runs were imposed on the model without the central overcore hole to initialize stress and displacement equilibrium.) Boundary displacements corresponding to the in situ stress field were then distributed uniformily on the total boundary of the model for total symmetry; that is, all displacements referenced to the center of the overcore hole. To be noted was near overall symetry along the horizontal and vertical axes between the secondary principal stress and measured hole deformations. Solutions subsequently presented should be considered as a two-dimensional plane strain displacement equilibrium analysis (based on planar overcore measurements taken beyond the influence of any surface boundary effects). 
Radial displacements at the experimental points of interest were obtained by superposition from the net displacement between the initial stress state and the final stress-relief condition represented by immediate completion of drilling of the overcore hole (minimum of one overcore hole diameter beyond the point of measurement). Therefore, finite element modeling is limited to only that immediate elastic rock behavior caused by drilling of the overcore hole.

Computer solutions were made with the A SOLID finite element program on Iine with CDC 3200 at SMRC and were little modified from the programs of E. L. Wilson (54-55). All executable solutions were run using only the plane strain and boundary element.

\section{Results}

Displacements from the two-dimensional finite element models discussed previously were compared with measured field deformations. These comparisons are shown in table 10. As an internal check on the finite element model, diameter change was also calculated at the three corresponding positions of borehole deformation $\left(U_{1}, 3,3\right)$ as recorded in the overcoring for the three TSR verification runs (and which were used in the calculation of secondary principal stresses). Exact correspondence was not anticipated from these values due to structuring of the problem, completed hole diameters were not precisely known, and the elastic modulus and Poisson's ratio were assumed from the best available data. One source of error may be the element width very near surface boundaries. This effect has been investigated (32) for thick wall cylinders and was found to be about 10 percent significant only very near the free surface. Discrepancies between field and finite element values for this investigation are well within this error for all comparisons of $U_{1}, 2,3$ borehole deformation.

TABLE 10. - Summary of finite element results

\begin{tabular}{|c|c|c|c|c|c|c|}
\hline & \multicolumn{3}{|c|}{ With overcore drilling } & \multicolumn{3}{|c|}{ With $5,000-1 \mathrm{~b}$ jacking load } \\
\hline & $\begin{array}{c}\text { Field } \\
\text { measured, } \\
\text { micro- } \\
\text { inches }\end{array}$ & $\begin{array}{l}\text { Finite } \\
\text { element, } \\
\text { micro- } \\
\text { inches }\end{array}$ & $\begin{array}{l}\text { Difference, } \\
\text { field-finite } \\
\text { element }\end{array}$ & $\begin{array}{c}\text { Field } \\
\text { measured, } \\
\text { micro- } \\
\text { inches }\end{array}$ & $\begin{array}{c}\text { Finite } \\
\text { element, } \\
\text { micro- } \\
\text { inches. }\end{array}$ & $\begin{array}{l}\text { Difference, } \\
\text { field-finite } \\
\text { element }\end{array}$ \\
\hline 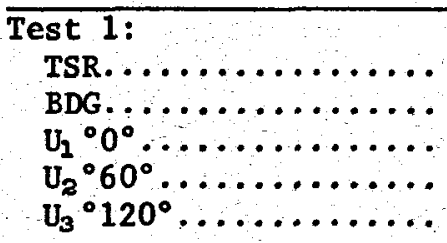 & $\begin{array}{r}900 \\
155 \\
1,577 \\
2,971 \\
2,626\end{array}$ & $\begin{array}{r}1,194 \\
101 \\
1,385 \\
3,107 \\
2,741\end{array}$ & $\begin{array}{r}-294 \\
54 \\
192 \\
-136 \\
-115\end{array}$ & 1,370 & $\begin{array}{r}2,039 \\
892 \\
2,589 \\
671 \\
661\end{array}$ & $\begin{array}{c}-669 \\
- \\
- \\
-\end{array}$ \\
\hline 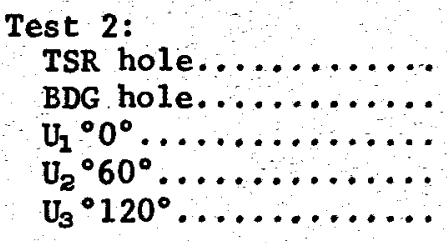 & $\begin{array}{r}3,500 \\
245 \\
2,176 \\
3,384 \\
3,224\end{array}$ & $\begin{array}{r}1,236 \\
334 \\
2,033 \\
3,472 \\
3,450\end{array}$ & $\begin{array}{r}2,264 \\
-89 \\
143 \\
-88 \\
-226\end{array}$ & $\begin{array}{l}6,275 \\
1,068\end{array}$ & $\begin{array}{r}1,818 \\
1,040 \\
2,548 \\
648 \\
649\end{array}$ & $\begin{array}{r}3,457 \\
28 \\
- \\
- \\
-\end{array}$ \\
\hline $\begin{array}{l}\text { Test } 3: \\
\text { TSR hole (left) } \ldots \ldots \\
\text { BDG hole (right) } \ldots \ldots \\
U_{1}^{\circ} 0^{\circ} \ldots \ldots \ldots \ldots \ldots \ldots \\
U_{2}^{\circ} 60^{\circ} \ldots \ldots \ldots \ldots \ldots \ldots \\
U_{3}^{\circ} 120^{\circ} \ldots \ldots \ldots \ldots \ldots \ldots\end{array}$ & $\begin{array}{r}1,000 \\
598 \\
3,923 \\
5,390 \\
3,066\end{array}$ & $\begin{array}{r}2,471 \\
522 \\
4,107 \\
5,455 \\
3,197\end{array}$ & $\begin{array}{r}-1,471 \\
76 \\
-284 \\
-65 \\
-131\end{array}$ & $\begin{array}{l}1,420 \\
891 \\
\left(\begin{array}{l}1 \\
1\end{array}\right) \\
\left(\begin{array}{l}1 \\
1\end{array}\right)\end{array}$ & $\begin{array}{r}1,756 \\
899 \\
2,504 \\
655 \\
656\end{array}$ & $\begin{array}{c}-336 \\
-9 \\
- \\
- \\
-\end{array}$ \\
\hline
\end{tabular}

1 Not measured. 
Opinion may be expressed that geologic conditions contribute to divergence in finite element results. Figure 39 shows a very thorough appraisal of all surface jointing at the face of overcore hole 4 (a more complete study of jointing will be made in a companion RI on a study of the behavior of later excavated 3- and 6-foot-diameter openings. However, in conclusion, no downhole geologic evidence (other than the horizontal rib cracking previously mentioned, which was most severe on the TSR gage side) was found to attribute jointing as a factor in this finite element study.

Accompanying table 10 are results of additional finite element runs with an internal load of 5,000 pounds applied to the interior of the $6-1 / 2-$ inch hole and with geometry modeled to exact dimensions of the original jacking shoe. Resulting finite element deformations were compared with jacking deformations obtained in the field. As an added check on this effort, the effect of horizontal thrust on the jack was found to produce closure on the vertical axis (recall vertical jacking produced measured horizontal closure, or a

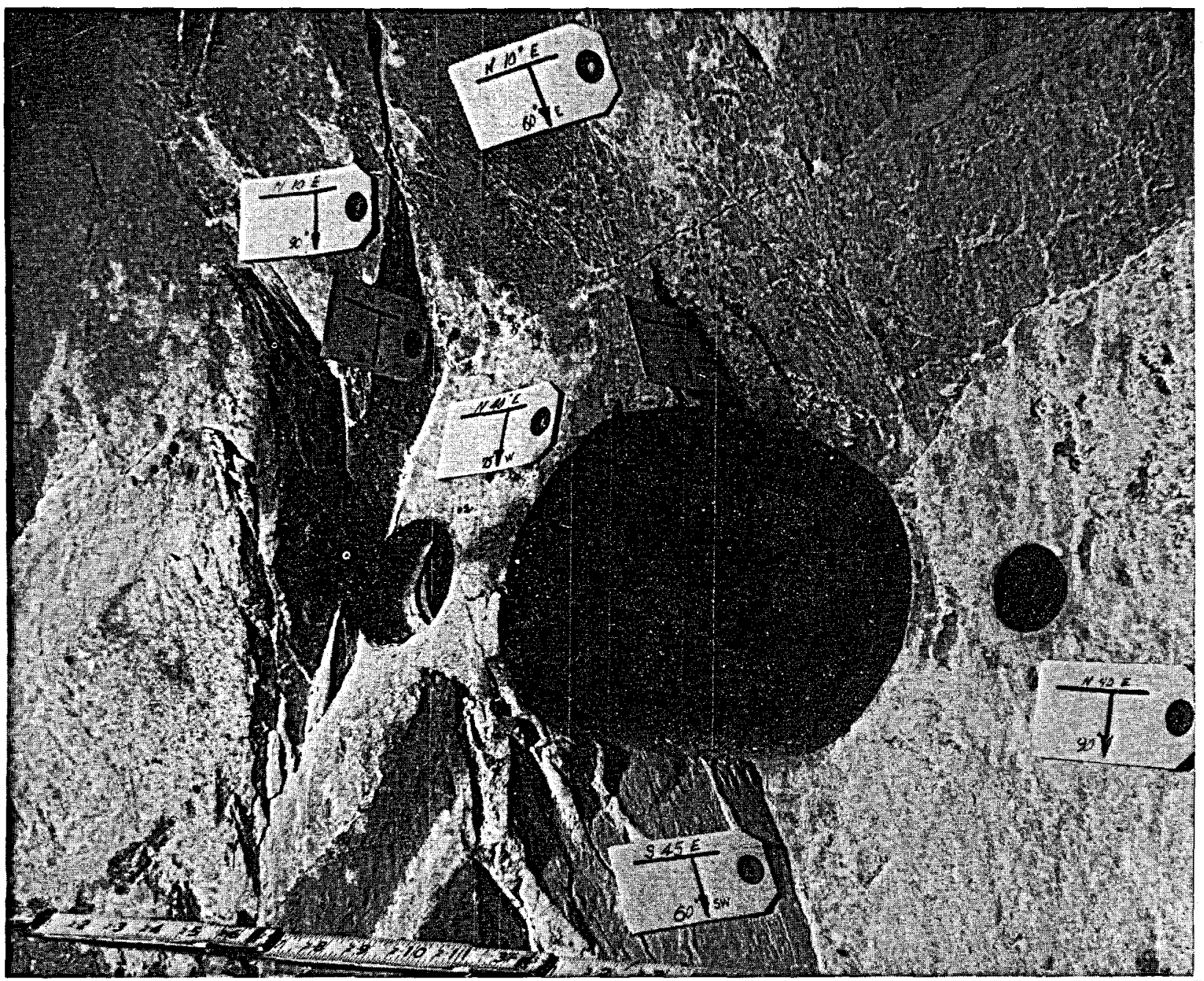

FIGURE 39. - Surface geology near overcore hole 4. 
situation similar to the calculated effort when jacking was horizontal). This work also confirms overall elastic behavior.

Another series of finite element runs were made to confirm a problem solved by Savin (45, pp. 160-164, and p. 167) on the interaction effect of two unequal sized holes. For this experimental work, this was done by varying the diameter of the overcore hole and holding the position of the small holes fixed. As Savin has shown, it appears true from finite element analysis that deformation recorded on the small hole wall closest to the bigger hole does experience a maximum before decreasing as the intervening pillar distance is reduced. This may be seen in photoelastic work wherein at some point, stress patterns seem to flow around the two holes rather than increase the stress through the pillar. The larger hole has considerable effect on stress near the small hole, and especially as the distance between holes becomes less than the diameter of the small hole.

In summary, this two-dimensional finite element analysis of two unequal size holes loaded in a biaxial stress field, and having horizontal and vertical axes in close alinement with the secondary principal stress field has shown the following results:

1. The range of agreement exceeds an order of magnitude between al1 results and in most instances agreement is much better.

2. Those field results obtained from the left side hole, containing the cracked rib section, consistently showed the lowest and the highest field measured deformation readings in both overcore and jacking tests.

3. Field measured results and finite element calculations from the right side hole were most consistent (this side contained no cracked sections).

4. Experimental error is certainly present but is considered within the range of ordinary skill in underground field testing.

5. Divergence between calculated boundary values for borehole deformation and field measured overcore borehole deformations are within the range of field experimental error and/or mesh element geometry imposed by the finite element technique.

As has been extensively discussed in the chapter on physical properties of this report, great variability has been documented for all measured physical properties. This is considered particularily significant when physical property testing was conducted under uniform testing procedures, and al1 rock samples were obtained from a limited test site area. The finite element method used only Poisson's ratio and elastic modulus as simple multiplicative factors. Slight variation in Poisson's ratio would result in some substantial change in numerical answers. However, the elastic modulus, and if all divergence were attributed to this, would result in significant differences between measured and calculated values. Table 11 is a comparative inite element evaluation based on elastic modulus when all variability is iven to that physical property. This table shows that all results are within 
the range of the previous extensive physical property analysis. The arithmetic mean of 84 samples was $7.10 \times 10^{6}$ psi with a standard deviation of $1.50 \times 10^{6} \mathrm{psi}$. Outlier values of $2.49 \times 10^{6}$ and $18.3 \times 10^{6}$ psi are valid values for the extreme low and high, respectively. It is, therefore, seen that all values obtained from field measurements and compared with the finite element analysis, which was based on $E=7.10 \times 10^{6} \mathrm{psi}$, are within the range of the very exhaustive physical property analysis previously made. The few very low values for elastic modulus are also in an area known to be fractured, and even these elastic modulus values do not appear unreasonable for fractured rock. Therefore, the comparative finite element results are consistent within the range of previously determined laboratory controlled test procedures for elastic modulus.

TABLE 11. - Comparative elastic modulus values

\begin{tabular}{|c|c|c|c|c|c|}
\hline Based on & TSR gage & Based on & BDG gage & \multirow{2}{*}{$\begin{array}{l}\text { Similar } \\
\text { physical } \\
\text { property, } \\
\times 10^{6} \text { psi }\end{array}$} & \multirow[b]{2}{*}{ Remarks ${ }^{1}$} \\
\hline $\begin{array}{l}\text { Overcore, } \\
\times 10^{6} \text { psi }\end{array}$ & \begin{tabular}{|l|} 
Jacking, \\
$\times 10^{6}$ psi
\end{tabular} & $\begin{array}{l}\text { Overcore, } \\
\times 10^{6} \text { psi }\end{array}$ & \begin{tabular}{|l|} 
Jacking, \\
$\times 10^{6}$ ps 1
\end{tabular} & & \\
\hline \multicolumn{6}{|c|}{ TEST 1} \\
\hline $\begin{array}{c}9.44 \\
-\end{array}$ & 10.55 & $\because$ & $\overline{-}$ & - & $\begin{array}{l}\text { Within } 2 \text { standard deviations. } \\
\text { Nearly within } 2 \text { standard } \\
\text { deviations. } \\
\text { Within } 2 \text { standard deviations. }\end{array}$ \\
\hline \multicolumn{6}{|c|}{ TEST 2} \\
\hline $\begin{array}{l}2.50 \\
- \\
- \\
-\end{array}$ & $\begin{array}{c}- \\
2.06 \\
-\end{array}$ & $\begin{array}{c}- \\
9.68 \\
-\end{array}$ & $\begin{array}{l}- \\
- \\
- \\
6.91\end{array}$ & $\begin{array}{c}2.49 \\
2.49 \\
- \\
- \\
\end{array}$ & $\begin{array}{l}\text { Recorded in hole } 2 . \\
\text { Do. } \\
\text { Within } 2 \text { standard deviations. } \\
\text { Within standard deviation. }\end{array}$ \\
\hline \multicolumn{6}{|c|}{ TEST 3} \\
\hline $\begin{array}{c}17.50 \\
- \\
-\end{array}$ & 6.20 & $\begin{array}{c}- \\
8.78\end{array}$ & $\begin{array}{l}- \\
- \\
- \\
7.15\end{array}$ & $\begin{array}{c}18.90 \\
- \\
-\end{array}$ & $\begin{array}{l}\text { Recorded in hole } 3 . \\
\text { Within standard deviation. } \\
\text { Nearly within standard } \\
\text { deviation. } \\
\text { Near arithmetic mean. }\end{array}$ \\
\hline
\end{tabular}

iA11 values based on $7.10 \times 10^{6}$ psi, \pm 1.50 standard deviation.

No conclusive result could be stated from this finite element study without final determination of the elastic modulus at those positions that nearly exactly duplicate positions of field measurement. To accomplish this, three specimens from that portion of rock core retrieved from test 2 were obtained by contiguous coring at the exact $\mathrm{C}_{1}, 2,3$, directions of field measurement (fig. 30). These nine samples were uniaxialiy tested by procedures identical to those previously described in the physical property section of this report. Exceptions to test procedures were that static Poisson's ratio was determined by strain gage techniques and a stiff testing machine was used (as a means of obtaining more in situ conditions). Results of this testing are shown in table 12, where (a) are values for the composite elastic modulus curve to failure, and (b) are elastic modulus values for a portion of the loading curve between 5,000 and $10,000 \mathrm{psi}$, which was done to approximate in situ loading conditions. 
TABLE 12. - Elastic modulus and compressive strength for test 2 core only

\begin{tabular}{|c|c|c|c|c|c|}
\hline \multirow[b]{2}{*}{ Orientation } & \multicolumn{2}{|c|}{ (a) } & \multicolumn{2}{|c|}{ (b) } & \multirow{2}{*}{$\begin{array}{c}\text { Compressive } \\
\text { strength, } \\
\text { psi }\end{array}$} \\
\hline & $\begin{array}{l}\text { Elastic } \\
\text { modulus, } \\
\text { psi } \times 10^{6}\end{array}$ & $\begin{array}{l}\text { Poisson's } \\
\text { ratio, } \mu\end{array}$ & $\begin{array}{r}\text { Elastic } \\
\text { modulus, } \\
\text { psi } \times 10^{6}\end{array}$ & $\begin{array}{l}\text { Poisson's } \\
\text { ratio, } \mu\end{array}$ & \\
\hline$C_{1}$ (Horizontal).... & $\begin{array}{l}8.12 \\
6.01 \\
7.06\end{array}$ & $\begin{array}{r}0.219 \\
.282 \\
.148\end{array}$ & $\begin{array}{l}8.53 \\
6.91 \\
7.53\end{array}$ & $\begin{array}{r}0.234 \\
.335 \\
.158\end{array}$ & $\begin{array}{l}31,060 \\
29,010 \\
29 ; 850\end{array}$ \\
\hline $\mathrm{C}_{2}{ }^{1}\left(60^{\circ} \mathrm{CW}\right) \ldots \ldots$ & $\begin{array}{l}5.48 \\
5.18 \\
4.88\end{array}$ & $\begin{array}{l}.079 \\
.045 \\
.011\end{array}$ & $\begin{array}{l}6.90 \\
6.64 \\
6.26\end{array}$ & $\begin{array}{l}.166 \\
.119 \\
.072\end{array}$ & $\begin{array}{r}13,610 \\
8,390 \\
6,810\end{array}$ \\
\hline$\left(120^{\circ} \mathrm{CW}\right) \ldots$ & $\begin{array}{l}5.54 \\
6.04 \\
8.05\end{array}$ & $\begin{array}{l}.101 \\
.105 \\
.112 \\
\end{array}$ & $\begin{array}{l}4.25 \\
4.92 \\
6.01\end{array}$ & $\begin{array}{l}.061 \\
.064 \\
.097\end{array}$ & $\begin{array}{r}10,210 \\
10,120 \\
7,660\end{array}$ \\
\hline
\end{tabular}

CW Clockwise.

(a) Values determined over entire loading curve.

(b) Values determined in range of 5,000 to $10,000 \mathrm{psi}$.

${ }^{1}$ Specimens at this angle exhibit about $50^{\circ}$ bedding angle with core axis.

In particular, the $C_{2}$ or horizontal position is first noted, which was the direction of all field test comparisons using finite element analysis. Here, the three elastic modulus values are $6.91,7.53$, and 8.53 with an average of $7.66 \times 10^{6} \mathrm{psi}$. On the basis of average values, the final summary is as follows:

Average of 84 static elastic modulus values....... $7.10 \times 10^{6}$ psi

Average of 36 dynamic elastic modulus values..... $7.93 \times 10^{6}$ psi

Average of 28 biaxial elastlc modulus values.....7.91 $710^{6}$ psi

Average of 8 finite element runs based on field data

for TSR tests $1,2,3$, jacking, and simultaneous

overcoring, excluding outliers, table $11 \ldots \ldots \ldots \ldots 7.91 \times 10^{6}$ psi

Average of 3 elastic modulus values at exact

positions of field measurement for test 2 only

$C_{1}$, or horizontal direction, table $12 \ldots \ldots \ldots \ldots \ldots 7.66 \times 10^{6} \mathrm{psi}$

Average of 9 elastic modulus values at exact

positions of field measurement for test 2 only

$\mathrm{C}_{2,2,3}$ using simulated in situ loading curve

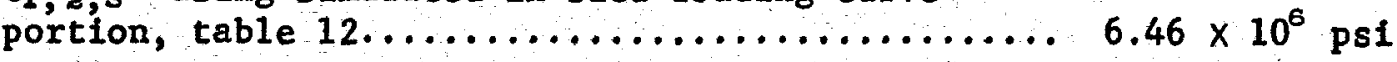

Variability of the overall data is apparent from tests at other directions, $C_{2,3}$ table 12 . The elastic modulus range of 4.25 to $8.53 \times 10^{6}$ psi given by nine uniaxial tests from test 2 core only compares with the range of lastic modulus given by eight finite element analysis of 4.55 to $10.55 \times 10^{6}$ si, table 11, but discarding outliers that were known to represent fractured rock. 
On the basis of these "average" elastic modulus an acceptable grouping of the final data can be achieved within one standard deviation for all results. However, no acceptable basis can be advanced for variation between individual tests when compared on a one for one correspondence. This comparison also discards all outlier values. In reality, many events play a part in this variation--field procedures, test data, analysis, laboratory testing, ${ }^{23}$ sample preparation, and the fact that selected intact rock samples are always tested. In addition, the exact same rock sample cannot be equally tested both in the field and in the laboratory. Surely, the same rock sample measured by the overcore procedure, by the initial deformation method, and by laboratory testing utilized very contiguous rock, but yet it was not exactly from identical rock by each test method (recall the overcore method measured change in central EX hole diameter, the external deformation of the hole rib was measured by initial deformation, and physical property testing was from the intervening intact recovered core). Therefore, finite element results combined with several field and laboratory testing methods has achieved the limit in this investigation to determine the elastic modulus from the most contiguous sampling possible. From these measurements and analysis it is concluded that more precision than "average" for the prediction of rock behavior based on physical properties, initial deformation method, and overcore stress measurement would be fortuitious if extended to exact point by point correspondence from individual tests. Results of the finite element analysis herein are consistent with the exhaustive physical property analysis previously discussed. The probabilistic nature of rock and test procedures must be re-evaluated for higher levels of interpretation.

However, the objectives of this investigation have been satisfied by this comparison between three methods for determining rock behavior. The very extensive analyses of this report have entirely supported the concept of great variability in rock properties and behavior that cannot be reduced at this time from an average to a more precise one to one correspondence.

\section{SUMMARY AND CONCLUSIONS}

The scope of work undertaken by the ground support determination project at the Spokane Mining Research Center was to develop methods for predicting magnitude, direction, and nature of loading occurring on artificial support in underground mines. Five categories of experimental information were considered for definition of mine opening behavior: (1) Summary of the geologic and mining environment, (2) definitive physical properties of the rock, (3) stress profiles surrounding the opening, (4) opening geometry, and (5) initial deformation based on a time history of mine opening behavior taken upon creation of the opening. This report has extensively examined four approaches to that problem.

The first is the ordinary description of the local and test site geologic environment within the mining system. Although entirely descriptive, this review does furnish the necessary geologic background and time frame within

${ }^{23}$ It is justified to even criticize the simple uniaxial test as a representative test. 
which the sequence of mine opening development can be appreciated. Such description should properly be considered as necessary to an understanding of the nature of the loading likely to be encountered by artificial support.

The second approach was the complete determination of the threedimensional stress ellipsoid using the. Bureau of Mines developed overcoring technique. A detailed analysis was also made of two-dimensional borehole deformation gage readings in terms of the strain rosette and derived secondary principal stresses. Particular attention was given to analys is and interpretation of the stress profile immediately adjacent to the opening, that is, within one diameter. This stress information determined magnitude and direction of the immediate loading expected to be carried by artificial support.

Character of the stress profiles at this test site are as follows: (1) The predominant orientation of secondary principal stress near the opening boundary and outward to the extremity of the stress concentration zone is vertical, beyond these areas the predominate stress direction changes to horizontal with nearly biaxial distribution; (2) the evidence from this test site is that the effective zone of stress concentration is about one opening diameter beyond the opening boundary and reaches a maximum value very near the theoretical value of twice the free field but does not occur at the opening boundary as theoretically predicted; (3) residual stress is present at the opening boundary and with the average elastic modulus for this test site, a residual stress between 1,000 and $1,500 \mathrm{psi}$ is probable; (4) the stress ellipsoid computation indicates a horizontal free field stress about 1.25 times the vertical stress and which conforms somewhat to local orientation of Big Creek anticline; and (5). the vertical stress is in good agreement with the theoretical overburden stress and calculated vertical stress and apparently conforms to normal incumbent overburden loading.

The third approach was an exhaustive program of physical property determination. This program was carried out simultaneously with overcoring and furnished numerical data with respect to 12 physical properties (density, 36 samples; longitudinal velocity, 37 ; bar velocity, 36 ; torsional velocity, 37; dynamic elastic modulus, 36; dynamic shear modulus, 37; dynamic Poisson's ratio, 37; uniaxial compressive strength, 85; static elastic modulus, 84; Shore hardness, 58; Brazilian tensile strength, 16; and biaxial elastic modulus, 28). These data illustrate that considerable variation occurs throughout each individual physical property. To satisfy project requirements for predictive techniques, the physical property data were reconstituted to computer stepwise regression programs to predict the static elastic modulus and the static compressive strength in terms of the remaining physical properties. These two properties have traditionally.been most used for purposes of support design and evaluation. Two candidates appear promising for predictive purposes-the longitudinal velocity and Shore scleroscope hardness. Others follow in ascending order. The physical property determinations well show inherent variability of rock properties even within a relatively small area.

The initial deformation method developed by the Bureau of Mines is based the thesis that just as the overcore technique measures deformation at the 
opening wall ( $r=a)$ similar deformation will occur deeper into the rib $(r>a)$. The mathematical formulation is very similar between the two techniques. Three successive field experiments were performed to validate this thesis simultaneously with three overcore runs. To completely visualize the phenomena occurring within the rib rock, strip chart recordings were used to show the direction and magnitude of deformation. Each of the three experiments were successful in verifying the initial deformation method with one experiment completely successful in all respects. Equations identical to those used for overcoring showed numerical correspondence between initial deformation results within the range of experimental error. The finite element method of numerical analysis was also used to correlate experimental and theoretical results.

It is concluded that these experiments completely validated the thesis of the initial deformation method. In addition to being able to directly obtain deformation data, the initial deformation method (if projected to full-scale actual field conditions) will more faithfully reproduce the true nature of loading on artificial support by showing other loading factors such as geologic variables, geometry, induced stresses such as by temperature variation and highly stressed rock without assessing the individual contribution. Test number 3 in the experimental series unexpectedly proved this valuable concept. The records from all three experimental initial deformation runs well demonstrate the complex phenomena that actually occur as an underground opening is created. Therefore, the initial deformation method has been devised to better reflect actual opening geometry, rates of opening deformation, in situ stress profiles, geologic features, and rock property characteristics without actually defining the significance and magnitude of each parameter. 


\section{REFERENCES}

1. Ageton, A. W. Deep Mine Stress Determinations Using Flatjack and Borehole Deformation Methods. BuMines RI 6887, 1967, 25 pp.

2. (assigned to U.S. Department of the Interior). Hydraulic Drive Drilling. U.S. Pat. 3,464,502, Sept. 2, 1969.

3. Allen, R. H. 1971 Annual Report. Gulf Resources and Chemical Corp., Houston, Tex., Mar. 31, 1972, 32 pp.

4. Austin, W. G. Development of a Stress Relief Method With a ThreeDimensional Borehole Deformation Gage. Bureau of Reclamation REC-OCE-70-10, March 1970, 76 pp.

5. Biggs, F. Bunker Hill Geology Department, Personal Communication, Kellogg, Idaho; available from Bunker Hill Geology Department.

6. Blackwe11, D. D. Heat-Flow Determinations in the Northwestern United States. J. Geophy. Res., v. 74, No. 4, Feb. 15, 1969, pp. 992-1007.

7. Blake, W. Stresses and Displacements Surrounding an Open Pit in a Gravity-Loaded Rock. BuMines RI 7002, 1967, 20 pp.

8. Campbe11, S. Mining Industry of Idaho, 29th Annual Report. State of Idaho, State Mine Inspector, 1927, $280 \mathrm{pp}$.

9. D'Andrea, D. V., R. L. Fischer, and D. E. Fogelson. Prediction of Compressive Strength From Other Rock Properties. BuMines RI 6702, 1965,23 pp.

10. Danlells, P. A. M. Experimental Measurement of Residua1 Strain in Rock. Unpublished M.S. Thes1s, Mining Engineering, S. Dak. School Mines Technol., Rapid C1ty, S. Dak., 1971, 43 pp. (available at library, South Dakota School of Mines and Technology).

11. Deere, D. U. (ed.). Determination of the In Situ Modulus of Deformation of Rock. ASTM Special Tech. Pub, 447, 1970, 198 pp.

12. Draper, N. R., and H. Smith. Applied Regression Analysis. John Wiley \& Sons, Inc., New York, 1966, 407 pp.

13. Dure111, A. J., L. Obert, and V. J. Parks. Stress Required To Initiate Core Disking. Trans. Soc. Min. Eng., AIME, v. 241, September 1968, pp. $269-276$.

14. Efroymson, M. A. Multiple Regression Analysis. Article 17, 191-203 in Mathematical Methods for Digital Computers, ed. by A. Ralston and H. Wilf. John wiley \& Sons, Inc. , New York, v. 1, 1960, 293 pp. 
15. Fitzpatrick, J. Biaxial Device for Determining the Modulus of Elasticity of Stress-Relief Cores. BuMines RI 6128, 1962, 13 pp.

16. Fryklund, V. C. Ore Deposits of the Coeur d'Alene District, Shoshone County, Idaho. With a Section on the Bleached Rock in the Coeur d'Alene District, by P. L. Weiss. U.S. Geo1. Survey Prof. Paper 445, 1964,103 pp.

17. Guenther, W. C. Analysis of Variance. Prentice-Ha11, Inc., New York, 1964, 199 pp.

18. Hooker, V., and C. F. Johnson. Near-Surface Horizontal Stresses Including the Effects of Rock Anisotropy. BuMines RI 7224, 1969, 29 pp.

19. Hooker, V., and W. I. Duva11. In Situ Rock Temperature. Stress Investigations in Rock Quarries. BuMines RI 7589, 1971, 12 pp.

20: Hetenyi, M. Handbook of Experimental Stress Analysis. John Wiley \& Sons, Inc., New York, 1950, 1077 pp.

21. Jaeger, J. C., and N. G. W. Cook. Fundamentals of Rock Mechanics. Methuen \& Co. Ltd. (London), 1969, 513 pp.

22. Johnson, J. B., and R. L. Fischer. Effects of Mechanical Properties of Materials on Cratering: A Laboratory Study. BuMines RI 6188, 1963, 24 pp.

23. Judd, W. R. Strain Distribution Around Underground Openings. Technical Report 2, statistical Methods To Compile and Correlate Rock Properties and Preliminary Results. Purdue Univ., School of Civil Eng., Lafayette, Ind., 1969,109 pp.

24. _ Strain Distribution Around Underground Openings. Technical Report 6, Statistical Relationship for Certain Rock Properties. Purdue Univ., School of Civil Eng., Lafayette, Ind., October 1971, 184 pp.

25. Judd, W. R., and C. Huber. Correlation of Rock Properties by Statistical Methods. Proc. Symp. Min. Res., Pergamon Press, New York, 1961, pp. 621-648.

26. Krempasky, G. T. Methods and Costs of Driving Drifts, Crosscuts, and Raises in the Coeur d'Alene Mining District, Shoshone County, Idaho. BuMines IC $7964,1960,45$ pp.

27. Leeman, E. R. The Measurement of Stress in Rock. J. S. African Inst. Min. and Met., v. 65, No. 2, September 1964, pp. 45-114.

28. Lewis, W. E., and S. Tandanand (ed.). Bureau of Mines Test Procedures for Rocks. BuMines IC 8628, 1974, 223 pp. 
29. Magnuson, R. G. Coeur d'Alene Diary. Metropolitan Press, Portland, Oreg. , 1968,319 pp.

30. McDowe11, G. A. Mining Industry of Idaho, 55th Annual Report. State of Idaho, State Mine Inspector, 1953, 215 pp.

31. McWilliams, J. R., and E. G. Erickson. Methods and Costs of Shaft Sinking in the Coeur d'Alene District, Shoshone County, Idaho. BuMines IC $7961,1960,49 \mathrm{pp}$.

32. Merend, A., and T. Slot. Stress Analysis of Thick-Walled Tube With Step Change in Thermal Expansion. Exper. Mech. (SESA), v. 12, No. 3, March 1972, pp. 136-141.

33. Merril1, R. H. Roof-Span Studies in Limestone. BuMines RI 5348, 1957, $38 \mathrm{pp}$.

34. Three-Component Borehole Deformation Gage for Determining the Stress in Rock. BuMines RI 7015, 1967, 38 pp.

35. Mutmansky, J. M., and M. M. Singh. A Statistical Study of Relationship Between Rock Properties. 9th Symp. on Rock. Mechanics, ed. by N. E. Grosvenor, AIME, 1968, 496 pp.

36. Obert, L. Effects of Stress Relief and Other Changes in Stress on the Physical Properties of Rock. BuMines RI 6053, 1962, 8 pp.

37. Obert, L., and W. I. Duval1. Rock Mechanics and the Design of Structures in Rock. John Wiley \& Sons, Inc., New York, 1967, 650 pp.

38. Obert, L., R. H. Merrill, and T. A. Morgan. Borehole Deformation Gage for Determining the Stress in Mine Rock. BuMines RI 5978, 1962, 11 pp.

39. O1ds, E. B., and E. W. Parsons. Methods and Costs of Deepening the Crescent Shaft, Bunker Hill and Sullivan Mining and Concentrating Co., Kellogg, Shoshone County, Idaho. BuMines IC 7783, 1957, 19 pp.

40. Oudenhoven, M. S., and G. T. Krempasky. Photoelastic Study of an Internally Stressed Circular Opening in a Biaxial Stress. Field. BuMines RI 6812, 1966, 25 pp.

41. Panek, L. A. Calculation of the Average Ground Stress Component From Measurements of the Diametral Deformation of a Drill Hole. BuMines RI 6732, 1966, $41 \mathrm{pp}$.

42. Perry, C. C., and H. R. Lissner. The Strain Gage Primer. McGraw-Hill Book Co., Inc., New York, 2d ed., 1962, 332 pp.

43. Rambosek, A. J. The Stress Field Within a Core Stub in a Borehole. BuMines RI $6462,1964,16 \mathrm{pp}$. 
44. Ransome, F. L.; and F. C. Calkins. The Geology and Ore Deposits of the Coeur d'Alene District, Idaho. U.S. Geo1. Survey Prof. Paper 62, 1908, 203 pp.

45. Savin, G. N. Raspredeleniye Napryazheniy Okolo Otverstiy (Stress Distribution Around Holes). NASA Tech. Trans1. TT F-607, 1970, 997 pp.

46. Schlosser, R. B. The Crescent Mine Cooling System. Paper pres. 73d Northwest Mining Convention, Spokane, Wash., Dec. 2, 1967, 14 pp.

47. Shenon, P. J., and R. H. McConnel. The Silver Belt of the Coeur d'Alene District, Idaho. Pamphlet 50, Idaho Bureau of Mines and Geology, 1939, 9 pp.

48. Tranter, C. J. On the Elastic Distortion of a Cylindrical Hole by a Localized Hydrostatic Pressure. Quart. App1. Math., v. 4, No. 3, 1946, pp. 298-302.

49. Wadde11, G. G., T. J. Crocker, and E. H. Skinner. Technique of Measuring Initial Deformation Around an Opening: Analysis of Two Raise-Bore Tests. BuMines RI 7505, 1971, 60 pp.

50. Waddel1, G. G., and E. L. Phillips (assigned to U.S. Department of the Interior). Stress Relaxation Gage. U.S. Pat. 3,600,938, Aug. 24, 1971.

51. Wallace, G. B., E. J. Slebir, and F. A. Anderson. Radial Jacking Test for Arch Dams. Paper pres. 10th Rock Mech. Symp., Austin, Tex., 1968, 46 pp.

52. Wang, F. D., M. C. Sun, and J. Wolgamott. A Computer Program for Generating Finite Element Models of Mine Structures. BuMines IC 8510, 1971 , 56 pp.

53. Wentworth, D. H. Some Factors Influencing Strain-Relief Overcoring. M.S. Thesis T-1097, Colo. School Mines, Golden, Colo., 1966, 136 pp.

54. Wilson, E. L. Finite Element Analysis of Two-Dimensional Structures. Structures and Materials Rept. 63-2, Univ. Calif., Berkeley, Calif., June 1963, 72 pp.

55. A Digital Computer Program for the Finite Element Analysis of Solids With Nonlinear Material Properties. Structural Engineering Laboratory, Univ. Calif., Berkeley, Calif., July 1965, 54 pp.

56. Zienkiewicz, 0. C. The Finite Element Method in Engineering Science. McGraw-Hi11 Book Co., Inc., New York, 2d ed., 1971, 521 pp. 


\section{APPENDIX A. -OVERCORE DRILLING OPERATIONS}

Since the Crescent mine overcoring program is one of the most complete to date by the Bureau of Mines in the Coeur d'Alene district, an extensive summary of overcoring operations is included herein. An air-motor-powered hydraulic drive diamond drill was designed by SMRC and constructed to specifications by Diamond Drill Contractors. Some detail on this drill was given in RI 6887 (1, p. 23). Patentable features (2) incorporated rotational drive by $a$ hydraulic motor and drill bit feed by independently activated hydraulic pistons. Its main advantages are high torque and low rpm capability through use of the hydraulic drive giving completely varlable advance and bit penetration. Portability and an operator's console with monitoring gages were also designed into the drill. Drill operation is manual, however. The entire drill is assembled as one unit at the drilling site. The drill had been previously successfully used in overcoring at the Star, Galena, and Bunker H111 mines, all in the Coeur d'Alene district. This experience has shown the value of a specially designed drill capable of vibrationless and closely controlled operation.

Extra safety precautions should be followed with respect to high-torque dri11s. Three regular 10-ton hydraullc roof-support Hy-Jaks by Commercial Shearing and Stamping Co. were used to securely brace the drill. The increased stability for drilling is also advantageous to overcoring operations.

Underground water and afr utflities common to regular mining were connected to the dri11; both could be regulated at the drill. Normal atr pressure was about $95 \mathrm{ps1}$, and water pressure, $35 \mathrm{psi}$ throughout dri11ing operations. Average mine water temperature ranged from about $40^{\circ}$ to $60^{\circ} \mathrm{F}$ throughout the year (measured at surface tank). Average pressure in the hydraulic drive system was about $350 \mathrm{psi}$ during normal drilling. Bit force was not precisely monitored but depended on the operating conditions and drillers' skill. It was Judged highly varlable, from 200- to 600-psi cylinder pressure. Generally, a lower rpm with sufficient bit pressure applied to effect bit advance without danger of diamond polishing was used. Bit speed was also variable, ranging from 105 to $120 \mathrm{rpm}$. This too depended on the drillers' preference.

Masonry overcore bits were used on hole 1 . The bits were $10 \mathrm{WW}, 6 \times 11$ gage, grade RS, with a 26-1/2-inch core barrel. The remaining holes used threaded bits. These were christensen narrow kerf, $6-1 / 2 \times 6$, grade $\mathrm{H}$, and stone size $60 \mathrm{p} / \mathrm{c}$ hard matrix. As noted in the summary later in this appendix, bit consumption was high owing to the extremely hard quartzites. No drilling additives were added to the mine water while drilling.

A summary of all overcore drilling operations at the Crescent mine is shown in table $A-1$. It is noted that the objective of overcoring is experimental data and therefore slower drilling progress necessarily occurs. This was especially true of hole 4, where an accurate drilling record cannot be interpreted. Hole 4 is only for reference to the complete experimental

jogram. 
TABLE A-1. - Crescent mine overcoring summary

\begin{tabular}{|c|c|c|c|c|c|c|c|c|}
\hline \multirow[t]{2}{*}{ Hole } & \multicolumn{2}{|c|}{ Dates } & \multirow{2}{*}{$\begin{array}{l}\text { Total } \\
\text { working } \\
\text { shifts }\end{array}$} & \multirow{2}{*}{\begin{tabular}{|l}
\multicolumn{1}{c}{ Net } \\
working \\
shifts
\end{tabular}} & \multirow{2}{*}{$\begin{array}{c}\text { Total } \\
\text { hole } \\
\text { depth, } \\
\text { inches }\end{array}$} & \multirow{2}{*}{$\begin{array}{c}\text { Inches } \\
\text { per } \\
\text { working } \\
\text { shift }\end{array}$} & \multirow{2}{*}{$\begin{array}{l}\text { Number } \\
\text { of } 6 \text {-inch } \\
\text { bits }\end{array}$} & \multirow{2}{*}{$\begin{array}{c}\text { Number } \\
\text { of } \\
\text { EX } \\
\text { bits }\end{array}$} \\
\hline & Begin & End & & & & & & \\
\hline $1 \ldots \ldots \ldots$ & $\begin{array}{l}\text { Oct. 27, } \\
1967\end{array}$ & $\begin{array}{l}\text { Dec. 21, } \\
1967\end{array}$ & 22 & 18 & 326 & 18.1 & 4 & 1 \\
\hline $2 \ldots \ldots \ldots$ & $\underset{1968}{\operatorname{Jan} .} 31$, & ${ }_{1968}^{\text {Mar. }} 5$ & 17 & 13 & 253 & 19.5 & 5 & 1 \\
\hline $3 \ldots \ldots \ldots$ & $\begin{array}{l}\text { Mar. 12, } \\
1968\end{array}$ & $\underset{1968}{\text { Apr. }}$ & 13 & $12-1 / 2$ & 246 & 19.7 & 2 & 1 \\
\hline $4 \ldots \ldots \ldots$ & $\begin{array}{c}\text { May 20, } \\
1968\end{array}$ & $\begin{array}{c}\text { June } 19, \\
1968\end{array}$ & 18 & 12 & 130 & $\left({ }^{2}\right)$ & 2 & 1 \\
\hline Tota1.. & & & 70 & $55-1 / 2$ & 955 & 18.96 & 13 & 4 \\
\hline
\end{tabular}

${ }^{1}$ Net working shifts based on total working shifts begun minus time lost owing to instrumentation failures, drill breakdowns, drilling difficulties, etc. ${ }^{2}$ Charged to other than overcore work, not applicable here.

Completed overcore runs were used for an evaluation of drilling. These data were for very successful runs from 10 to 15 inches long, requiring 15 to 53 minutes to complete. The average completion time of these runs is 25 minutes. For 10 completed runs with timed overcore drilling data, the drilling rates range from about $1 / 3$ to 1 inch per minute. Along with drilling, stops were necessary at 1 -inch increments of depth to record borehole deformation data. Depending upon extraordinary difficulties in taking readings, about 1 minute was required per stop. This time is not reflected in the total drilling rate noted previously. Mention should be made that a substantial amount of the working shift was spent in preparing for overcore drilling and instrumentation checkout. No record of this time was made. A normal shift at the Crescent mine was about 5-1/2 hours, caused by simple in-out logistics of the test site.

Stress-relief measurements by the overcoring technique were made using the three-component borehole deformation gage developed by the Bureau of Mines. This process requires two holes: (1) A 1-1/2-inch-diameter EX hole that is drilled first and (2) a 6-inch-diameter core hole drilled later but centered over the smaller hole--hence the name overcoring. The borehole deformation gage (BDG) is inserted into the smaller hole and oriented with respect to the deformation measuring positions. The three-component gage was described in RI 7015 (34), and the overcore technique was more fully described in RI $5978(\underline{38})$.

Briefly, the procedure used on this project was as follows. After the 6-inch bit was centered over the EX hole (in which the deformation gage is positioned), the water was turned on. After a few minutes the gage indicated instrument stability (shown by zero drift on the strain gage recorder). When gage stability was achieved, overcoring was begun. Thereafter, gage readings were normally taken at drilling increments of 1 inch. 
Drilling was continued until no further change is shown on the strain gage recorder. At the Crescent mine, this normally required a depth of 6 inches beyond gage placement in the EX hole. Thus, a minimum overcore run required a length of solid core at least 8 inches long. Twelve-inch lengths were preferred. The difference between the initial reading and the final steady strain at the end of the overcore run was used for calculation. After the aforementioned measurements were completed, the rock core was removed for laboratory testing of physical properties. These cores. were always oriented with respect to the gage measurement point and angles. Upon completion of one typical overcore run, as just described, the deformation gage was then inserted another 6 inches or so further into the EX hole, and the overcoring process was repeated. Usually many additional overcore runs are desired for either check purposes or because the rock is fractured such that the first readings are not reliable.

Each individual overcore run has three, initial minus final, readings corresponding to the three angular components of the gage. A complete solution to the stress ellipsoid can be obtained when these data are taken from three different holes, preferably two holes oriented at about $60^{\circ}$ with respect to each other and the third hole either vertically upward or downward. A number of individual overcore runs in each hole are required for an accurate stress ellipsoid.

Strain measurements were taken with a portable digital strain indicator, model P-350, manufactured by the Instruments Division of the Budd Co. The indicator was used to determine static strain with resistance-type strain gages. It is a manually operated null-balance galvanometer having a sensitivity of 1 microstrain. A built-in zero balance control assures a nul1 position with a direct reading digital display of the readout. It has a range of $\pm 50,000$ microstrain with 10,000 microstrain units on the main balance. Gage factor is adjustable between 0.10 and 10.0. External connections allow ful1, half, or quarter bridge circuits. Only full bridge circuits were used for this project. Internal circuitry is transistorized and battery powered.

An overcoring performance summary is shown in table A-2. Success of a run was based on (1) core breakage almost immediately after commencing a run; (2) core breakage shortly before the gage was reached; (3) core breakage shortly beyond the gage; and (4) completion of a run. Only 33 of 74, or 45 percent, of all runs were considered successful. Usefulness of data from each run lowers the overall success to about 33 percent. Immediate core breakage is perhaps indicative of stress disking effects (13) and core breakage near the gage may be related to stress effects in the downhole core stub (43). Core disking phenomena was suggested only in hole 1 at depths of 214 to 222 inches and 241 to 266 inches.

Accompanying table $\mathrm{A}-2$, the amount of data obtained from all overcore holes is shown in table A-3. These data represent cumulative readings taken from each increment of depth. Hole 4, however, was read on continuous chart recorders. For all readings, about 85 percent of data were usable before nditing and selection for stress ellipsoid computation. 
TABLE A-2. - Crescent mine overcore resu1ts

\begin{tabular}{c|c|c|c|c|c}
\hline Hole & Total runs & $\begin{array}{l}\text { Core broke } \\
\text { immediately }\end{array}$ & $\begin{array}{c}\text { Core broke } \\
\text { before BDG }\end{array}$ & $\begin{array}{c}\text { Core broke } \\
\text { after BDG }\end{array}$ & $\begin{array}{c}\text { Runs considered } \\
\text { successful }\end{array}$ \\
\hline $1 \ldots \ldots \ldots \ldots$ & 33 & 12 & 6 & 3 & 12 \\
$2 \ldots \ldots \ldots \ldots$ & 22 & 8 & 1 & 1 & 12 \\
$3 \ldots \ldots \ldots \ldots$ & 16 & 1 & 4 & 3 & 6 \\
$4 \ldots \ldots \ldots \ldots$ & 3 & 0 & 0 & 0 & 3 \\
\cline { 2 - 5 } & 74 & 21 & 11 & 7 & 33 \\
\hline
\end{tabular}

TABLE A-3. - Crescent mine overcore data retrieval

\begin{tabular}{|c|c|c|c|c|c|c|c|}
\hline \multirow[t]{2}{*}{ Hole } & \multirow{2}{*}{$\begin{array}{c}\text { Gage } \\
\text { calibrations }\end{array}$} & \multicolumn{3}{|c|}{ Number of data points } & \multicolumn{3}{|c|}{ Usable data points } \\
\hline & & $C_{2}$ & $\mathrm{C}_{2}$ & $\mathrm{C}_{3}$ & $\mathrm{C}_{1}$ & $\mathrm{C}_{2}$ & $\mathrm{C}_{3}$ \\
\hline $\begin{array}{l}1 \ldots \ldots \ldots \\
2 \ldots \ldots \ldots \\
4^{3} \ldots \ldots \ldots \ldots\end{array}$ & $\begin{array}{r}180 \\
132 \\
102 \\
61 \\
\end{array}$ & $\begin{array}{c}142 \\
107 \\
88 \\
- \\
\end{array}$ & $\begin{array}{r}129 \\
116 \\
87 \\
- \\
\end{array}$ & $\begin{array}{r}129 \\
109 \\
88 \\
- \\
\end{array}$ & $\begin{array}{r}113 \\
94 \\
80 \\
- \\
\end{array}$ & $\begin{array}{r}98 \\
101 \\
80 \\
- \\
\end{array}$ & $\begin{array}{r}102 \\
99 \\
79 \\
- \\
\end{array}$ \\
\hline Total...... & 475 & 337 & 332 & 326 & 287 & 279 & 280 \\
\hline
\end{tabular}

${ }^{1} C_{1}, C_{2}, C_{3}$ refers to measurement components of the three-component borehole deformation gage.

2Data on hole 4 recorded here on continuous charts.

If only an initial and final reading is taken from each channel, then for the 33 runs only 99 data points are required as minimum necessary data retrieval. This is about one-tenth of all data; however, with the overcore technique it is prudent to make readings at every inch, or alternatively, continuous recordings. Therefore, additional calibration and data recording effort must be made.

Table A-3 also contains the total number of gage calibrations. Extensive underground gage calibration was required to insure reliability of data retrieval, to check gage operation before and after each run, and to insure uniform overcore results. Since the strain gage indicator was sensitive to 1 microstrain, along with known high in situ stress levels and elastic modulus, considerable error could occur should maximum gage calibration effort not be performed. Review of overcore calibration records are as follows:

\begin{tabular}{|c|c|c|c|c|c|}
\hline \multirow[b]{2}{*}{ Hole } & \multirow{2}{*}{$\begin{array}{c}\text { Number of } \\
\text { average } \\
\text { calibrations }\end{array}$} & \multicolumn{2}{|c|}{ Calibration factors } & \multirow{2}{*}{$\begin{array}{c}\text { Arithmetic } \\
\text { mean }\end{array}$} & \multirow{2}{*}{$\begin{array}{l}\text { Standard } \\
\text { deviation }\end{array}$} \\
\hline & & High & Low & & \\
\hline $\begin{array}{l}1 \\
2 \\
3\end{array}$ & \begin{tabular}{|l|}
46 \\
33 \\
24 \\
\end{tabular} & $\begin{array}{l}7.0883 \\
5.7842 \\
5.0452 \\
\end{array}$ & $\begin{array}{l}4.8978 \\
4.3916 \\
4.0217 \\
\end{array}$ & $\begin{array}{l}5.5082 \\
5.1481 \\
4.7137\end{array}$ & $\begin{array}{r}0.592 \\
.342 \\
.222\end{array}$ \\
\hline
\end{tabular}

The calibration factor is defined as the result of division of the specified set deflection of the gage contact button, in microinches, (when fixed in the calibration $j i g$ ) by the recorded gage output measured at the above set deflection, in microinches. This calibration procedure was repeated 3 to 6 times for each run to obtain an average calibration factor for each channel of the three-component borehole deformation gage. A reference 
callbration standard was also read during each gage calibration. Therefore, it Is seen that calibration depends on the individual gage, recording channe1, dally conditions, and progress of the work.

A considerable number of minor and major mechanical and electrical problems occurred. A discussion and analysis of these details are beyond the scope of this appendix. Factors influencing the entire strain-relfef overcoring process have been studied by Wentworth ( $\underline{53})$ in a thesis under Bureau of Mines guldance. Major overcoring equipment is listed:

overcoring drill, complete with tools.

Dril1 rods, 2- and 5-foot lengths.

Three, 10-ton hydraulic jacks.

EX and 6-inch bits (EX coring and noncoring desirable).

50-foot cable, 8 conductor, 1 (meeting underground operating specifications).

Three Budd model $\mathrm{P}-350$, strain gage indicators.

One Budd SR-4 20-point switch and balance unit.

One borehole deformation gage calibration unit.

Two three-component borehole deformation gages (Bureau of Mines design)

(additional backup gages desirable).

One borehole gage orlentation tool.

For maximum accuracy, the same identical cable must be used when obtalning downhole data and in calibration of the borehole deformation gage.

This overcoring summary well illustrates the magnitude of difficulties in gathering sufficient and accurate borehole deformation data in the Coeur d'Alene mining district. A combination of highly stressed and hard quartzites, which are also well fractured, along with generally unfavorable underground conditions in the deeper mines makes the coeur d'Alene district especially challenging for overcore operations. 


\section{APPENDIX B.--INITIAL DEFORMATION INSTRUMENTATION}

To monitor rock deformation at depth within the mine drift rib as well. as outside the perimeter of another drill hole (as opposed to measurement inside the drill hole as done by the borehole deformation gage), it was necessary to develop a new instrumentation method. An instrumentation system to satisfy these requirements was designed and developed by SMRC ( $\underline{50})$. A view of this instrumentation while operating was previously shown in figure 25 . A typical installation diagram is shown in figure $B-1$. Other details and previous uses of this instrument were described in RI 7505 (49).

External to the rock surface, a support reference pipe (2.0 inch nominal, Schedule 80 pipe) having one end cemented into another drill hole several feet away and outside the influence of experimental work was used to stabilize subsequent downhole instrumentation. The length of this reference anchor can be variable depending on the physical arrangement of the test site. For this

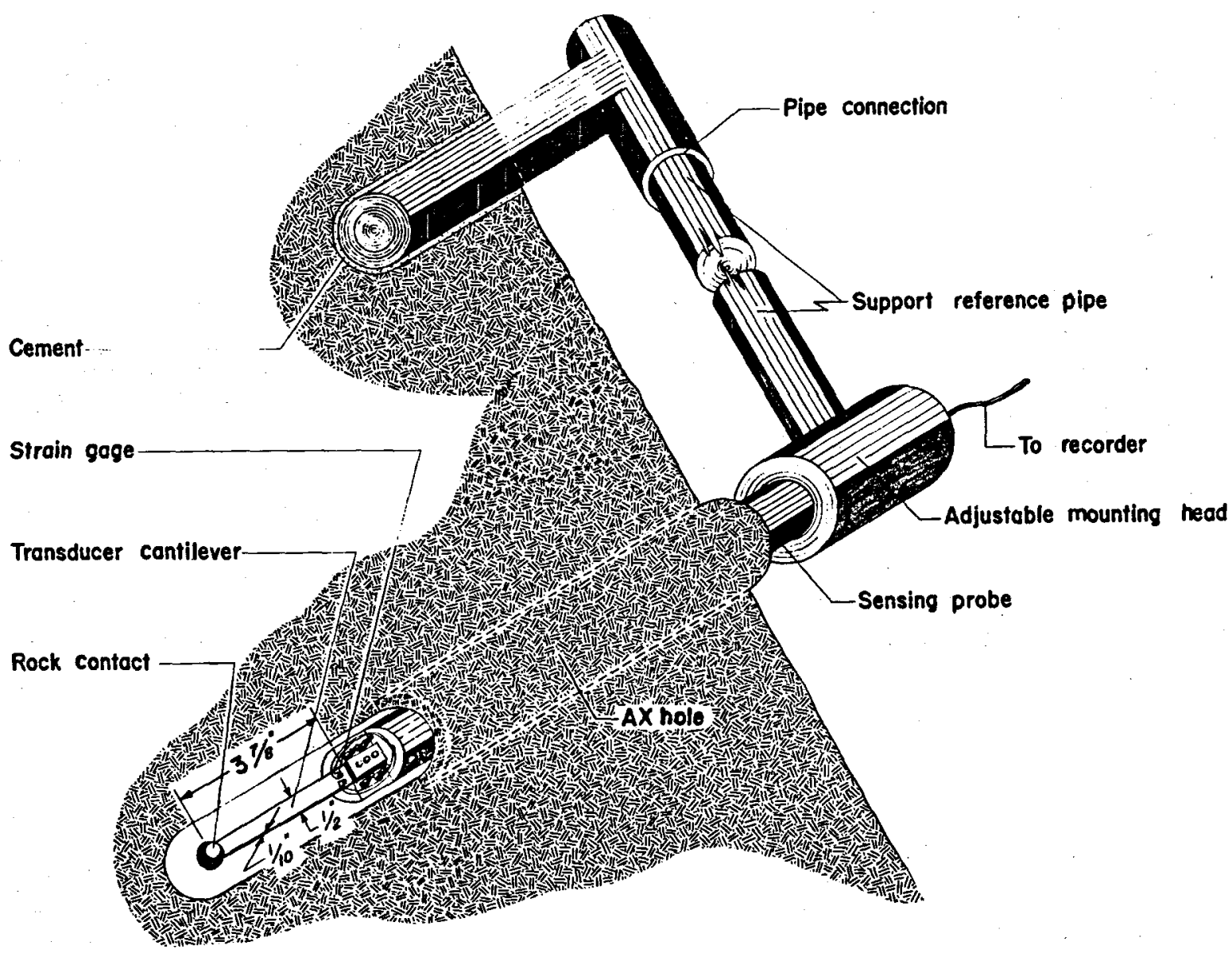

FIGURE B-1. - Installation diagram of TSR gage. 
experiment, 3 feet of reference anchor was cemented with Lumnite cement into overcore hole 3. An adjustable mounting head, shown in figure 25, was fabricated from Cor-Ten steel for underground corrosion resistance. Its purpose is to furnish an adjustable yet rigidly clamped support for the sensing probe, which is inserted downhole. This mounting head device provides 3 degrees of freedom for adjustment of the sensing probe.

The sensing probe operates as a compound cantilever with total deflection given by

$$
\Delta_{\text {Total }}=\Delta_{1}+\Delta_{2},
$$

where subscripts 1 and 2 indicate the partial deflection contribution from two rigidly connected individual cantilevers. At the extreme downhole end, on the shorter transducer cantilever, a four-arm balanced bridge strain gage circuit is mounted for the deflection-actuated electrical transducer. Two strain gage elements on opposite sides of the cantilever form a signal additive four-arm bridge. Waterproofing was by acrylic paint.

The longer cantilever portion of the sensing probe assembly was 20 BWG seamless steel tubing (1-5/8-inch $O D$, nominal). Total length of the complete sensing probe was 5 feet; this allowed a maximum of 4 feet of sensing probe to be inserted downhole with the remaining 1 foot needed at the collar for clamping at the mounting head.

Dimensions and materials for the transducer cantilever were directly applied from previous experience with the borehole deformation gage. Beryllium-copper was again used because of its excellent elastic properties, high strength, good corrosion resistance, and knowledge of fabrication technique. The cantilever dimensions and strain gage circuit provided transverse and temperature stability exactly as the borehole deformation gage. The cantilever length, however, was increased in direct proportion to the expected deflection. Cantilever equations were directly from RI 5978. Test procedures for drift and previously mentioned electrical-mechanical aspects of the gage were satisfactorily resolved before underground tests began.

For dimensions of the compound cantilever used, and at the total cantilever length of 50 inches, maximum calibration instrument sensitivity was about 50 microinches per inch. This compares with 143 microinches per inch for the borehole deformation cantilever (38). Instrument response, as linearity and repeatability, was obtained through repeated calibration runs with curve-fitting procedures employed to determine linear instrument characteristics. This was done by loading the cantilever in directions normal to its plane (fig. B-2). Normally a deflection range of 0.3 inch was used for calibration. In the field, however, the instrument was preloaded with a set range of about 0.1 inch and positioned in the direction such that increasing strain corresponds to closure of the opening. A typical operating range of the instrument is also shown in figure B-2. Calibration procedure requires that each probe must be individually calibrated as well as calibrated at the

"train sensitivity is defined herein as the slope of the input-output instrument calibration curve. 
STRAIN GAGE OUTPUT, microstrain $\times 1000$
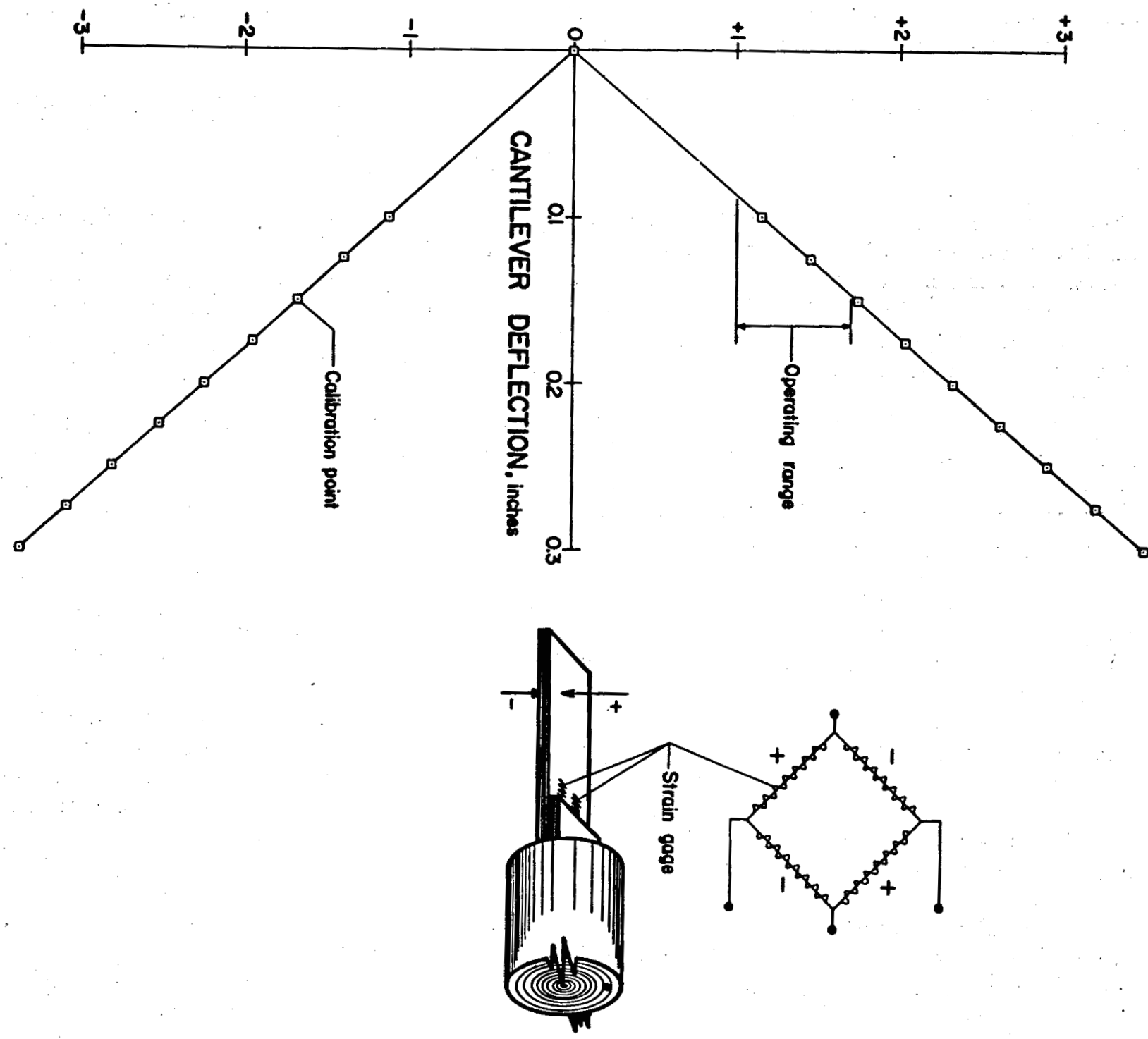

FIGURE B-2. - Typical calibration output.

exact length used. A minimum of three field calibrations were performed, both before and after each test. A special rigid frame was used for these calibrations (49).

The same identical cable and length was used in both calibration and field installation. Field readings were also accompanied by readings on a reference calibration standard. 
Data acquisition in the field was identical to that used for the borehole deformation gage; the recorders used were described in the overcore drilling operations, appendix A. Since all instrumentation described in this report operates on the strain gage principal, any recorder compatible with strain gage data acquisition is suitable for this type of experimental work. 